DOE/ER-0081

\title{
Satellite Power System (SPS) Brightness Due to Reflected Sunlight
}

\section{MASTER}

October 1980

Prepared for:

U.S. Department of Energy

Office of Energy Research

Satellite Power System Project Division

Under Contract 31-109-38-5448

DOE/NASA

Satellite Power System

Concept Development and

Evaluation Program 


\section{DISCLAIMER}

This report was prepared as an account of work sponsored by an agency of the United States Government. Neither the United States Government nor any agency Thereof, nor any of their employees, makes any warranty, express or implied, or assumes any legal liability or responsibility for the accuracy, completeness, or usefulness of any information, apparatus, product, or process disclosed, or represents that its use would not infringe privately owned rights. Reference herein to any specific commercial product, process, or service by trade name, trademark, manufacturer, or otherwise does not necessarily constitute or imply its endorsement, recommendation, or favoring by the United States Government or any agency thereof. The views and opinions of authors expressed herein do not necessarily state or reflect those of the United States Government or any agency thereof. 


\section{DISCLAIMER}

Portions of this document may be illegible in electronic image products. Images are produced from the best available original document. 


\section{NOTICE}

This report was prepared as an account of work sponsored by the United States Government. Neither the United States nor the United States Department of Energy, nor any of their employees, makes any warranty, express or implied, or assumes any legal liability or responsibility for the accuracy, completeness, or usefulness of any information, apparatus, product, or process disclosed, or represents that its use would not infringe privately owned rights. Reference herein to any specific commercial product, process, or service by trade name, mark, manufacturer, or otherwise, does not necessarily constitute or imply its endorsement, recommendation, or favoring by the United States Government or any agency thereof. The views and opinions of authors expressed herein do not necessarily state or reflect those of the United States Government or any agency thereof.

Avallable from:

National Technical Information Service (NIIS)

U.S. Department of Commerce

5285 Port Royal Road

Springfield, Virginia 22161

Price:

Printed Copy

$\begin{array}{ll}\text { Printed Copy: } & \$ 6.00 \\ \text { Microfiche: } & \$ 4.00\end{array}$ 
DOE/ER-0081

Dist. Category UC-34b

\section{Satellite Power System (SPS) Brightness Due to Reflected Sunlight}

October 1980

Prepared for:

U.S. Department of Energy

Office of Energy Research

Satellite Power System Project Division

Washington, D.C. 20585

Prepared by:
Boeing Aerospace Company w untere

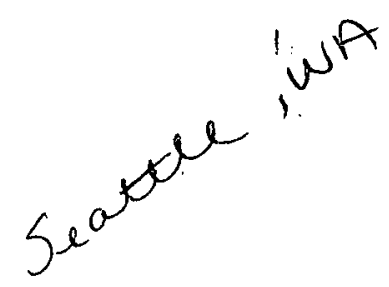

For:

Argonne National Laboratory

Argonne, II 60439

Under Contract No. 31-109-38-5448

DOE/NASA

Satellite Power System

Concept Development and

Evaluation Program

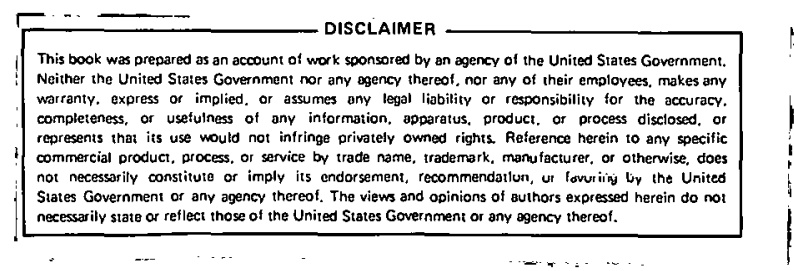


Page

1.0 SUMMARY 1

2.0 STATEMENT OF PROBLEM $\quad 3$

2.1 BACKGROUND 3

2.2 SCOPE OF INVESTIGATION

$\begin{array}{lll}3.0 & \text { RESEARCH AND ANALYSIS } & 7\end{array}$

3.1 REFLECTANCE OF VEHICLES

3.1.1 Reflection Analysis 7

3.1.2 Structure Characteristics 9

3.1.2.1 Description of Spacecraft Elements 11

3.1.2.2 Reflection Qualities of Materials 33

3.1.3 Ground Illumination 41

3.1.3.1 Geometrical Considerations 41

3.1.3.2 Irradiance Levels 43

3.2 SKY BRIGHTNESS $\quad 56$

4.0 CONCLUSIONS AND -RECOMMENDATIONS

$\begin{array}{llr}5.0 & \text { REFERENCES } & 69\end{array}$

Appendix A. Computer Code for Vector Rotations 70.

Appendix B. Radiant Quantities and Units 71 


\section{LIST OF FIGURES AND TABLES}

Figure

Number

1
Title

Page

Typical Reflection Configuration for the Solar Power Satellite at GEO

The Ground Irradiance Due to Specular Reflection of Sunlight

Spectral Reflectance Unit Vector Definition

LEO Staging Base Configuration

LEO Staqing Base With OTV Structure

LEO Staging Base Coordinate System

Orbit Transfer Vehicle Configuration

Orbit Transfer Vehicle Structural Details

Orbit Transfer Vehicle Structure Perspective

Orbit Transfer Vehicle Coordinate System

Solar Power Satellite Configuration

Sular Power Satellite Subelement Structure

Solar Power Satellite Coordinate System

Directional. Reflectance Characteristics of Magnesium Oxide $(\lambda=0.5 \mu \mathrm{m})$

Oxide $(\lambda=2,0 \mu \mathrm{m})$ Magnesium Oxide

Spectral Reflectance of Z-93 Paint

Spectral Reflectance of Aluminum

Spectral Reflectance of Carbon Graphite Various Spacecraft Materials 
LIST' OF FIGURES AND TABLES (continued)

Figure

Number

Title

Page

22

Diffuse Reflection From SB in LEO During OTV

Configuration (DI)

Diffuse Reflection From SPS in GEO (D2)

Diffuse Reflection From OTV During Transit from LEO (D3)

Angular Dependence of OTV-Earth Distance and Irradiance

Specular Reflection From SPS Solar Panels in GEO

Around Equinoxes (S2)

Specular Reflection From SPS Antenna in GEO

Around Equinoxes (S3)

Specular Reflection From OTV in LEO During Uncontrolied Maneuvers During Uncontrolled Maneuvers

LEO Staging Base Element Descriptions

Orbit Transfer Vehicle Element Description

Solar Power Satellite Element Description 


\subsection{SUMMARY}

The development and operation of a Satellite Power System would place very large structures in orbit around earth for several decades. Sunlight reflected off such structures, particularly specular components from large flat areas, is expected to create ground illumination that will attract observers. In order to assure that this illumination does not exceed the irradiance tolerances of the eye, reflections from these satellites must be carefully controlled by vehicle orientation and surface specifications.

The solar power satellite (SPS) at geosynchronous earth orbit (GEC) has $55 \mathrm{~km}^{2}$ of glass covered solar cells that are oriented normal to the sun, as well as a $1 \mathrm{~km}^{2}$ microwave antenna. Transportation of construction materials from low earth orbit (LEO) to GEO) requires 23 Orbit Transfer Vehicles (OTVS) that have $1.6 \mathrm{~km}^{2}$ solar panels oriented normal to the sun during their. 6 month transits. The Staging Base (SB) at LEO, that accommodates OTV fabrication and cargo transfer, consists of $0.5 \mathrm{~km}$ arms protruding from a $.44 \mathrm{~km}^{2}$ open grid aligned with its orbit plane. Diffuse reflections would make the.SB/OTVs readily discernible in the daytime and the OTVs and SPSs observable all night (except during eclipse). Sporadic specular glints would appear on the ground from the OTVs and SPSS near the midnight meridian, from the solar panel surfaces of OTVs during LEO fabrication around midday, and from OTVs near LEO at dawn and dusk.

The ground level irradiance has been evaluated for several unusually bright configurations using the present system design. ${ }^{1,2}$

The brightest specular reflection is produced during the daytime by the aluminized backside of the OTV as it nears completion in LEO during the solstices. Assuming the panel surfaces are misaligned by $1.5^{\circ}$ overall, the irradiance is $2 \mathrm{~W} / \mathrm{m}^{2}$. in a spot about $25 \mathrm{~km}$ across (a perfectiy flat surface would produce $19 \mathrm{~W} / \mathrm{m}^{2}$ in an $8 \mathrm{~km} \mathrm{spot}$ ) moving at the satellite speed of $8 \mathrm{~km} /$ sec. The cover glass on the front side of the OTV solar cells produces 16 times less illumination. At night the brightest specular reflection is from the SPS antenna around the equinoxes. This flat aluminum surface produces an irradiance of $0.01 \mathrm{~W} / \mathrm{m}^{2}$ in a spot about $350 \mathrm{~km}$ across which moves at $150 \mathrm{~km} / \mathrm{sec}$ as the 
antenna tracks the ground receiver. Several other cases are calculated including diffuse reflections that are orders of magnitude dimmer than specular beams from the same element. For purposes of comparison with starlight, the apparent stellar magnitude of the SPS antenna is -13.8 , comparable to the full moon, and the diffuse reflection from the entire SPS is -3.6 , comparable to Venus.

These worst case irradiances may be reduced significantly and perhaps el iminated by appropriate modifications to the design and/or operation of the Space Power System spacecraft. By slight changes in vehicle orientation the specular reflections from the large solar panels can be directed away from the earth. Another modification is to introduce surface curvature or misalignment of flat panels that diverges the specular beams. Finally the specular surface quality of the SPS antenna, for example, can be eliminated (or sharply reduced) by etching or coating the material to create a diffuse reflection.

The methodology for calculating sky brightness created by a diffuse source is also presented. For observations directed well away from the source, typical skylight is on the order of $1 \%$ of the direct irradianse. A complete set of equations and tabular entries is provided for evaluation of explicit cases. 


\subsection{STATEMENT OF PROBLEM}

\subsection{BACKGROUND}

Limited terrestrial energy sources have led to investigation of Space Power systems, that would collect solar energy and beam it via microwaves to power stations on the ground. The Reference system ${ }^{l}$ consists of a Staging Base in LEO, a fleet of Orbit Transfer Vehicles for movement of supplies from LEO to GEO and assembly and operation of Solar Power Satellites in GEO. All of the structures would be very large in comparison with today's satellite sizes, and include large plane surfaces to collect solar energy. As many as 60 SPSs are presently contemplated for deployment early, in the 'next century, which would require a substantial entourage of assembly and service vehicles.

'Due to the enormous size of these spacecraft and their assembly vehicles, they may be viewed routinely by large numbers of ground observers. The brightness of sunlight reflections off various components changes markedly as the 'vehicles rotate along their trajectories. Many surfaces will undoubtedly be 'coated with optically diffusing material, but the present baseline configurations also include large flat areas that are specular such as glass, polished metal, and smooth composites. Owing to the large size, relatively low altitude (at LEO), and/or specularity, some reflections will be exceptionally bright. A typical reflection configuration for SPS at GEO is illustrated schematically in Figure 1 .

The level of ground illumiration is needed to evaluate potential effects, if any, such as radiant energy in observer's eyes, skybrightness for optical astronomy, and changes in animal behavior. For example, there is reason to investigate how well the human eye can adapt to this unusual light source. The reflections will appear to ground observers as very bright starlike points of light in relatively dark right sky. Since contraction of the iris is controlled by overall illumination levels, the eye pupil may accept more light energy than desirable from these point sources, and produce abnormally high retinal irradiance. Since the eye relies only on the iris and blink reflex to control total irradiance, it is important that the power density of such point-source retinal images does not exceed safe limits. 


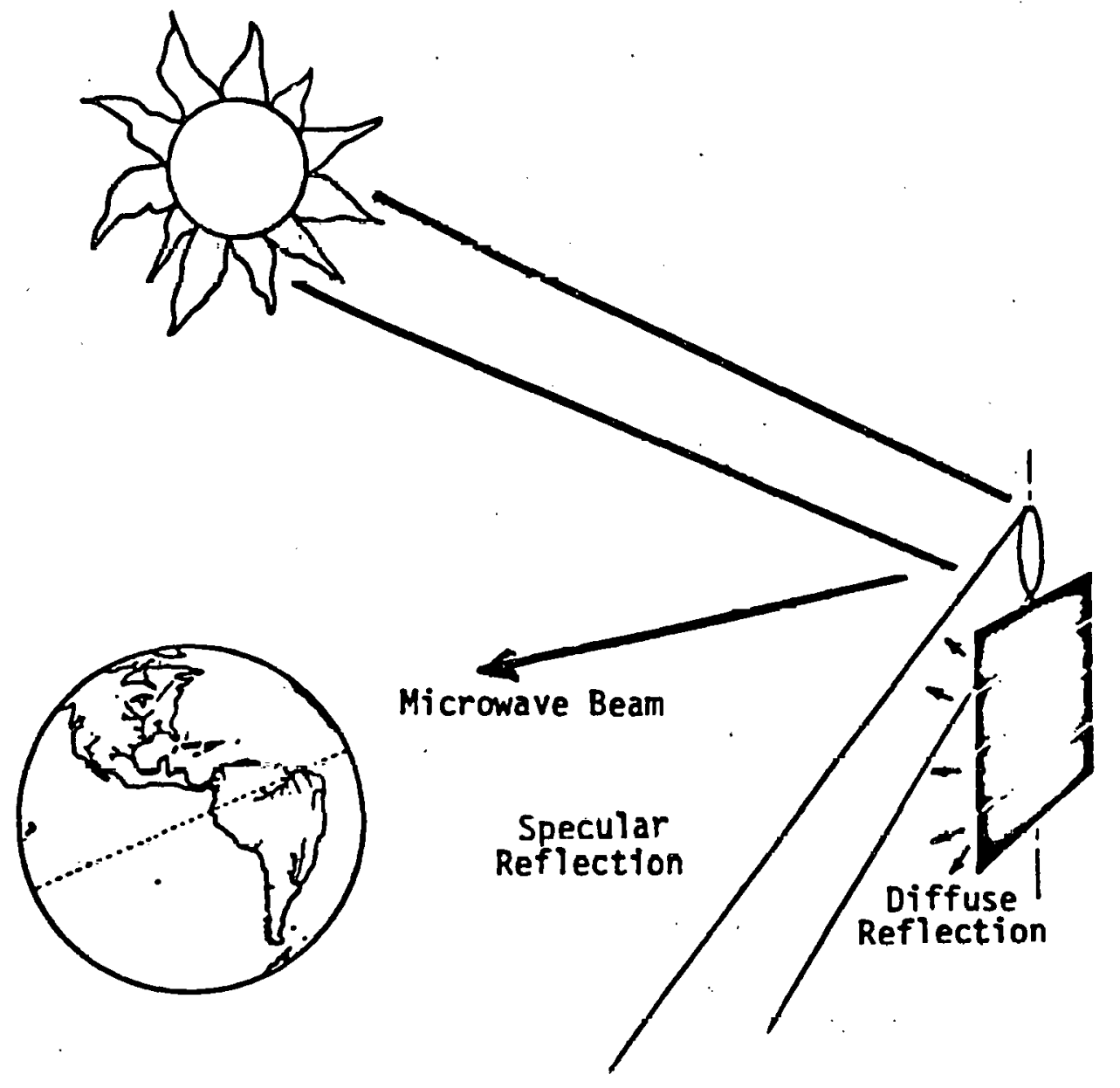

Figure 1. Typical Reflection Configuration for the Sollar Power Satellite at GEO 
This assurance is best provided by thoughtful design of the Solar Power system. If the brightness of baseline vehicles exceeds accepted limits for eye safety, certain constraints on reflectivity of surfaces and the orientation of vehicles are the most likely procedures that would lower ground illumination. However, additional surface preparations that are spaceworthy may require more work and added cost. Similarly, shifts in vehicle orientation, however small, may reduce the utility of power collection systems and adversely affect overall efficiency. Thus, it will be important to explore a number of options.

\subsection{SCOPE OF INVESTIGATION}

This study has evaluated the components of the various Satellite Power System vehicles as presently defined ${ }^{1,2}$ to determine the reflectances which will significantiy contribute to the ground illumination. The various system configurations considered include the Staging Base (SB) in LEO, the Orbital Transfer Vehicles operating between LEO and GEO, and the Solar Power. Satellite (SPS) in GEO. The formulations and analysis procedures are presented in a manner which allows one at a later time to transform the results to any desired geometrical relationship between the earth, sun, orbit, and vehicle in order to assess the reflected light effects on the human eye, biota, and optical astronomy under a variety of conditions. In addition to ground illumination effects, the means are also provided for one to estimate the sky illumination at any combination of sun location, observer location, and apparent point in the sky.

Based on the Satellite Power System Reference System ${ }^{1}$, the three major structures (SB, OTV, and SPS) have been examined in detail to ascertain the reflection characteristics of primary surface areas. When vehicle design configurations were more fully specified in the Boeing Baseline Design ${ }^{2}$, this information was incorporated into the study as appropriate. Where the specific materials have uncertain optical qualities or materials were not specified, reasonabie assumptions have been made and annotated about the reflectivity. The size of these representative areas and their orientation have been taken from the Reference System information ${ }^{1}$, from the Boeing Baseline Design ${ }^{2}$, or otherwise estimated from good engineering judgment. 
Several configurations where bright reflections are directed earthward have been analyzed to ascertain the level of ground illumination. Typical situations include the daytime reflections from the SB at LEO, OTV in transit near LEO at dawn and dusk, OTVS near GEO, and SPSS at GEO around the equinoxes.

All parameters and the required approach to determining sky brightness have been defined. A specific example of sky brightness determination has been computed to illustrate our approach. 


\subsection{RESEARCH AND ANALYSIS}

\subsection{REFLECTANCE OF VEHICLES}

The reflection of the various system components is best considered in two parts. That is the elements that could significantly contribute to the ground illumination are identified and their qualities are described. The second part describes the general formulation for determining ground illumination intensities for any given reflector as a function of the reflector characteristics.

\subsubsection{Reflection Analys is}

Most of our surroundings consist of diffuse surfaces where the light is reflected over a broad range of angles, usually a full $2 \pi$ steradians. The angular dependence of the reflection can vary due to surface orientation qualities such as nap and reflections may be peaked in one direction or another with a normalized angular dependence $G\left(\theta_{j}, \theta_{r}\right)$ where $\theta_{i}$ and $\theta_{r}$ are incident and reflected directions measured from the surface normal. A Lambertian surface has a diffuse reflection that varies as $2 \cos \theta_{r} \cos \theta_{i}$.

Reflected energy from a diffuse surface at the center of a hemisphere of radius $R$ has an apparent brightness at the hemisphere that is diminished by $G / 2 \pi R^{2}$. For a spacecraft surface area $A$ with diffuse reflectivity $r_{d}$, the radiant flux above the atmosphere is proportional to $r_{d} A H_{\odot}$. Atmospheric extinction and light scattered by any optical instruments further degrade the brightness and are denoted by the factor $k$. Combining these quantities gives the general expression for diffuse irradiance,

$$
H_{d}=\kappa r_{d} A H_{\odot} G\left(\theta_{r}, \theta_{i}\right) / 2 \pi R^{2} \text {. }
$$

where $H_{\odot}$ is the sun's irradiance at the top of the atmosphere, $0.14 \mathrm{~W} / \mathrm{cm}^{2}$.

Any surface that produces a discernible reflection image is partially specular due to minute optically flat elements. Some surfaces like glass and polished metal are optically flat over large areas and their specular response is more noticeable due to bright sunlight glints. A representation of the 
fine structure suitable for all types of specular surfaces utilizes a theoretical model prepared earlier ${ }^{3}$ for another application.

The specular surface is assumed to be simulated by a mosaic of microscopic specular areas $\delta a$ which are optically flat to $\lambda / 10$ where $\lambda$ is a characteristic wavelength. The coherent reflection which is produced by each element $\delta a$ has an angular diameter given approximately by the diffraction limit $\rho \simeq \lambda / d$ where $d$ is a characteristic scale size for $\delta a$. Any angular deviation between the planes of the area elements will spread the solar image cone. This is treated by assuming that the surface normals of the elements are distributed randomly over an angular diameter $\varepsilon$, i.e., their distribution is rectangular. If, in addition, the reflector consists of an array of small mirrors, the distribution of their principal normals is characterized by an angular diameter $n$. The combined effect of these deviations produces a solar image divergence which has a total, angular diameter $\tau=2(\varepsilon+\eta)$.

The brightness of the solar image cone is readily derived for these reflector characteristics. The light that is emitted by the Sun is conveniently described for this application by an average visual disk radiance $N_{\odot}\left(2.0 \times 10^{7}\right.$ watts/ster $\left.\mathrm{m}^{2}\right)$. If the spacecraft is located a distance $\$$ from the Sun, the radiant flux on a reflector element $\delta a$ from an infinitesimal area $d A$ on the solar disk is given by $N_{\odot} d A \delta a \cos (\alpha / 2) / S^{2}$ where $\alpha$ is the "phase". angle at the spacecraft between the Sun and the Earth. The reflected intensity of this parallel beam is diminished by the specular reflectance $r_{s}$ of the surface and by the divergence of the 1 ight rays into a narrow cone of diameter $p$ which is assumed to be uniformly illuminated. Thus, the differential irradiance at Earth neglecting atmospheric effects is $N_{\odot} d A r_{s}$ da $\cos (\alpha / 2) / s^{2}\left(\pi \rho^{2} R^{2} / 4\right)$ where $R$ is the spacecraft range from Earth. Integration over the solar disk which subtends an angle $\sigma$ yields an irradiance $\mathrm{N}_{\odot} \sigma^{2} r_{s} \delta a \cos (\alpha / 2) /(\rho+\sigma)^{2} R^{2}$ over an image cone $\rho+\sigma$. Integration over the reflector introduces the divergence due to deviations in the surface, and the total irradiance from the reflector is $N_{\odot} \sigma^{2} r_{s} a \cos (\alpha / 2) /(\rho+\sigma+\tau)^{2} R^{2}$ above the atmosphere. At the surface of the Earth the irradiance is degraded further by atmospheric extinction and the optical response of the instrument which are denoted by the factor $k$. Thus the complete expression for the irradiance is 


$$
H_{s}=\kappa N_{0} \frac{r_{s} a \cos (\alpha / 2)}{R^{2}} \frac{\sigma^{2}}{(\rho+\sigma+\tau)^{2}}
$$

The linear diameter of the image disk at Earth is $(\rho+\sigma+\tau) R$.

A plot of the irradiance and its equivalent stellar magnitude for optimum conditions $(\kappa=1)$ is shown in Figure 2 as a function of spacecraft range from Earth. The curve is parametric in $r_{s} a \cos (\alpha / 2)$ which represents the projected area of an equivalent perfect reflector and $\sigma /(\rho+\sigma+\tau)$, which is the beam divergence factor.

\subsubsection{Structure Characteristics}

The calculation of reflected solar intensity from the various satellite system elements requires description of the elements and description of the geometry of potential reflectance paths. To reduce the calculation to a tractable problem only the nominally flat element surfaces were considered since the curved surfaces spread the light making their contribution negligibly small at the large orbital distances. In addition, the curved surfaces were found to be a small fraction of the total reflection areas. Each surface is further defined by its approximate reflectivity and an estimate of its "flatness".

In addition to determining that a surface is likely to reflect a significant intensity, it is also necessary to determine the conditions under which it will illuminate a portion of the earth. The orientation of each reflecting surface is therefore also necessary. To simplify the presentation of the element orientation, a number of convenient coordinate systems are used. The convention used was to define a coordinate system for each vehicle and to reference each element to that vehicle reference system. Each orientation can then be transformed to any other system such as a solar or an earth reference system, as may simplify a particular calculation. These data describing the reflecting elements are provided below in section 3.1.2.1.

The reflected intensity is also dependent on the material properties and surface qualities of the reflecting surface. In section 3.1.2.2, the wavelength dependence of the reflectivity is presented for the several imaterials. The bi directional reflectivity of the paint used on many surfaces is also provided. 


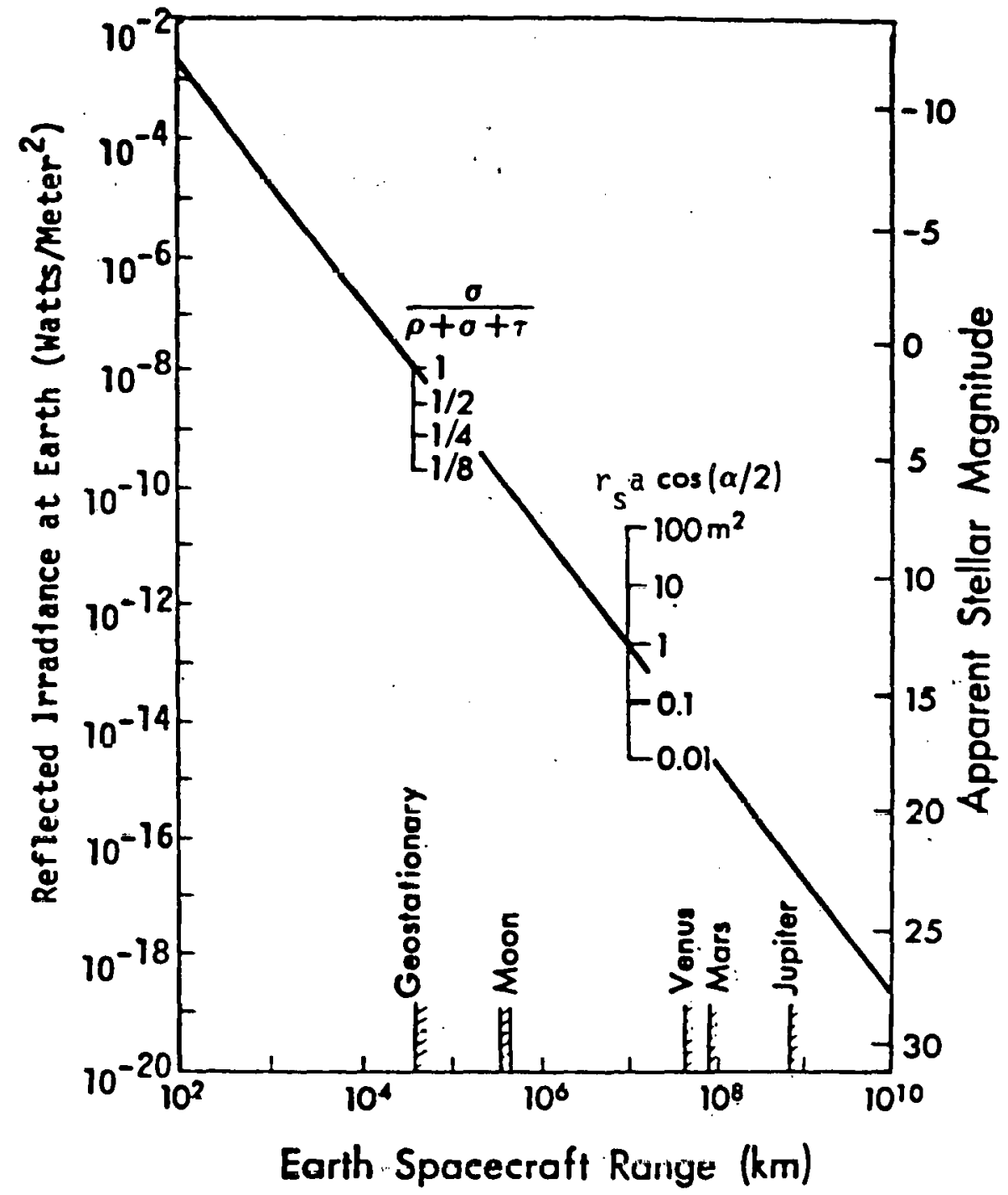

Figure 2. The Ground Irradiance Due to Specular Reflection of Sunlight ${ }^{3}$ 


\subsubsection{Description of Spacecraft Elements}

The major structures of the SPS system are the staging base (SB), the electrical orbital transfer vehicle (OTV) and the solar power satellite (SPS). In this section a general vector approach will be presented which allows one to determine what reflections from structural elements will strike the earth. The major reflection surfaces will be identified for each of the three vehicles.

The following explicit parameters will be needed in the specular reflection calculations :

1. Orientation of structural elements,

2. The total area of all elements of a given type,

3. The specular reflectance, $\rho$

4. The spreading angle, $\tau$, due to uneven surfaces.

Each major system, the SB, the OTV, and the SPS will be treated separately below. The above parameters along with the direction cosines of the reflected light will be tabulated for the major elements of each major system.

The reflection unit vector $r$ shown in Figure 3 can be expressed in terms of the incident and normal unit vectors $\hat{i}, \hat{n}$. Appendix $A$ gives the computer program for vector rotation which was used to find the direction cosines of the surface normals for each of the major systems which are presented in Tables 1-3.

\section{STAGING BASE}

The SB alone is shown in Figure 4, and construction of an OTV on the SB is shown in Figure 5 . The coordinate systems for the vector calculations are defined in Figure 6 . The plane defined by vectors $\hat{a}$ and $\hat{c}$ is the ecliptic plane while the $\hat{i}-\hat{k}$ plane is the orbital plane with an inclination (Kennedy launch) of about $30^{\circ}$. The SB and the OTV lie in this plane so that $\hat{x}=\hat{i}$, $\hat{y}=\hat{j}$, and $\hat{z}=\hat{k}$. Table 1 gives parameters for the various $S B$ elements defined in the figures. A11 elements are assumed to be covered with Z-93 white paint with a specular reflectance of 0.75 . Note the battens (which are triangular structural members which, along with cables, hold three stringers in a rigid beam) provide considerably less area than the beams and attached equipment. 


$$
\dot{r}=\hat{i}-2(\hat{n} \cdot \hat{i}) \hat{n}
$$

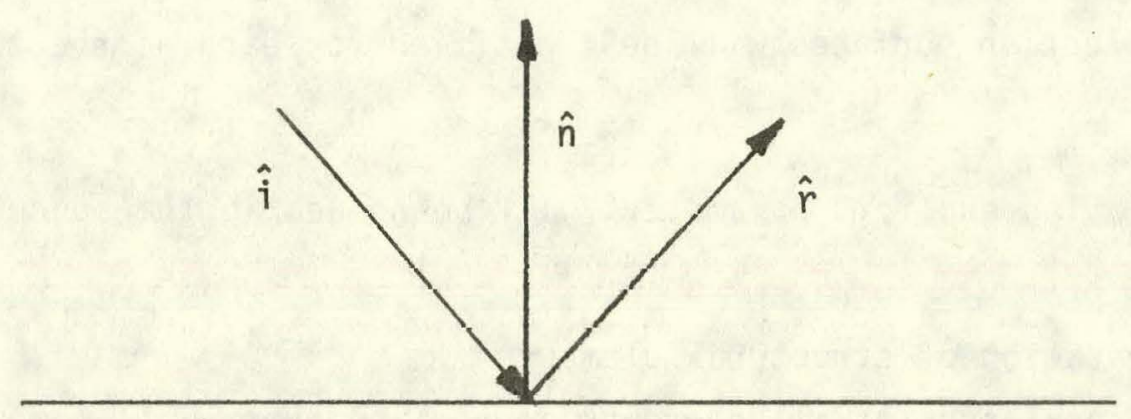

Figure 3. Spectral Reflectance Unit Vector Definition

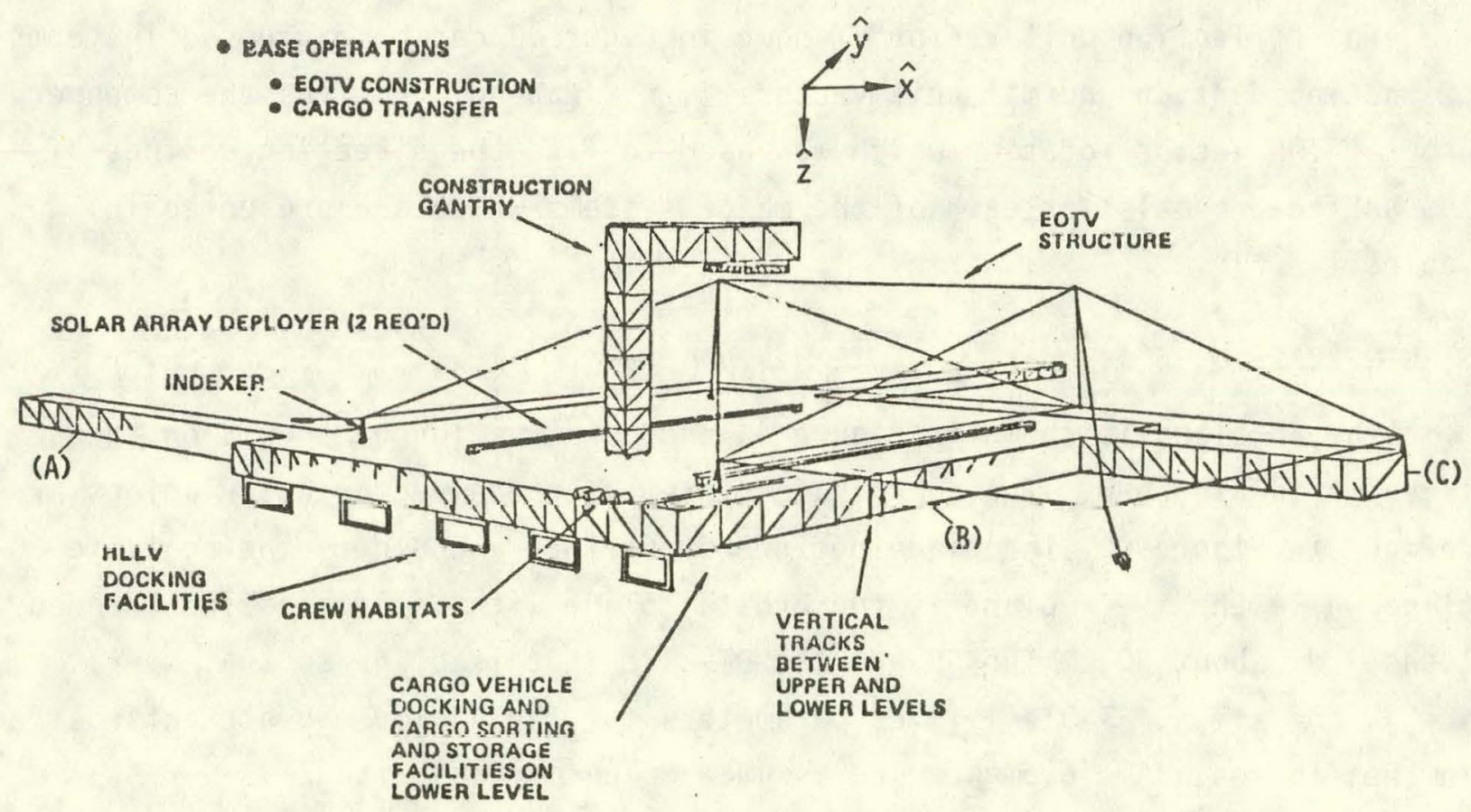

Figure 4. LEO Staging Base Configuration ${ }^{2}$ 


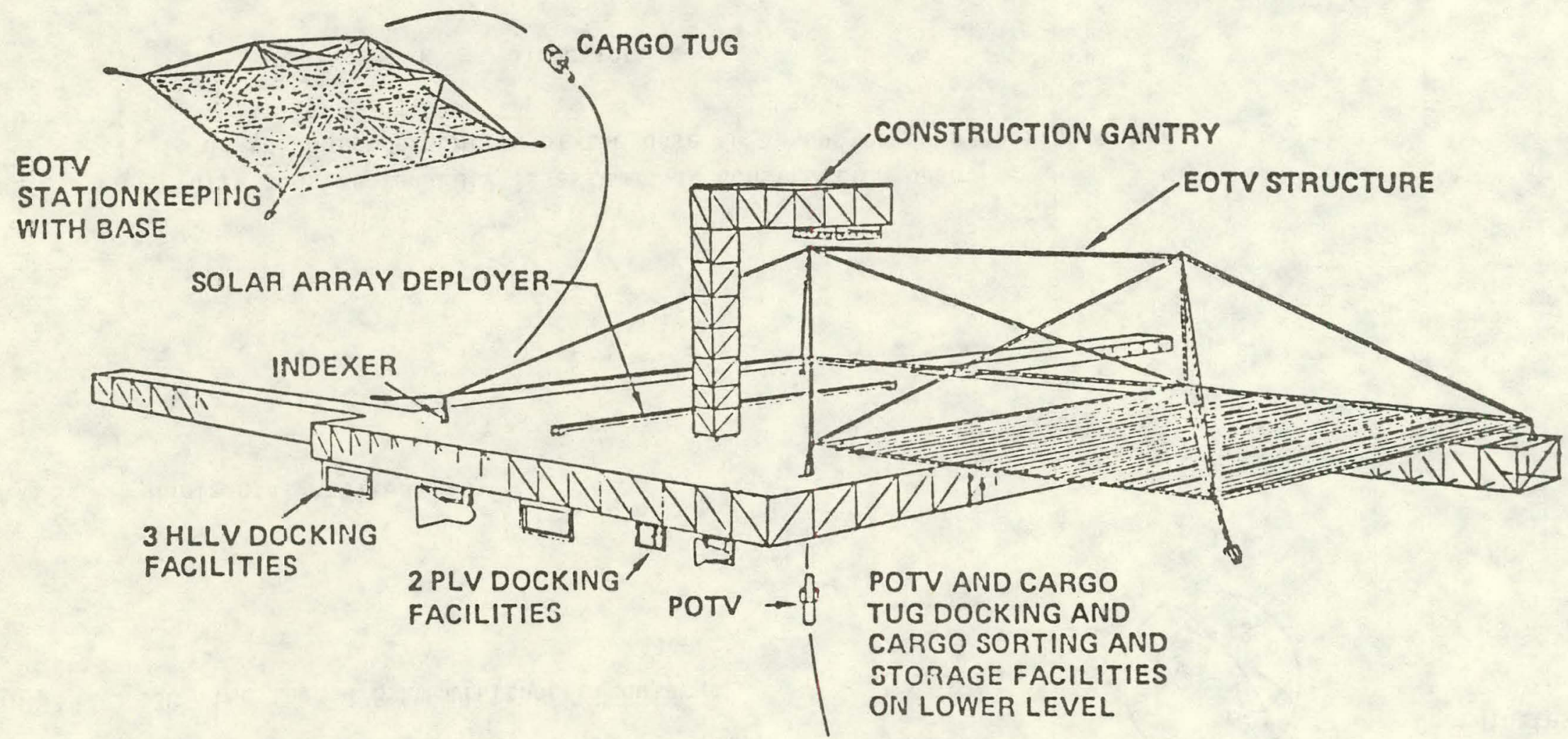

Figure 5. LEO Staging Base With OTV Structure ${ }^{2}$ 
Sunlight Coordinates
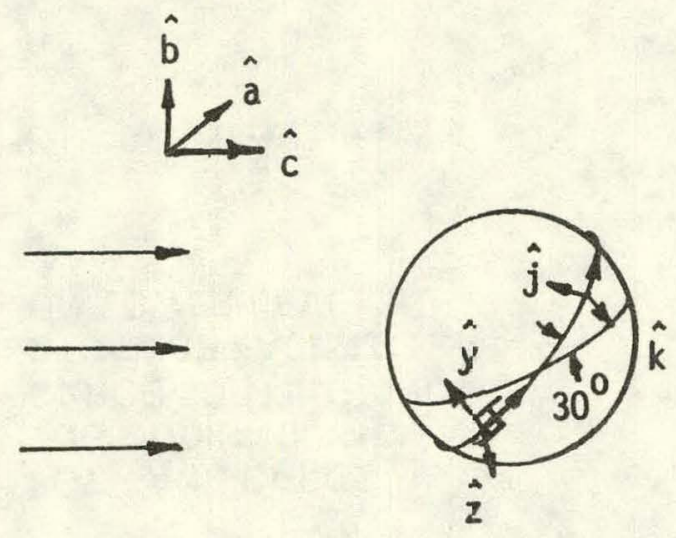

Coordinates

ORBIT: $\quad 30^{\circ}$ inclined $478 \mathrm{~km}$ altitude circular

AXES: Horizontal Attituce

$\hat{x}=\hat{i}$
$\hat{y}=\hat{j}$
$\hat{z}=\hat{k}$

NOTE: One fully constructed EOTV is assumed at construction base.

It is on the outside portion of the base in an upside down configuration.

I.e., cells face in the

$$
-\dot{z}=\hat{k} \text { direction. }
$$

NOTE: a-c plane is ecliptic plane

$i-k$ plane is orsital piane

Figure 6. LEO Staging Base Coordinate System 
Table 1. LEO Ștaging Base Element Descriptions

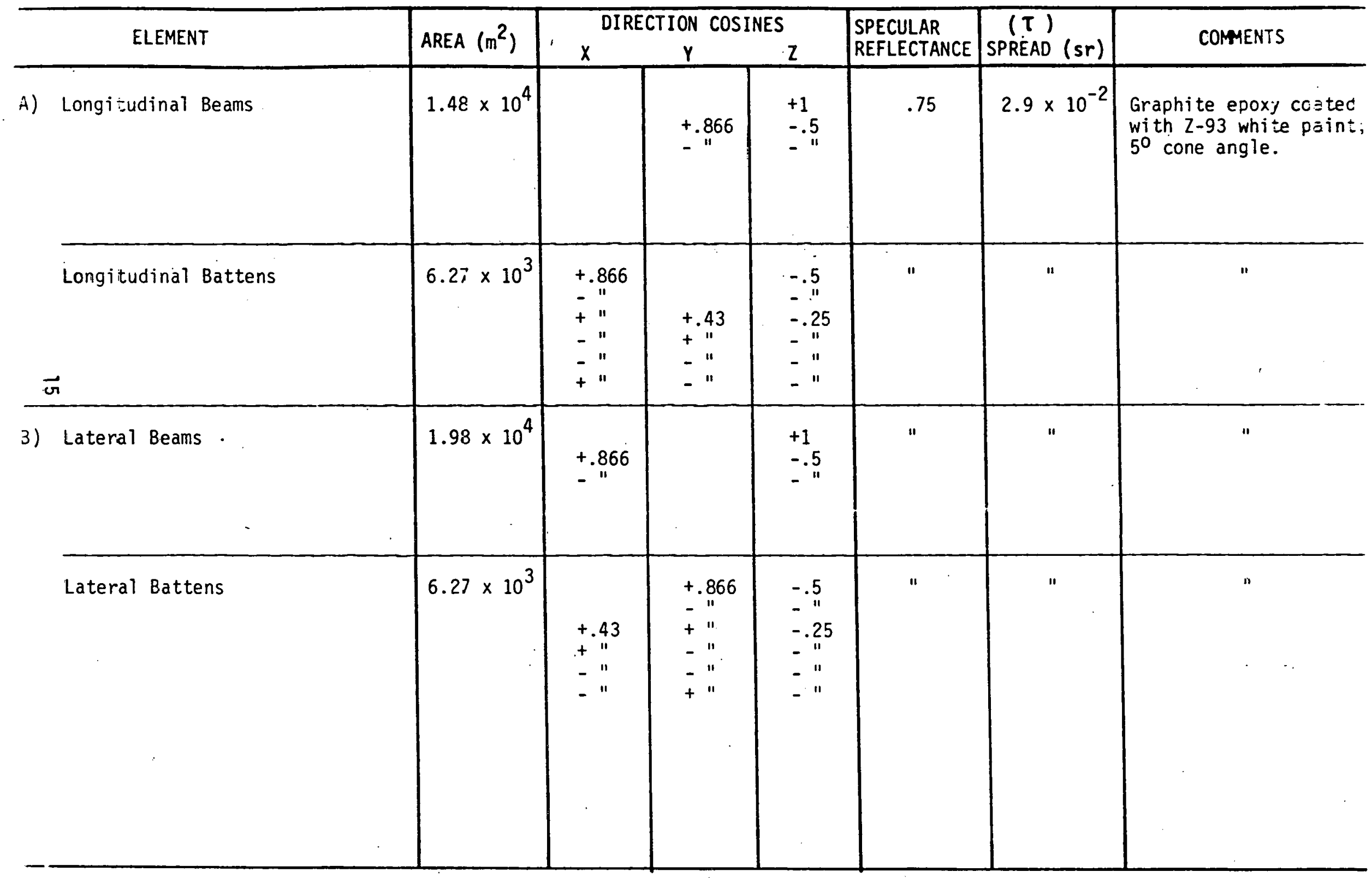


Table 1. LEO Staging Base Element Descriptions (cortinued)

\begin{tabular}{|c|c|c|c|c|c|c|c|}
\hline ELEMENT & AREA $\left(m^{2}\right)$ & $x^{D ! .3 E}$ & $\begin{array}{c}\mathrm{ION} \operatorname{COS} \\
\mathrm{Y} \\
\end{array}$ & & $\begin{array}{l}\text { SPECULAR } \\
\text { REFLECTANCE }\end{array}$ & $\begin{array}{c}(\tau) \\
\operatorname{SPREAD}(s r)\end{array}$ & COMMENTS \\
\hline Vertical Beams & $1.48 \times 10^{4}$ & $\begin{array}{l}-1 \\
+.5 \\
+\end{array}$ & $\begin{array}{l}+.866 \\
-11\end{array}$ & & .75 & $2.9 \times 10^{-2}$ & $\begin{array}{l}\text { Graphite epoxy coated } \\
\text { with } Z-93 \text { white } \\
\text { paint; } 5^{\circ} \text { cone angle. }\end{array}$ \\
\hline Vertical Battens & $6.27 \times 10^{3}$ & $\begin{array}{l}+.5 \\
+11 \\
+.25 \\
+" 1 \\
+" 1 \\
+\end{array}$ & $\begin{array}{l}+.43 \\
=11 \\
-" 1 \\
+11\end{array}$ & $\begin{array}{l}+.866 \\
-" 11 \\
+11 \\
+" 1 \\
-" 1 \\
-" 1\end{array}$ & $"$ & " & " \\
\hline $\begin{array}{l}\text { Longitudinal Diagonal Bearis } \\
\vec{a}\end{array}$ & $5.25 \times 10^{3}$ & $\begin{array}{l}+.70- \\
-11 \\
+.35 i \\
-" 11 \\
-11 \\
+11\end{array}$ & $\begin{array}{l}+.866 \\
+11 \\
-" 1 \\
=" 1\end{array}$ & $\begin{array}{l}+.707 \\
+11 \\
-.354 \\
-11 \\
-11 \\
-11\end{array}$ & $"$ & $"$ & " \\
\hline Longitudinal Diagonal Battens & $2.22 \times 10^{3}$ & $\begin{array}{l}+.966 \\
-11 \\
+.259 \\
-11 \\
+.436 \\
+11\end{array}$ & $\begin{array}{l}+.433 \\
-" 1\end{array}$ & $\begin{array}{l}-.259 \\
-11 \\
+.966 \\
+11 \\
-.789 \\
-11\end{array}$ & $"$ & $"$ & " \\
\hline$"$ & $"$ & $\begin{array}{l}-.436 \\
-11 \\
-.789 \\
-11 \\
+11 \\
+11\end{array}$ & $\begin{array}{l}-.433 \\
+11 \\
-.433 \\
+11 \\
+11 \\
-" 1\end{array}$ & $\begin{array}{l}-.789 \\
-" 1 \\
+.436 \\
+11 \\
+11 \\
+11\end{array}$ & " & $"$ & " \\
\hline
\end{tabular}


Table 1. LEO Staging Base El̃ement Descriptions (continued)

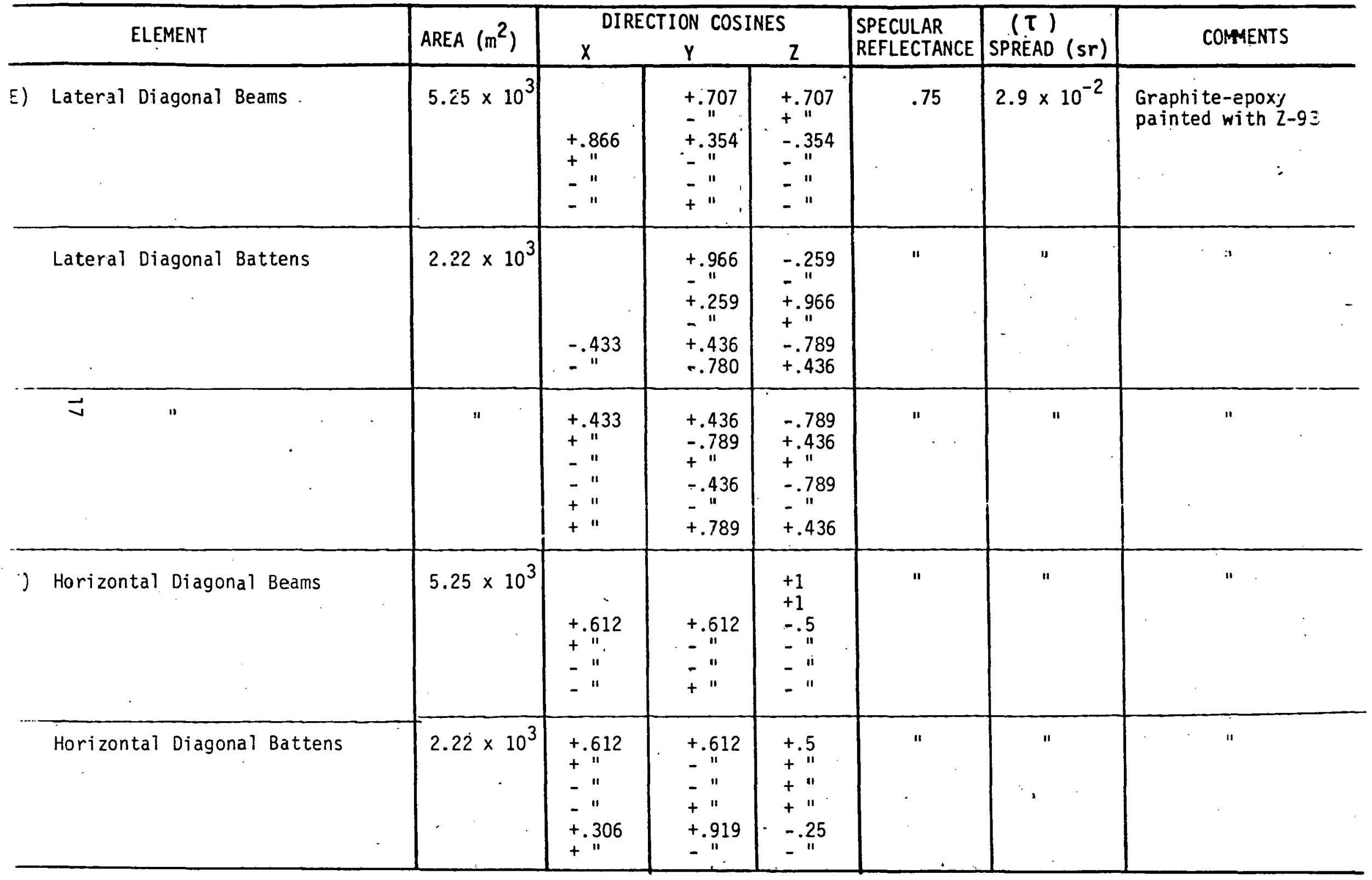


Table 1. LEO Staging Base Element Descriptions (continued)

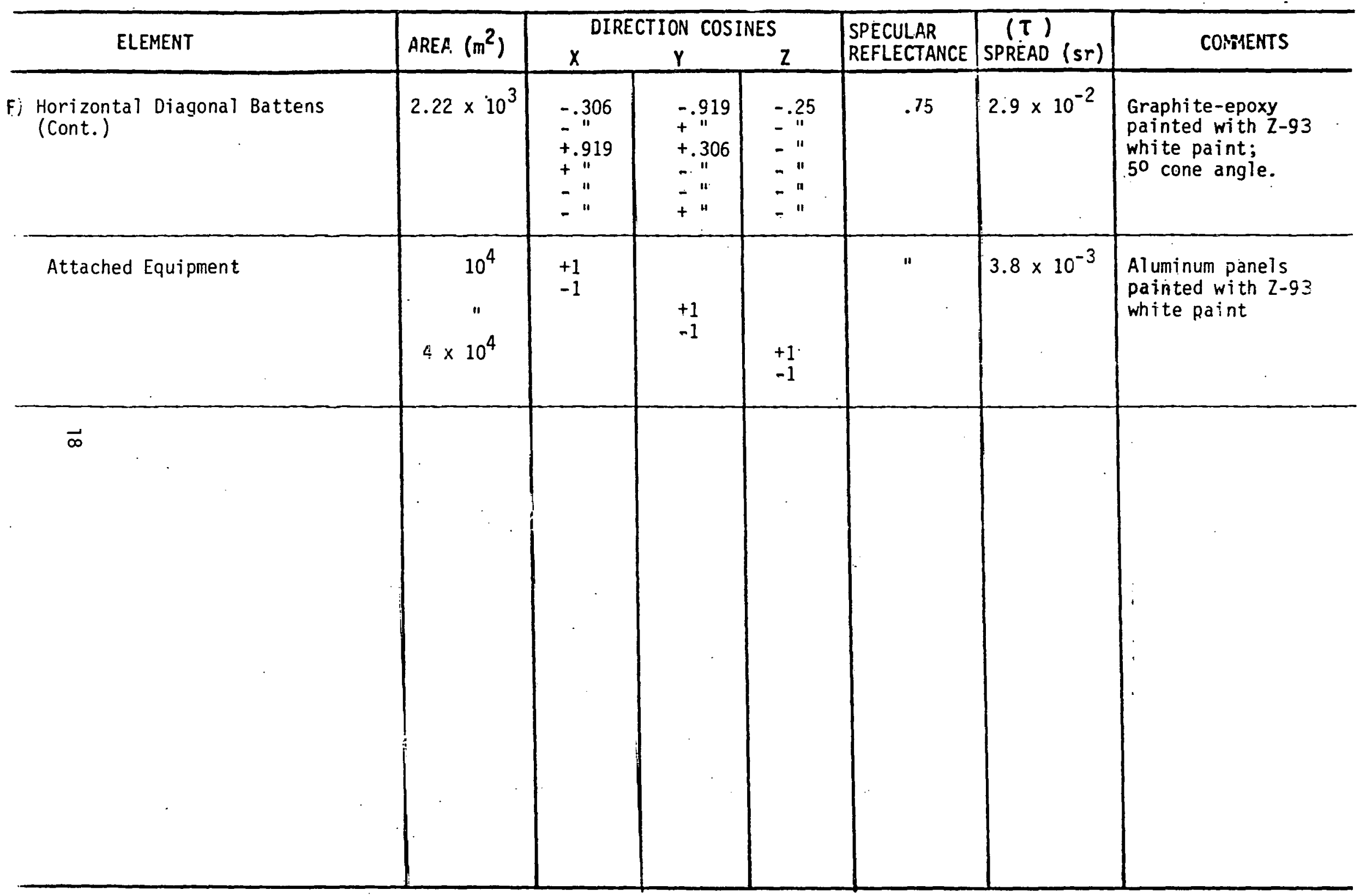




\section{ELECTRIC ORBITAL TRANSFER VEHICLE}

This system is sketched in Figure 7. Details and other views are given in Figures 8 and 9.

For the EOTV in LEO (worst case for reflections) the vector coordinates are defined in the same way as those for the SB. However, since the OTV is inverted at the staging base we have $\hat{z}=\hat{c}$ where $\hat{z}$ is normal to the solar panel side of the OTV (see Figure 10).

Table 2. gives parameters for the EOTV for the elements illustrated in Figures 7-9. Note that the back of the solar array with its large area and high reflectance is the dominant reflecting surface, and note that some subsystems of the EOTV are often shadowed.

\section{SOLAR POWER SATELLITE}

This system is sketched in Figure 11 and construction details are shown in Figure 12. Vector definitions and pointing equations are given in Figure 13 for both the transmitting array and for the solar array. The former always is pointed at a rectenna on the surface of the earth.

Table 3 gives parameters for the SPS for the elements illustrated in Figures 11-12. The major sources of specular reflection are the antenna and the solar array. If control should be lost of the SPS then the aluminum rear. side of the array could be the largest contributor. 


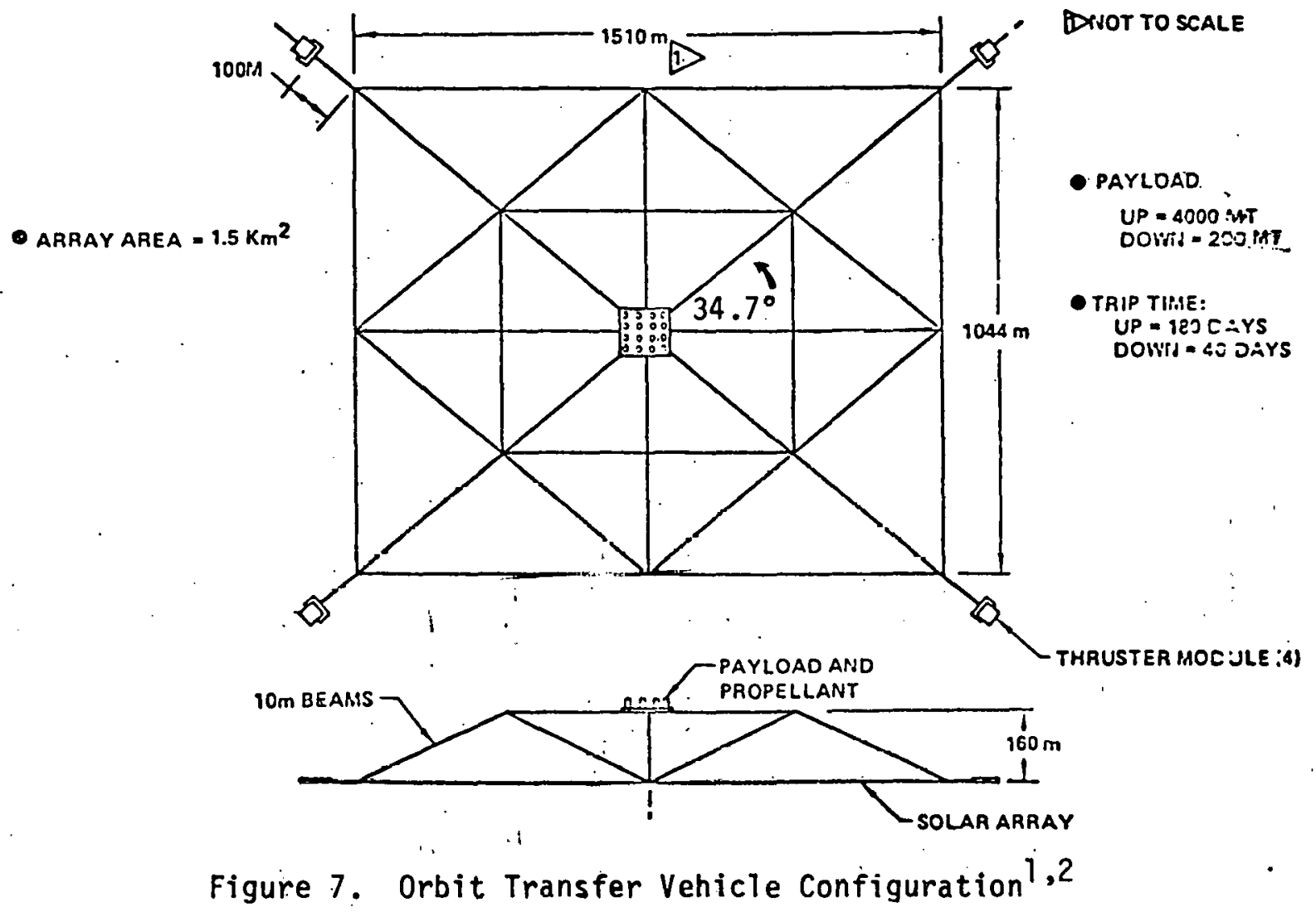

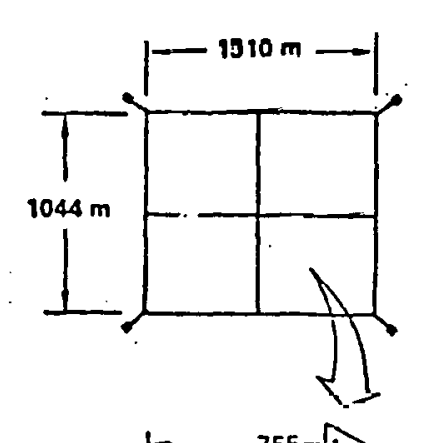

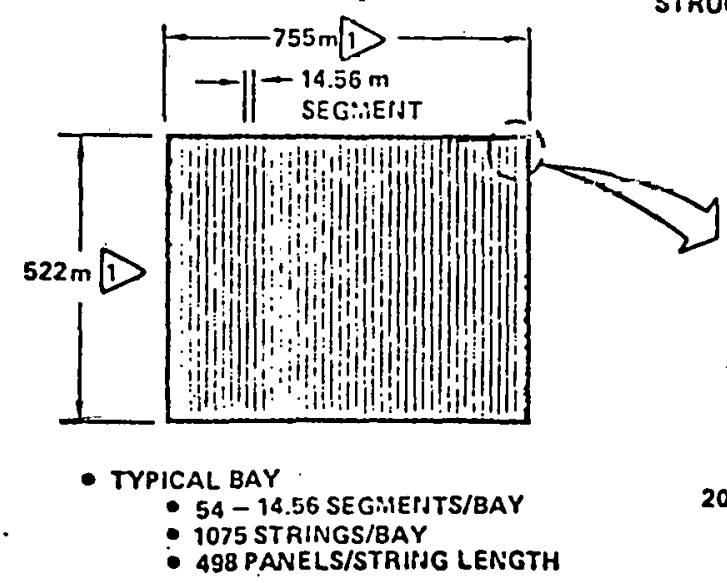

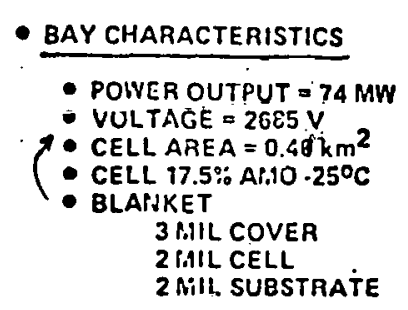

1. ingludes outside STRUCTURAL FRAME $(10 \mathrm{~m})$

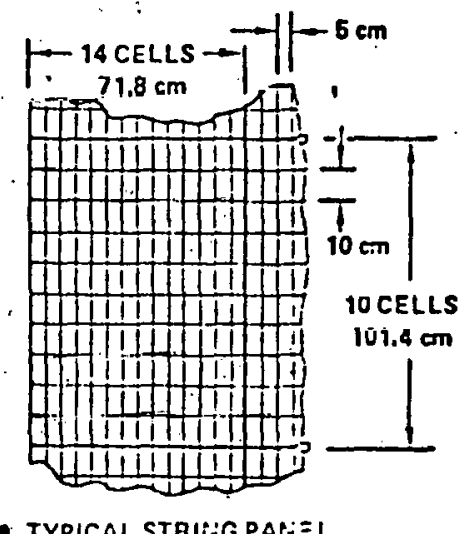

- typical staliig parjel

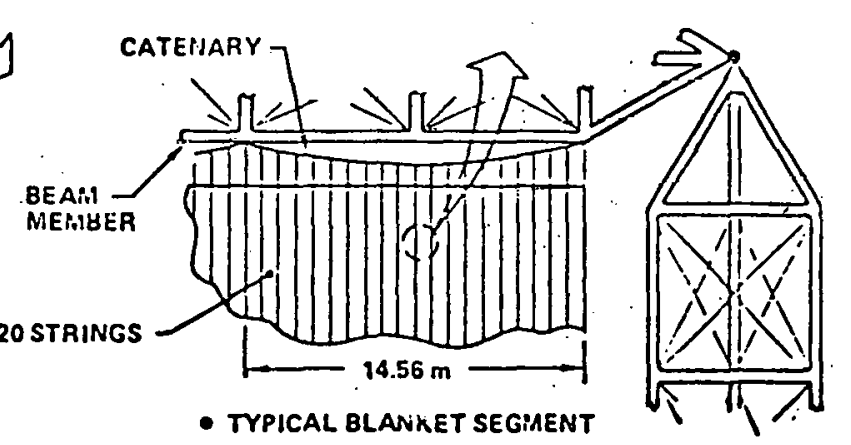

Figure 8. Orbit Transfer Vehicle Structural Details 


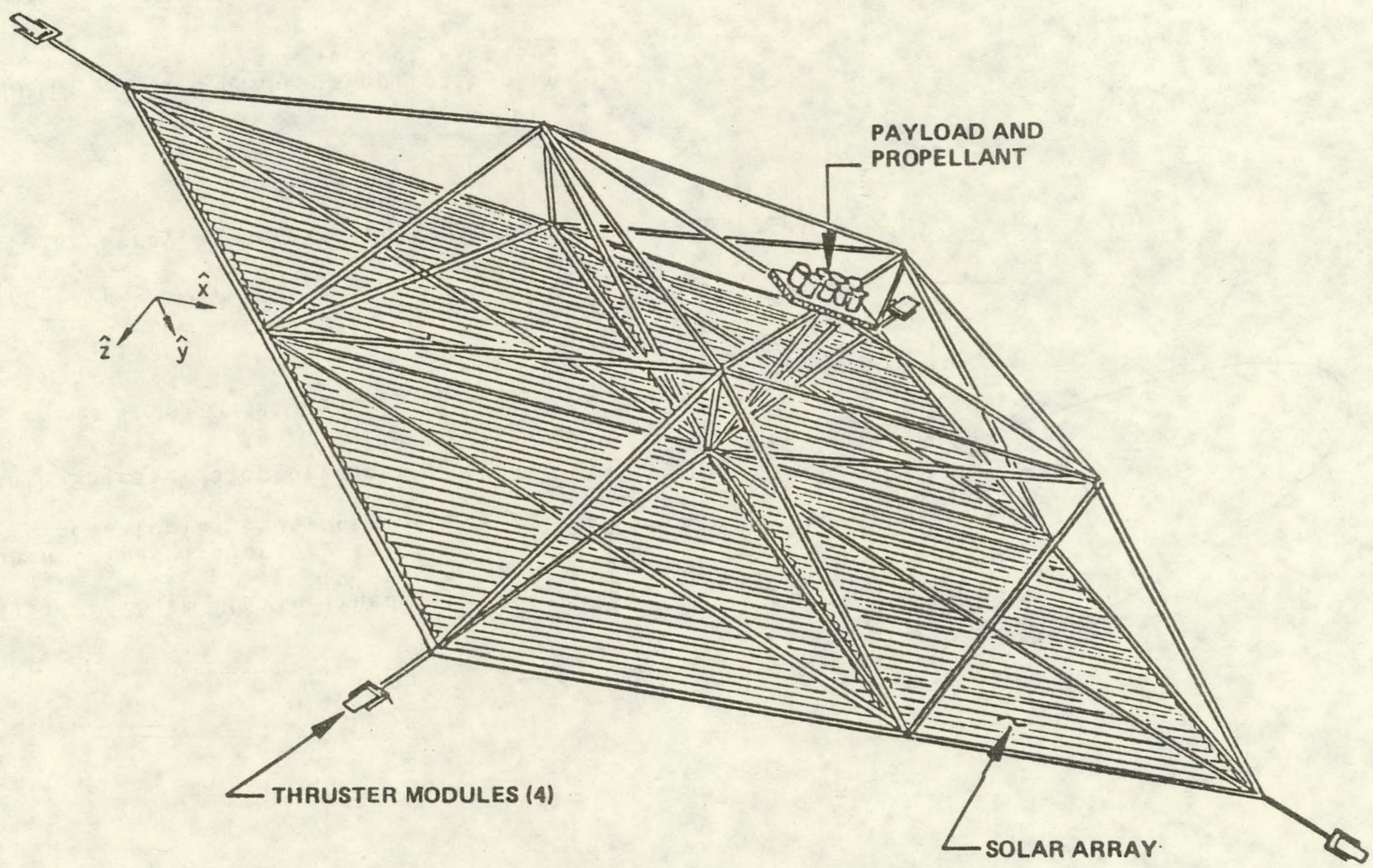

Figure 9. Orbit Transfer Vehicle Structure Perspective ${ }^{2}$ 
ORBITS: $\quad 478 \mathrm{~km} 30^{\circ}$ inclined

6-month Spiral Trajectory to Equatorial Geosynchronous

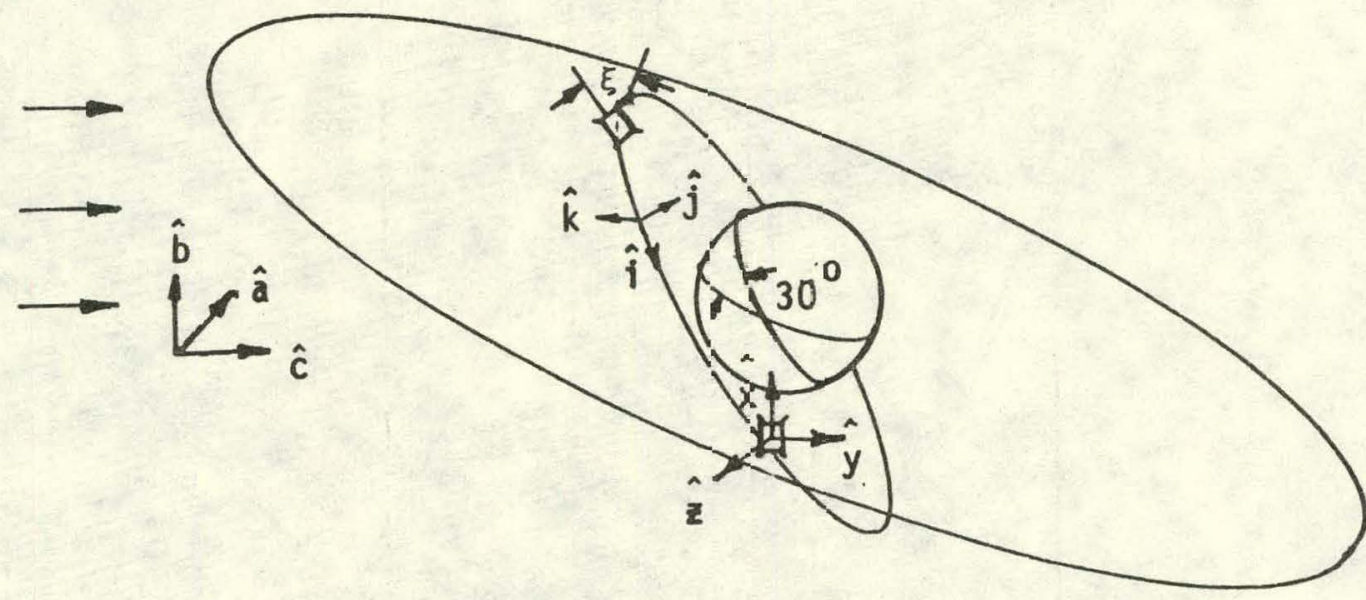

VEHICLE AXES :

Solar Array: Jerpendicular to Ecliptic Plane (PEP)

$\hat{z}=-\hat{c}$

NOTE: $\quad$ a-c plane is ecliptic plane

$i-k$ plane is orbital plane

Figure 10. Orbit Transfer Vehicle Coordinate System 
Table 2. Orbit Transfer Vehicle Element Description

\begin{tabular}{|c|c|c|c|c|c|c|c|c|}
\hline \multicolumn{2}{|r|}{ ELEMENT } & AREA $\left(m^{2}\right)$ & \multicolumn{3}{|c|}{ DIRECTION COSINES } & \multirow{2}{*}{\begin{tabular}{|l|} 
SPECULAR \\
REFLECTANCE \\
.05 (front) \\
.80 (back)
\end{tabular}} & $\begin{array}{l}(\tau .) \\
\text { SPREAD (sr) }\end{array}$ & COMMENTS \\
\hline (A) & Solar Array & $1.56 \times 10^{6}$ & & & $\begin{array}{l}+1 \\
-1\end{array}$ & & $9.6 \times 10^{-4}$ & $\begin{array}{l}\text { Silicon cells } \\
\text { Aluminum backing } \\
1^{\text {O cone angle }}\end{array}$ \\
\hline \multirow[t]{2}{*}{ (B) } & $\begin{array}{l}\text { Longitudinal (Cell Platform) } \\
\text { Beams + (Thruster Platform) }\end{array}$ & $\begin{array}{l}3.4 \times 10^{3} \\
1.15 \times 10^{3}\end{array}$ & & \pm .866 & $\begin{array}{l}+1 \\
-.5 \\
-\quad 11\end{array}$ & .75 & $2.9 \times 10^{-2}$ & $\begin{array}{l}\text { Graphite-Epoxy coated } \\
\text { with Z-93 white paint } \\
5^{0} \text { cone angle. } \\
\text { Thruster platform } \\
\text { nominally shadowed. }\end{array}$ \\
\hline & $\begin{array}{l}\text { Longitudinal (Cell Platform) } \\
\text { Battens + (Thruster Platform) } \\
\tilde{\omega}\end{array}$ & $\begin{array}{l}1.72 \times 10^{3} \\
5.75 \times 10^{2}\end{array}$ & $\begin{array}{l}+.866 \\
-\quad 11 \\
+.866 \\
-\quad " 11 \\
-\quad 11\end{array}$ & $\begin{array}{l}+.43 \\
+" 1 \\
-" 1 \\
-" 1\end{array}$ & $\begin{array}{l}+.5 \\
+" 11 \\
-.25 \\
-4 \\
-" 4 \\
-"\end{array}$ & $"$ & $"$ & $"$ \\
\hline \multirow[t]{2}{*}{ (C) } & $\begin{array}{c}\text { Lateral Beam (Ce11 } \mathrm{P}^{-} \text {atform) } \\
+ \text { (Thruster Pla } \text { :form) }\end{array}$ & $\begin{array}{l}2.38 \times 10^{3} \\
7.93 \times 10^{2}\end{array}$ & $\begin{array}{l}+.866 \\
-\quad 11\end{array}$ & & $\begin{array}{l}+1 \\
-.5 \\
-11\end{array}$ & $"$ & $"$ & $"$ \\
\hline & $\begin{array}{c}\text { Lateral Battens (Cell Platform) } \\
+ \text { (Thruster Pla:form) }\end{array}$ & $\begin{array}{l}1.19 \times 10^{3} \\
4.97 \times 10^{2}\end{array}$ & $\begin{array}{l}+.43 \\
+11 \\
-" 1 \\
-" 1\end{array}$ & $\begin{array}{l}+.866 \\
-\quad 11 \\
+.866 \\
-\quad 11 \\
-\quad 11 \\
+\quad 11\end{array}$ & $\begin{array}{l}+.5 \\
+" 11 \\
-.25 \\
-" 11 \\
-" 1 \\
-" 1\end{array}$ & $"$ & $"$ & $"$ \\
\hline (D) & $\begin{array}{l}\text { Flat Diagonals (Cell Platform) } \\
\text { (Symmetric) }+ \text { (Thruster Platform) } \\
\text { (Antisymmetric) }\end{array}$ & $\begin{array}{l}3.67 \times 10^{3} \\
1.84 \times 10^{3}\end{array}$ & $\begin{array}{l}+.49 \\
-11 \\
-.49 \\
+11\end{array}$ & $\begin{array}{l}+.71 \\
-\quad " 1 \\
+.71 \\
-\quad 11\end{array}$ & $\begin{array}{l}-.5 \\
-" 11 \\
-.5 \\
-" 11\end{array}$ & " & $"$ & $"$ \\
\hline
\end{tabular}


Table 2. Orbit Transfer Vehicle Element Description (continued)

\begin{tabular}{|c|c|c|c|c|c|c|c|c|}
\hline \multicolumn{2}{|r|}{ ELEMENT } & AREA $\left(m^{2}\right)$ & \multicolumn{3}{|c|}{ DIRECTION COSINES } & $\begin{array}{l}\text { SPECULAR } \\
\text { REFLEC ANCE }\end{array}$ & $\begin{array}{c}(\tau) \\
\text { SPREAD }(s r)\end{array}$ & COMMENTS \\
\hline (D) & $\begin{array}{l}\text { Diagonal Battens (Ce11 Platform) } \\
+\quad \text { (Thruster Plat=orm) } \\
\text { (Symmetric) }\end{array}$ & $\begin{array}{l}1.84 \times 10^{3} \\
9.20 \times 10^{2}\end{array}$ & $\begin{array}{l}+.61 \\
-11 \\
-.47 \\
+.96 \\
-11 \\
+.47\end{array}$ & $\begin{array}{l}+.61 \\
-11 \\
+.85 \\
-.14 \\
+11 \\
-.85\end{array}$ & $\begin{array}{l}-.5 \\
-" 11 \\
-.25 \\
-" 11 \\
-" 1 \\
-" 1\end{array}$ & .75 & $2.9 \times 10^{-2}$ & $\begin{array}{l}\text { Graphite-Epoxy coated } \\
\text { with Z-93 white paint; } \\
5^{0} \text { cone angle. } \\
\text { Thruster platform } \\
\text { nominally shadowed }\end{array}$ \\
\hline$\stackrel{D}{D}$ & (Antisymmetric) & & $\begin{array}{l}+.61 \\
-11 \\
-.96 \\
+.47 \\
-11 \\
+.96 \\
\end{array}$ & $\begin{array}{l}-.61 \\
+11 \\
-.14 \\
+.85 \\
+11 \\
+.14 \\
\end{array}$ & $\begin{array}{l}-.5 \\
- \\
-.25 \\
-" 11 \\
-" 11 \\
-" 11\end{array}$ & $"$ & $"$ & $"$ \\
\hline$(E-H)$ & Diagonals & $2.83 \times 10^{3}$ & $\begin{array}{l}+.07 \\
-11 \\
-11 \\
+11 \\
+.46 \\
-11\end{array}$ & $\begin{array}{l}+.05 \\
+11 \\
-11 \\
-11 \\
+.74 \\
+11\end{array}$ & $\begin{array}{l}+.996 \\
+11 \\
+11 \\
+11 \\
-.50 \\
-11\end{array}$ & .75 & $"$ & $\begin{array}{l}\text { Graphite-Epoxy } \\
\text { coated with Z-93 } \\
\text { white paint; } 5^{0} \text { cone } \\
\text { angle; nomina11y } \\
\text { shadowed. }\end{array}$ \\
\hline & Diagonal Battens & $1.43 \times 10^{3}$ & $\begin{array}{l}+.67 \\
-11 \\
-11 \\
+11 \\
+.75 \\
-11 \\
\end{array}$ & $\begin{array}{l}+.47 \\
+11 \\
-11 \\
-11 \\
+.52 \\
+\quad 11 \\
\end{array}$ & $\begin{array}{l}+.57 \\
+11 \\
+11 \\
+11 \\
+.42 \\
+\quad 11 \\
\end{array}$ & $"$ & $"$ & $"$ \\
\hline & & $"$ & $\begin{array}{l}-.75 \\
+11 \\
+.48 \\
-11 \\
-11 \\
+.48\end{array}$ & $\begin{array}{l}-.52 \\
-" 1 \\
+.86 \\
+" 1 \\
-" 11 \\
-" 1\end{array}$ & $\begin{array}{l}+.42 \\
+" 1 \\
-.17 \\
-11 \\
-" 11 \\
-" 1\end{array}$ & $"$ & $"$ & $"$ \\
\hline
\end{tabular}


Table 2. Orbit Transfer Vehicle Element Description (continued)

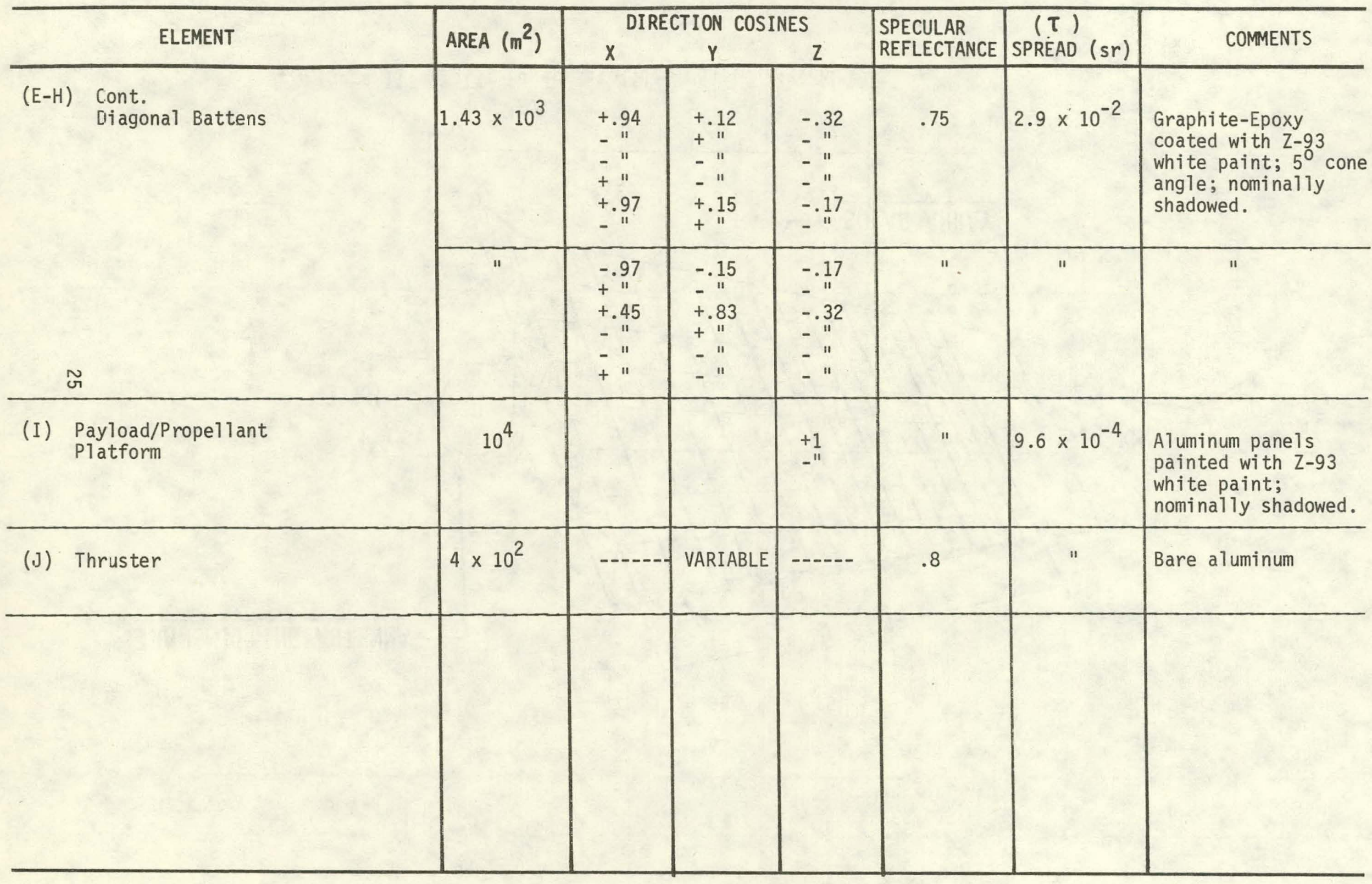




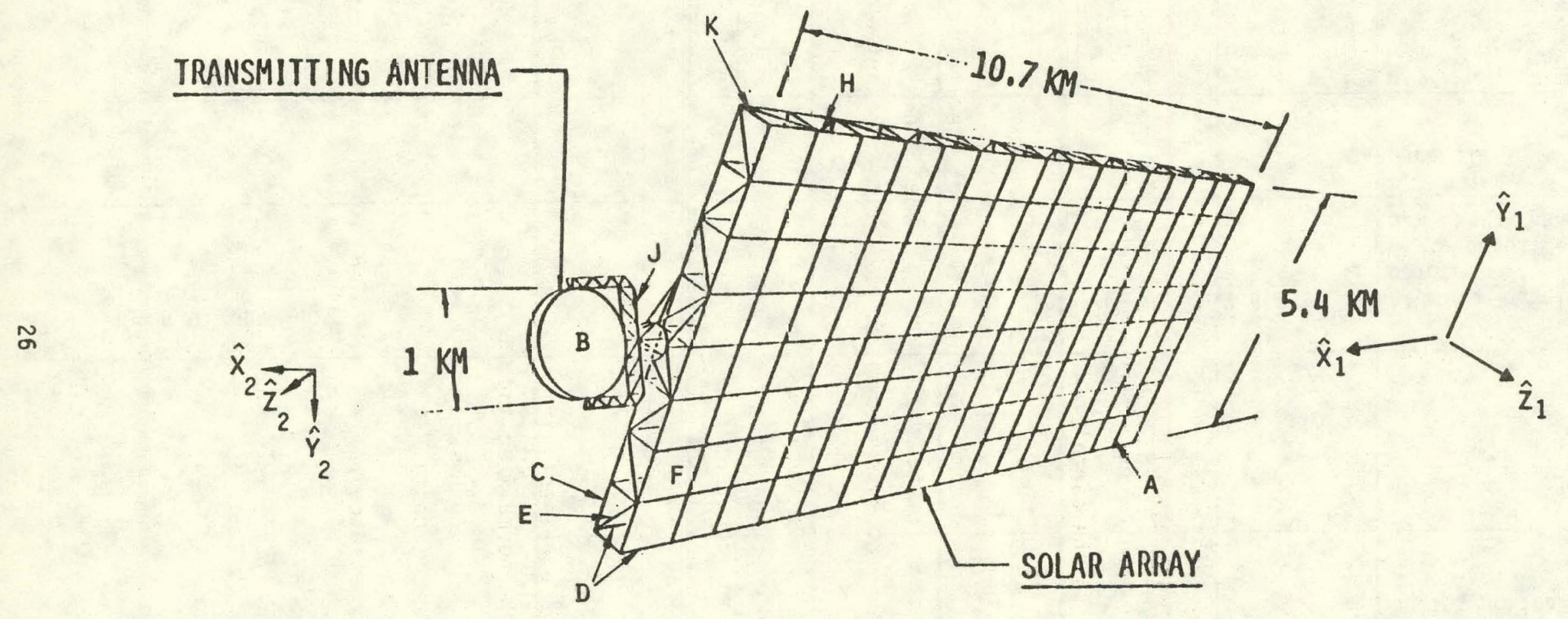

Figure 11. Solar Power Satellite Configuration 


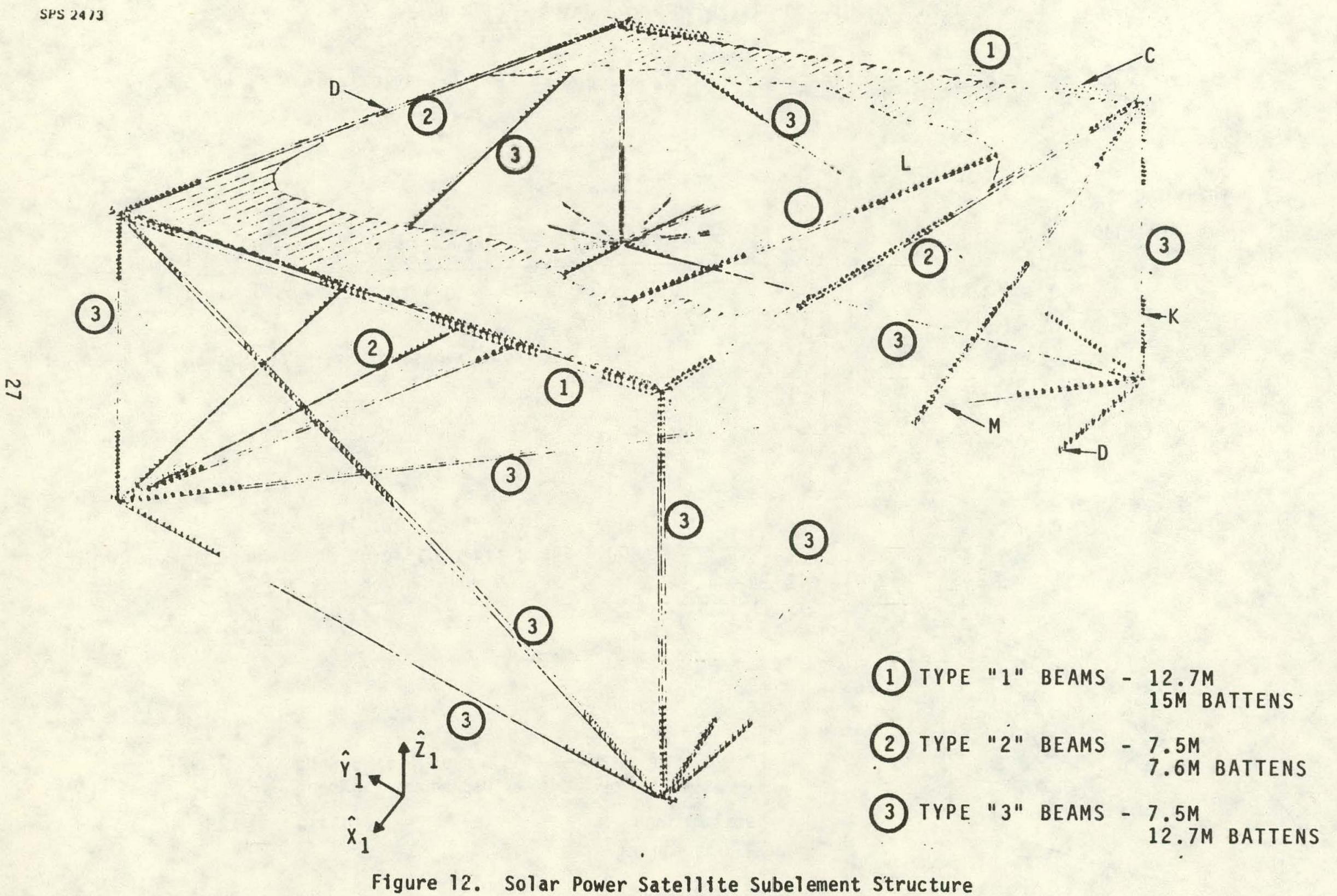




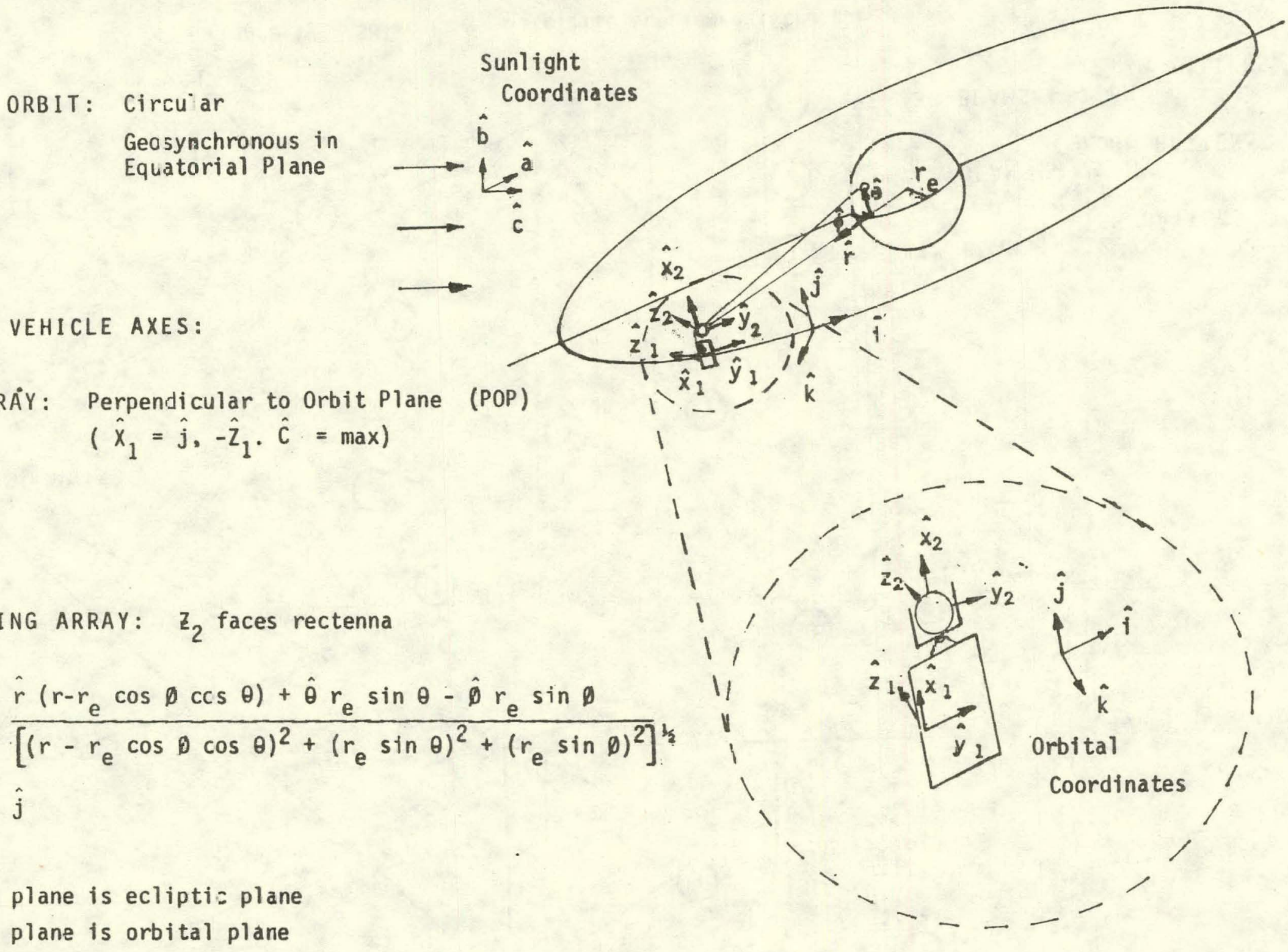

Figure 13. Solar Power Satellite Coordinate Systen 
Table 3. Solar Power. Satellite Element Descriptions

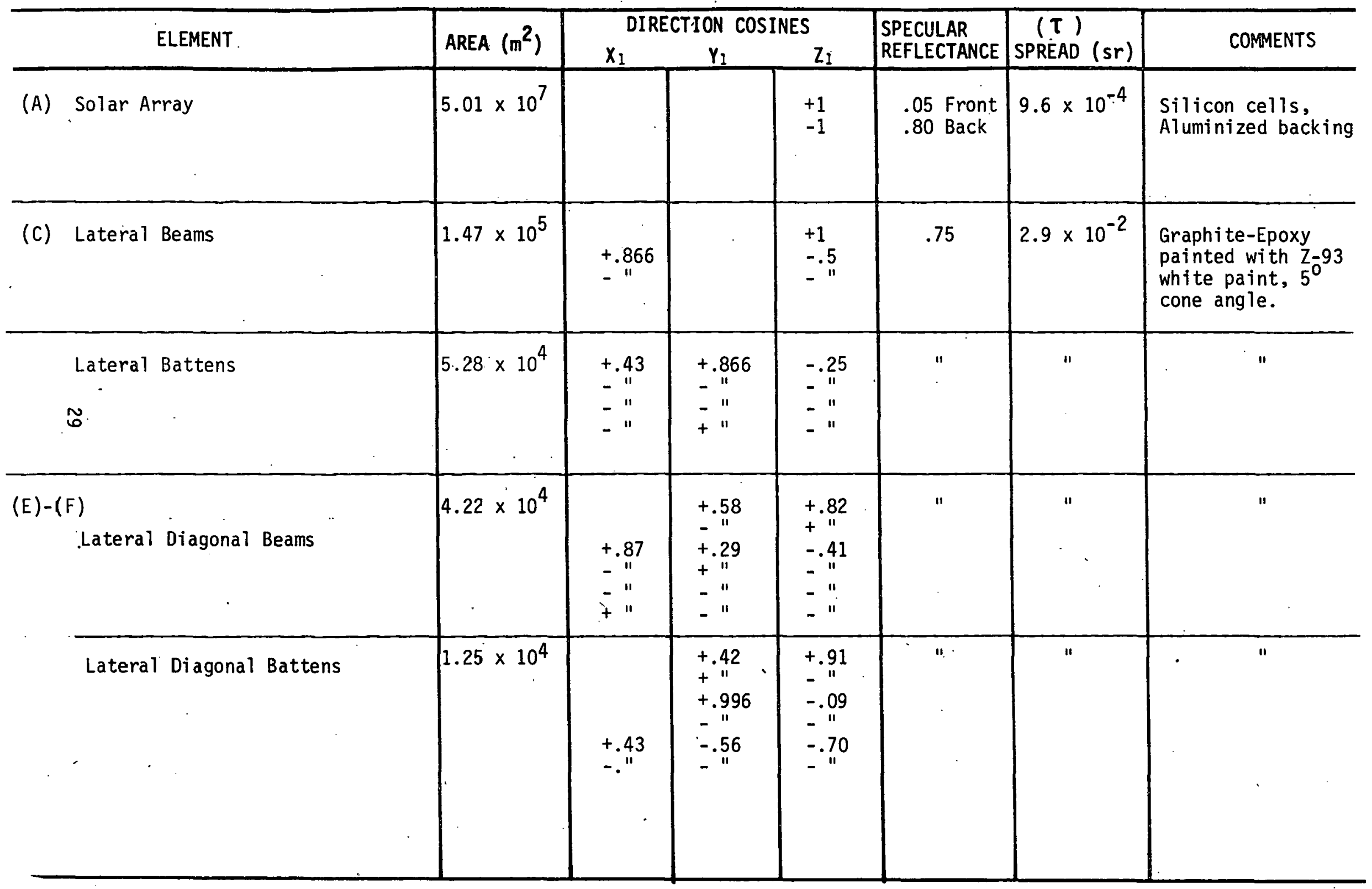


Table 3. Soiar Power jatellite El ement Descriptions (continued)

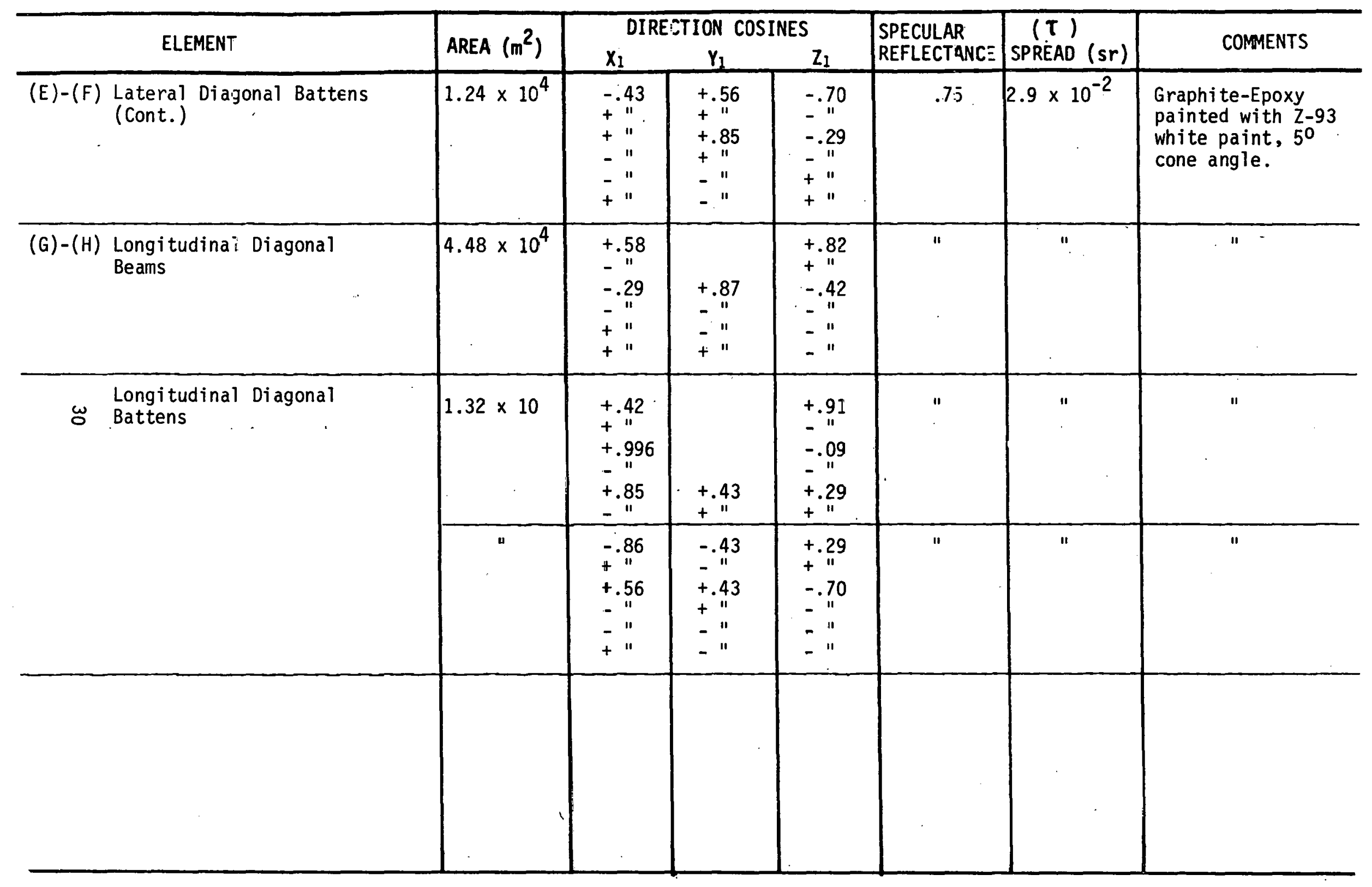


Table 3. Solar Power Satellite Element Descriptions (continued)

\begin{tabular}{|c|c|c|c|c|c|c|c|}
\hline \multirow{2}{*}{ ELEMENT } & \multirow{2}{*}{ AREA $\left(m^{2}\right)$} & \multicolumn{3}{|c|}{ DIRECTION COSINES } & \multirow{2}{*}{$\begin{array}{l}\text { SPECULAR } \\
\text { REFLECTANCE }\end{array}$} & \multirow{2}{*}{\begin{tabular}{|c|}
$(\tau)$ \\
SPREAD (sr) \\
\end{tabular}} & \multirow{2}{*}{ COMMENTS } \\
\hline & & $x_{1}$ & $Y_{1}$ & $z_{1}$ & & & \\
\hline (K) Vertical Beams & $5.47 \times 10^{4}$ & $\begin{array}{l}+1 \\
-1 \\
-.5 \\
-.5\end{array}$ & $\begin{array}{l}+.866 \\
-.866\end{array}$ & & .75 & $2.9 \times 10^{-2}$ & $\begin{array}{l}\text { Graphite epoxy coated. } \\
\text { with Z-93 white paint; } \\
5^{0} \text { cone angle. } \\
\text { Nominally perpendicula } \\
\text { to incident sunlight. }\end{array}$ \\
\hline Vertical Battens & $1.62 \times 10^{4}$ & $\begin{array}{l}-.25 \\
-11 \\
-11 \\
-11\end{array}$ & $\begin{array}{l}+.43 \\
+" 1 \\
-" 1 \\
-" 1\end{array}$ & $\begin{array}{l}+.86 \\
-" 1 \\
-11 \\
+" 1\end{array}$ & $"$ & ." & $"$ \\
\hline $\begin{array}{l}\text { (Li Cross Bay Diagonal Beams } \\
\omega\end{array}$ & $5.02 \times 10^{4}$ & $\begin{array}{l}+.315 \\
-11 \\
+.455 \\
-11 \\
+.770 \\
-11\end{array}$ & $\begin{array}{l}+.315 \\
+11 \\
-.770 \\
-11 \\
+.455 \\
+11\end{array}$ & $\begin{array}{l}+.895 \\
+11 \\
-.448 \\
-11 \\
-" 1 \\
-\end{array}$ & .75 & $2.9 \times 10^{-2}$ & $\begin{array}{l}\text { Graphite epoxy coated } \\
\text { with Z-93 white paint. } \\
\text { Normally shadowed }\end{array}$ \\
\hline Cross Bay Diagonal Battens & $1.48 \times 10^{4}$ & $\begin{array}{l}+.391 \\
-11 \\
+.706 \\
-11 \\
+.933 \\
-11\end{array}$ & $\begin{array}{l}-.391 \\
-11 \\
+.706 \\
-11 \\
-.321 \\
-11 \\
\end{array}$ & $\begin{array}{l}+.834 \\
+11 \\
+.616 \\
+11 \\
+.162 \\
+11 \\
\end{array}$ & $"$ & $"$ & $"$ \\
\hline & & $\begin{array}{l}+.163 \\
-11 \\
+.321 \\
-11 \\
+.776 \\
-11\end{array}$ & $\begin{array}{l}+.776 \\
+11 \\
-.933 \\
-11 \\
+.163 \\
+11\end{array}$ & $\begin{array}{l}-.610 \\
-" 1 \\
-.162 \\
-11 \\
-.610 \\
-" 1\end{array}$ & $"$ & $"$ & $"$ \\
\hline
\end{tabular}


Table 3. Solar Power Satellite Element Descriptions (continued)

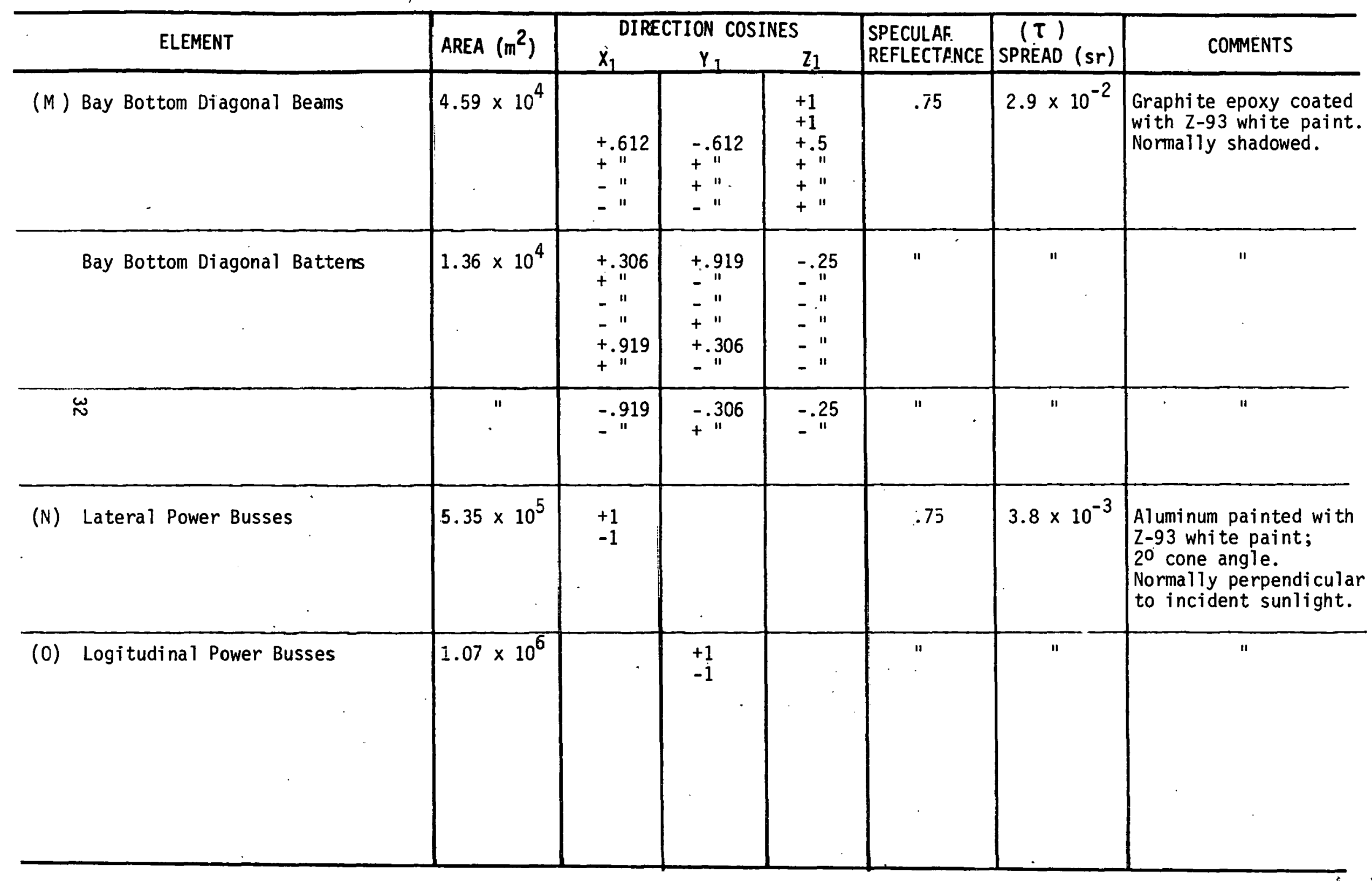




\subsubsection{Reflection Qualities of Materials}

The reflection properties of the structure surfaces are provided in this section in graphical format. ${ }^{4,5,6}$ The wavelength dependence of the reflectivity for the various materials are contained in Figures $14-20$. The roughness of the reflecting surface will also influence the intensity of light at some given angular location. A truly specular reflection will retain the character of the incident beam, but a strictly diffuse reflector will distribute normally incident light proportionate to the cosine of the observation angle measured from the surface normal. The actual performance of a surface is usually somewhere between the two extremes.

Figures 14 and 15 show the bidirectional reflection distribution of smoked magnesium oxide, which, although not a coating to be used on SPS, is often a standard for reference to other coatings. The white paint which will probably be used on SPS structures is Z-93. Assuming that the binders of the two paints are the same, or at least produces similar surface properties, these figures can be scaled to represent the bidirectional reflectance of Z-93 paint. Its relative reflectance value is the ratio of the intensity measured at some angular location to the corresponding intensity which would result by perfectly diffuse total reflection of the incident flux.

The general relationship is,

$$
I_{r} / I_{i}=R\left(\frac{\rho_{1}}{\rho_{2}}\right)\left(\cos \theta_{M} / \cos \theta_{I}\right)
$$

where $R$ is the relative reflectance plotted in Figures 14 and $15, \rho_{1}$ is the reflectance value of smoked magnesium oxide, $\rho_{2}$ is that of Z-93 paint, $\theta_{M}$ is the measurement angle, and $\theta_{I}$ is the incident angle. To $i l l u s t r a t e$ the use of this relationship, one could find the reflected intensity from Z-93 paint at a measurement angle of $20^{\circ}$ for green light $(\lambda=0.5 \mu)$ incident at an angle of $30^{\circ}$. Figure 16 provides a "relative reflectance", $R$, of about .9 for smoked magnesium oxide. From Figure 16, it is seen that for green light ( $\lambda=.5$ micrometers) the reflectance, $\rho_{1}$, of smoked magnesium oxide is about .98. Figure 17 shows that the reflectance, $\rho_{2}$, of Z-93 paint is about .9. It follows, then, that the anticipated reflected intensity is

$$
I_{r}=(.9) \frac{(.9)}{(.98)} \frac{\cos 20^{\circ}}{\cos 30^{\circ}} I_{\mathbf{i}}=.9 I_{\mathbf{i}}
$$




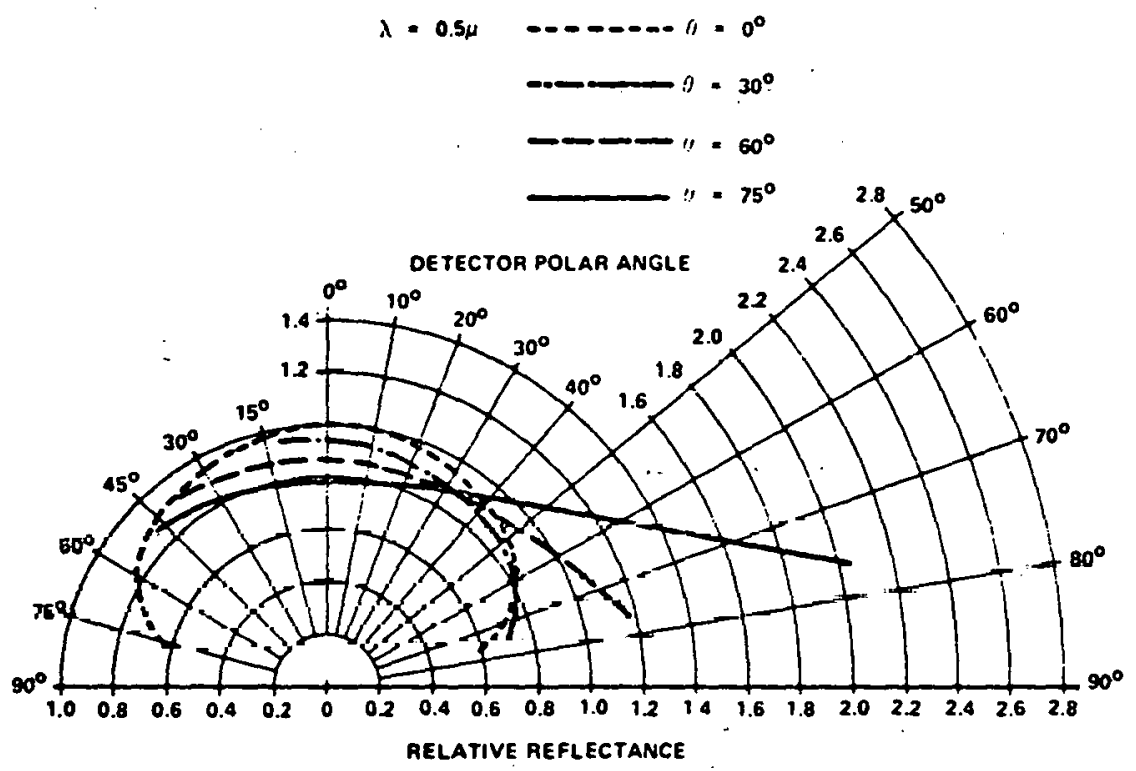
Figure 14. Directional Reflectance Characteristics of
Magnesium $0 x i d e \cdot(\lambda=0.5 \mu \mathrm{m})^{4}$

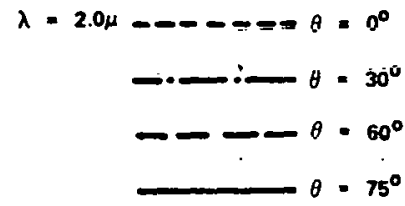

OETECTOR POLAR ANGLE

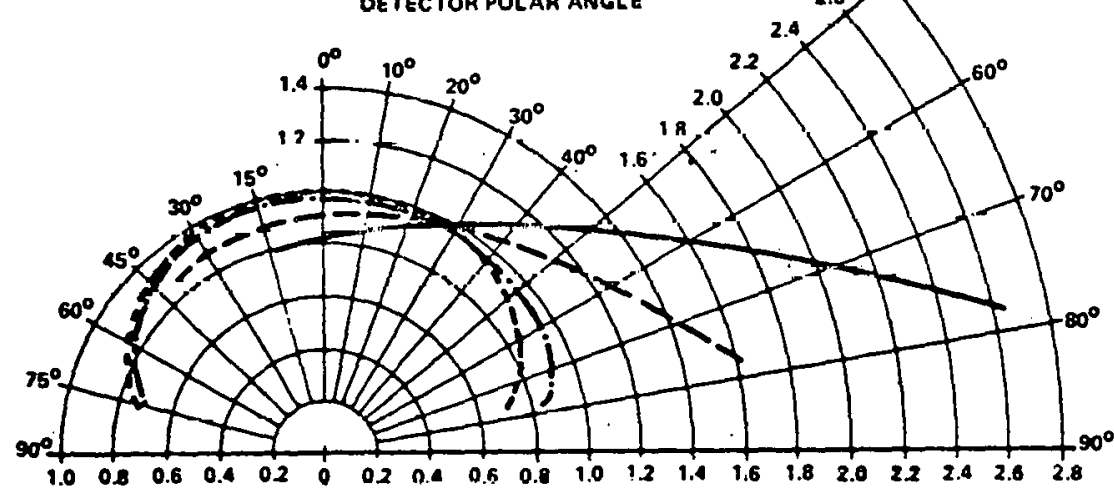

Relative AEFLECTANCE

Figure 15. Directional Reflectance Characteristics of Magnesium $0 x i d e(\lambda=2.0 \mu \mathrm{m})^{4}$ 


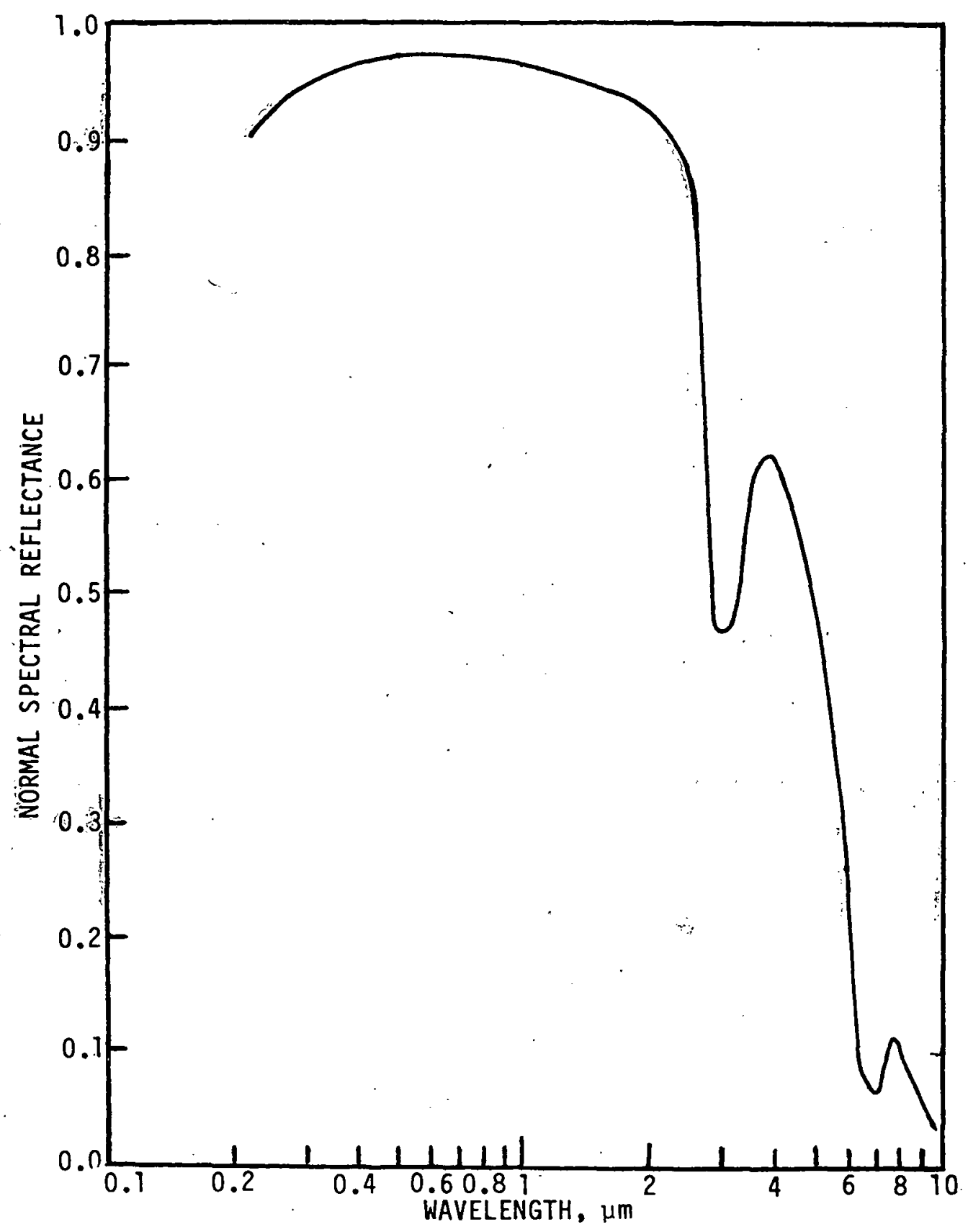

Figure 16. Analyzed Normal Spectral Refiectance of Smoked Magnesium 0xide 5 


$$
\mathbb{E}
$$


The spectral reflectance of aluminum and graphite are shown in Figures 18 and 19. The relative specuiarity of polished aluminum and other spacecraft materials are displayed in Figure 20.

The diffuse and specular reflectivities, $r_{d}$ and $r_{s}$, of materials that will be used on Satellite Power System vehicles are unspecified for the most part. Consequently, for this analysis some educated judgments are needed to get reasonable estimates at this time. One item that will appear extensively is the cover glass on solar cells. For purposes of this study, the overall specular reflectance of these solar panels is assumed to be $5 \%$, the nominal value of smooth glass. Coatings or fine scale roughening might alter this value slightly but not enough to affect the study conclusions.

The corresponding diffuse reflectivity of the solar cells is more difficult to assess due to lack of data insofar as the authors are aware. Specular surfaces generally are very poor diffuse reflectors as evidenced by the curve for polished aluminum in Figure 20. On the other hand, even black velvet has a diffuse reflectivity of $1 \%$ or so. Consequently, for this study, the value of $r_{d}$ for the solar panels was taken as 0.05 which is believed to be valid within a factor of two.

The present Baseline calls for polished aluminum on the back of the OTV solar panels and the SPS antenna. Its specular component has a reflectivity of $80 \%$ or so depending on the finishing process and the thermal requirements. Its diffuse reflectivity is assumed to be the remaining $20 \%$ of the total illumination.

Painted surfaces can be estimated in an analogous manner. It is noteworthy that the cat-a-lac black paint and the Z-93 paint have strong specular components like polished aluminum whereas the silicon paint is quite diffuse as shown in Figures 17 anid 20. 


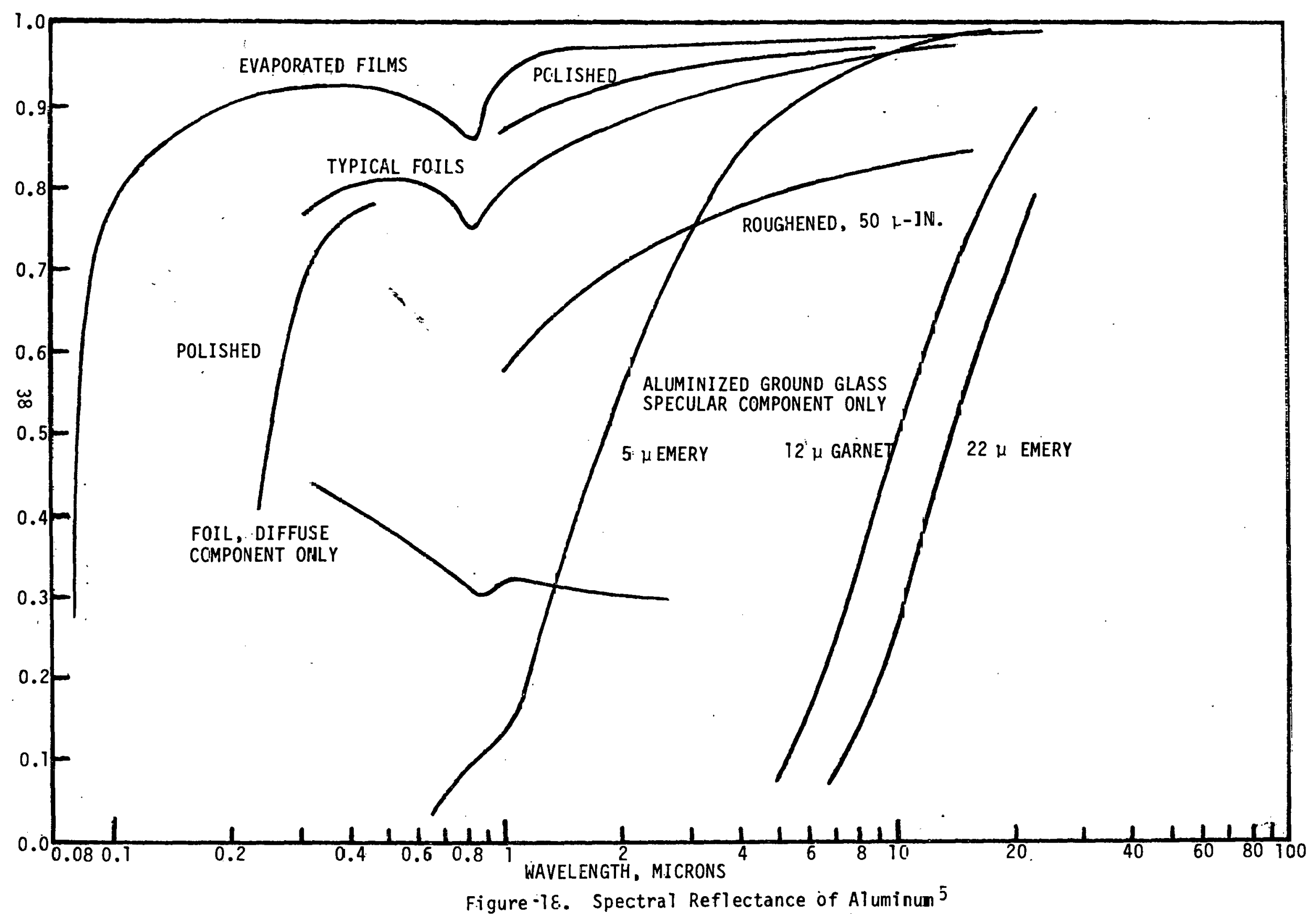




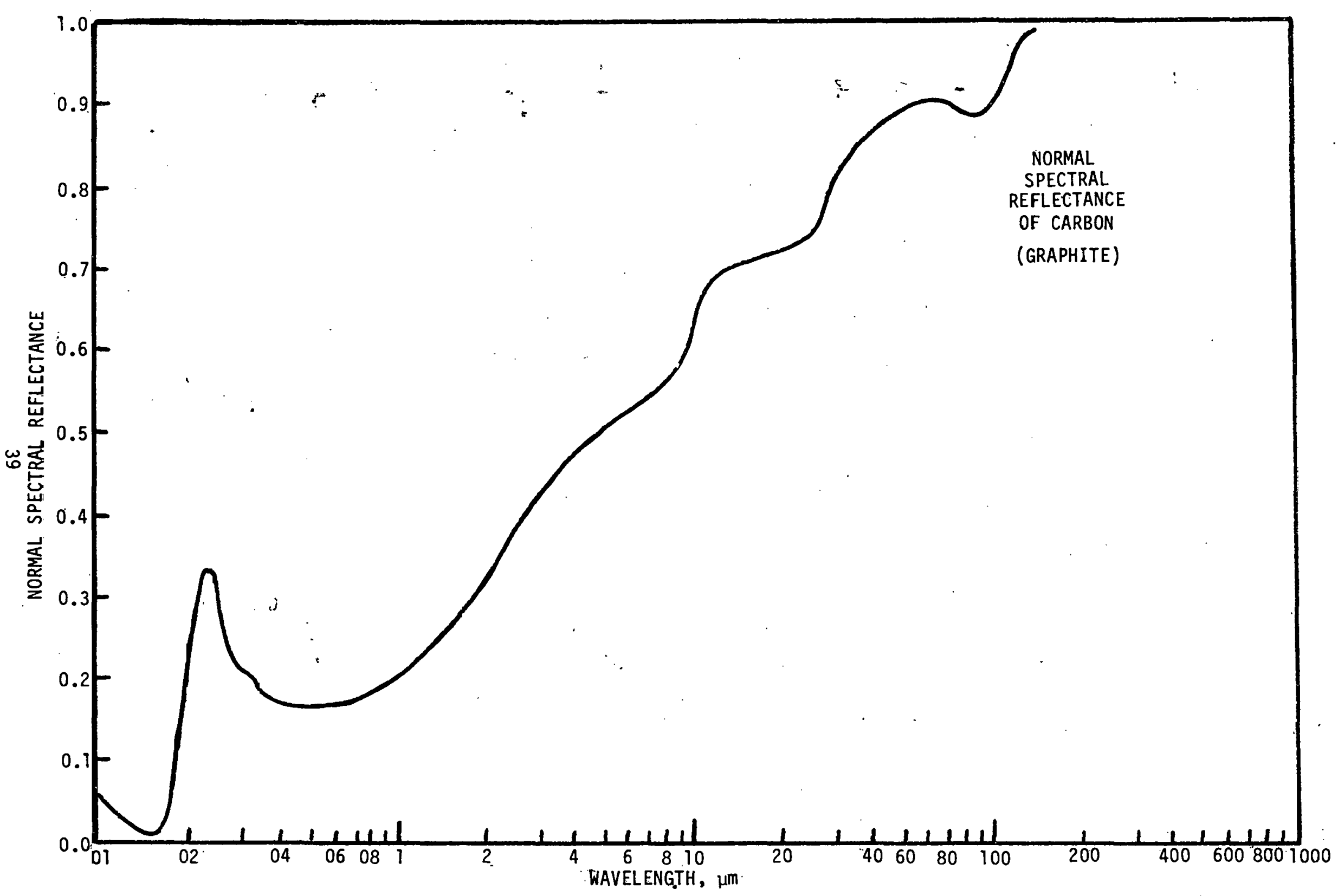

Figure 19. Spectral Reflectance of Carbon Graphite 5 


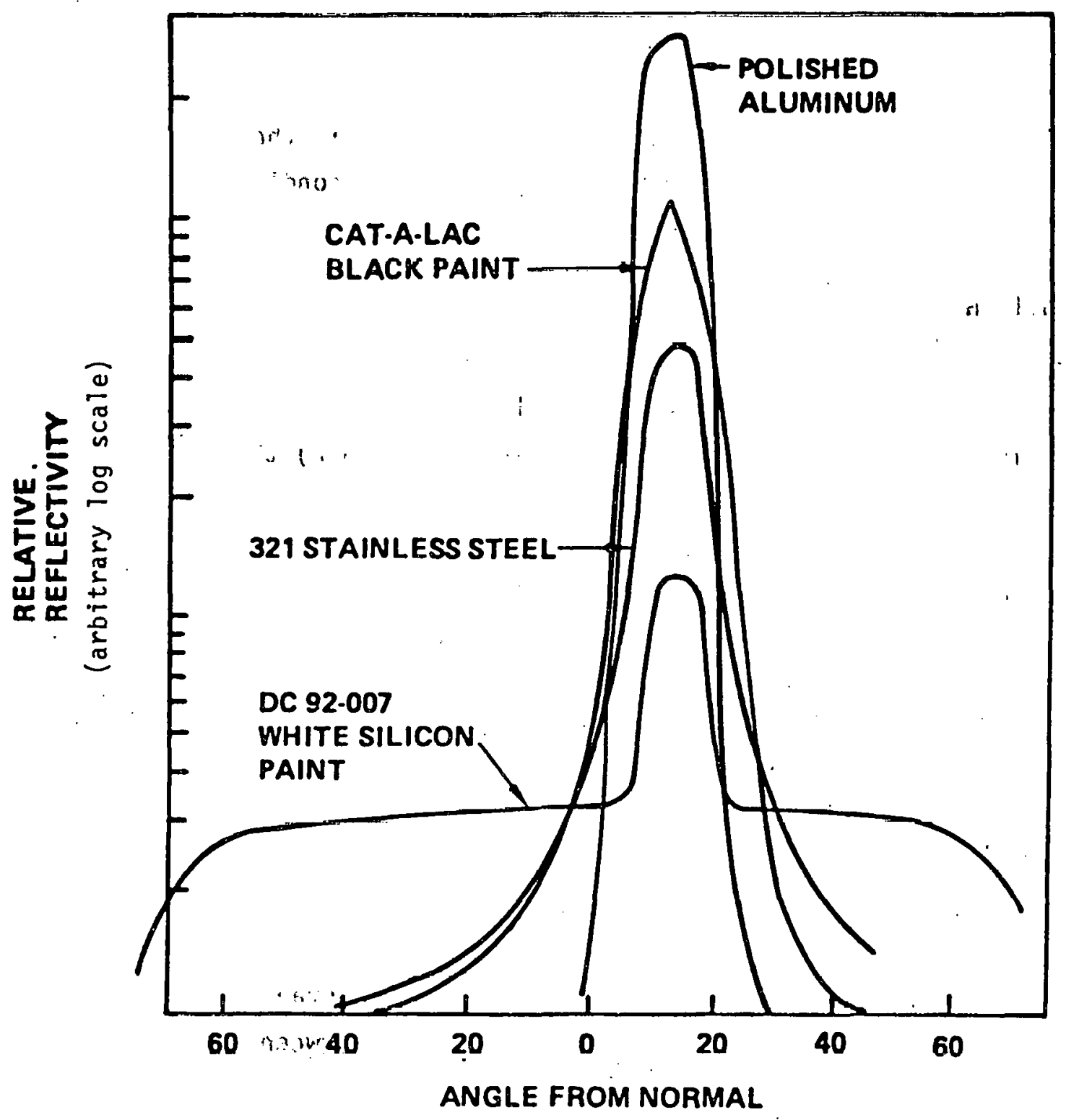

Figure 20. Relative Reflective Intensity Distribution From Various Spacecraft Materials 6 


\subsubsection{Ground Iilumination}

Reflected sunlight from Satellite Power System spacecraft is directed toward earth for prescribed vehicle orientations and orbit locations. Mathematical relationships that determine where these reflections will strike earth and how large an area is illuminated are presented in the first subsection. Calculations of ground irradiance for a variety of conditions where the illumination is bright are cited in the second subsection.

\subsubsection{Geometrical Considerations}

In determining possible ground illumination, two cases are considered: 1) the reflecting surface rotates in orbit such that its orientation to the earth is constant (e.g., the satellite antenna) and 2) the orientation of the reflecticn surface to the sun is constant (e.g., the satellite solar arrays). Since in both cases the angle $\phi$ is dependent only on the orbital altitude, it only remains to determine the relative values of angles $\alpha$ and $\theta$ for the two cases.

In the first case, it is seen that $\alpha$ is a constant, $\alpha_{c}$. As the reflecting surface orbits, therefore, only the value of $\theta$ changes. From Figure 21 it is seen that the values of $\theta$ for which reflected light will fall on the earth must be between $\left(\phi-\alpha_{c}\right)$ and $\left(\phi+\alpha_{c}\right)$ :

$$
\left(\alpha_{c}-\theta\right) \leq \phi \leq\left(\alpha_{c}+\theta\right) \text {. }
$$

In the second case, it is seen that $\theta$ is a constant, $\theta_{c}$, and $\alpha$ varies. Similarly it is seen that the value of $\alpha$ must be between $\left(\theta_{c}+\phi\right)$ and $\left(\theta_{c}-\phi\right)$ for reflected light to fall on the earth.

$$
\left(\theta_{c}-\phi\right) \leq \alpha \leq(\theta+\phi)
$$

When the center of the earth is not in the plane defined by the incident and emergent light beams the above relationships remain valid as long as the value of $\phi$ is reduced accordingly.

Once the orientation of a surface is found using the techniques of Section 3.1.1.1 it is a relatively simple matter to determine whether or not that surface will reflect the sun's light to the earth. Expressions for these angles may be determined from the following relationships. 


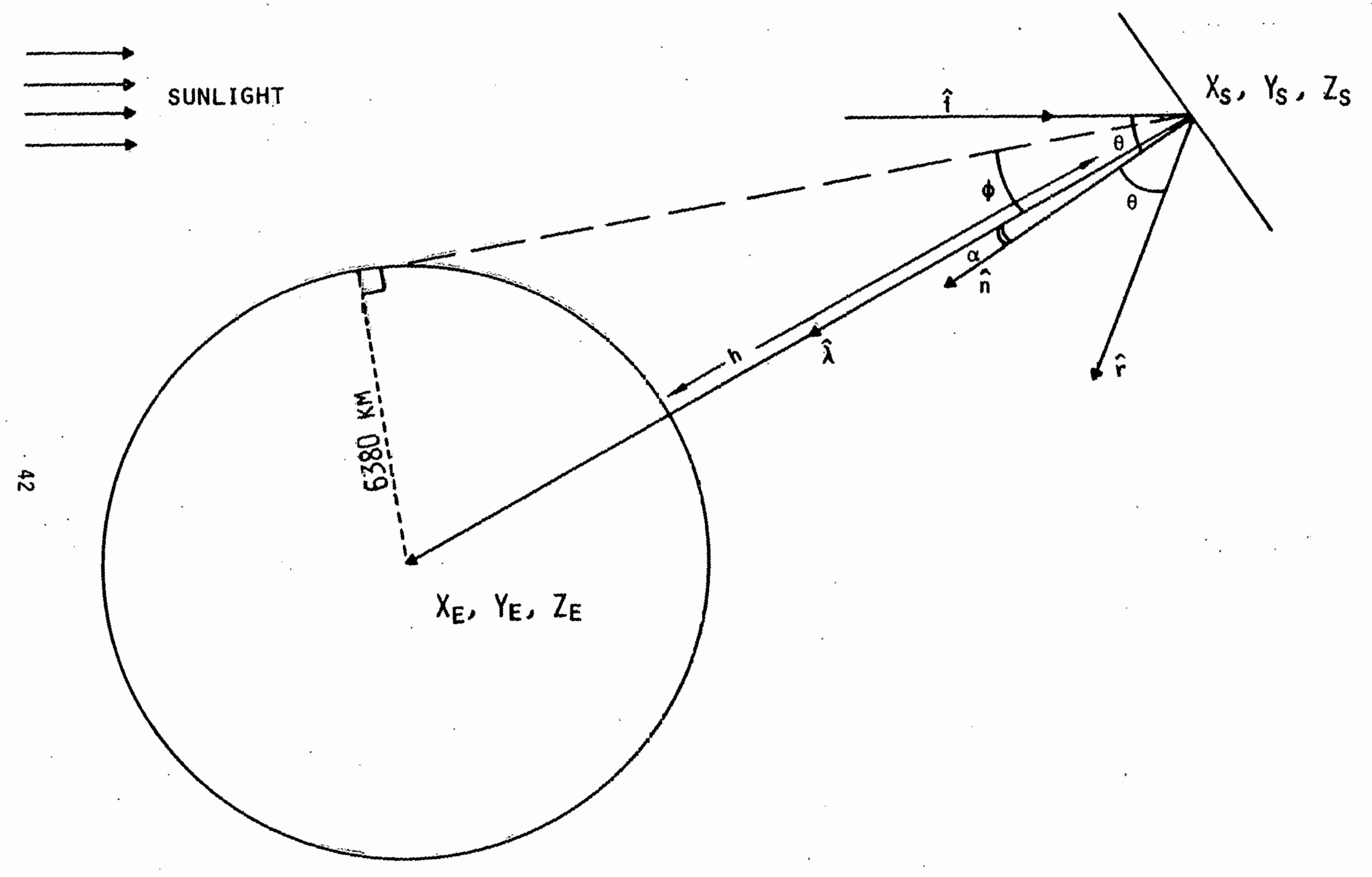

Figure 21. Spectar Reflectance Unit Vector Defintion 


$$
\begin{aligned}
\hat{n} \cdot \hat{i} & =\cos \theta \\
\frac{6380}{h+6380} & =\sin \phi \\
\hat{\lambda} \cdot \hat{n} & =\cos \alpha \\
\hat{\lambda} & =\left[\left(x_{s}-x_{e}\right) \hat{i}+\left(Y_{s}-Y_{e}\right) \hat{j}+\left(z_{s}-z_{e}\right) \hat{k}\right] / D \\
\text { where } D^{2} & =\left(x_{s}-x_{e}\right)^{2}+\left(Y_{s}-Y_{e}\right)^{2}+\left(z_{s}-z_{e}\right)^{2}
\end{aligned}
$$

In these relationships, $\hat{i}$ is the unit vector of the sun's incident light, $h$ is the orbital altitude, and $6380 \mathrm{~km}$ is the earth's radius. Again $\hat{n}$ is the reflecting surface's unit normal vector and $\hat{\lambda}$ is the unit vector from the reflecting surface to the earth's center.

\subsubsection{Irradiance Levels}

Reflections toward earth produce ground irradiance that is described by the diffuse and specular expressions derived in Section 3.1.1 above. The formulas (Equations 1 and 2) are summarized here for convenience along with the definitions and units of the various factors and terms that enter the expressions.

The diffuse irradiance produced by SPS elements in $W / \mathrm{m}^{2}$ is given by.

where

$$
H_{d}=\kappa r_{d} \text { a } H_{\odot} G\left(\theta_{r}, \theta_{j}\right) / 2 \pi R^{2}
$$

$H_{\odot}=1.4 \times 10^{3} \mathrm{~W} / \mathrm{m}^{2}$ is the solar constant at earth.

$r_{d}$ is the diffuse reflectivity, and

$G\left(\theta_{r}, \theta_{i}\right)$ is the normalized angular dependence where $\theta_{i}$ and $\theta_{r}$ are the incident and reflected directions measured from the surface normal (2 $\cos \theta_{r} \cos \theta_{i}$ for Lambertian surfaces).

The specular irradiance in $W / \mathrm{m}^{2}$ produced by reflected light from an SPS subsystem is

$$
H_{S}=k N_{\odot} \frac{r_{s} a \cos (\alpha / 2)}{R^{2}} \frac{\sigma^{2}}{(\rho+\sigma+\tau)^{2}}
$$


where

$K$ is the degradation due to atmospheric extinction and optical response of instruments

$N_{0}=2.0 \times 10^{7}$ watts/ster $-m^{2}$ is the average visual disk radiance of the sun

$r_{s}$ is the specular reflectance of the SPS surface

a is the area of the surface in $\mathrm{m}^{2}$,

$\alpha$ is the angle between the incident and reflected rays

$R$ is the distance from the SPS subsystem to the earth in meters

$\sigma$ is the angle at the SPS subtended by the solar disk

$\rho$ is the diffraction limit for coherent reflection from an element of SPS area $\delta a \mathrm{~m}^{2}$, and

$\tau$ is the angular divergence of the solar image due to the fact that the reflectors are not optically flat mirrors.

In some calculations below the angles $\rho$ and $\tau$ will be assumed to be zero. This maximizes the irradiance which is certainly a worst case since in general the SPS structure is not and need not be rigid.

Note that no factor is included in Eq. (1) to account for non-normal incidence of the reflected light on the earth since it is assumed that the observer will be looking directly at the SPS subsystem.

In the following illustrative cases of interest, " $D$ " will denote diffuse reflections and "S" speculiar reflections.

CASE DI: . OTV IN LEO - CONSTRUCTION PHASE

The solar panel plane of the OTV is aligned with the'staging base plane during construction which is always in the orbital plane around the earth. 1 Thus the top and bottom of the OTV alternately reflect light onto the earth. The worst case, depicted in Figure 22 , occurs at the solstices with the just completed OTV on the SB in the noontime position. (Only the worst noontime case will be considered here. In the specular case, S1, general orbital locations are treated.) 
FIGURE 24. OTV AND SB IN LEO, WORST CASE

\&

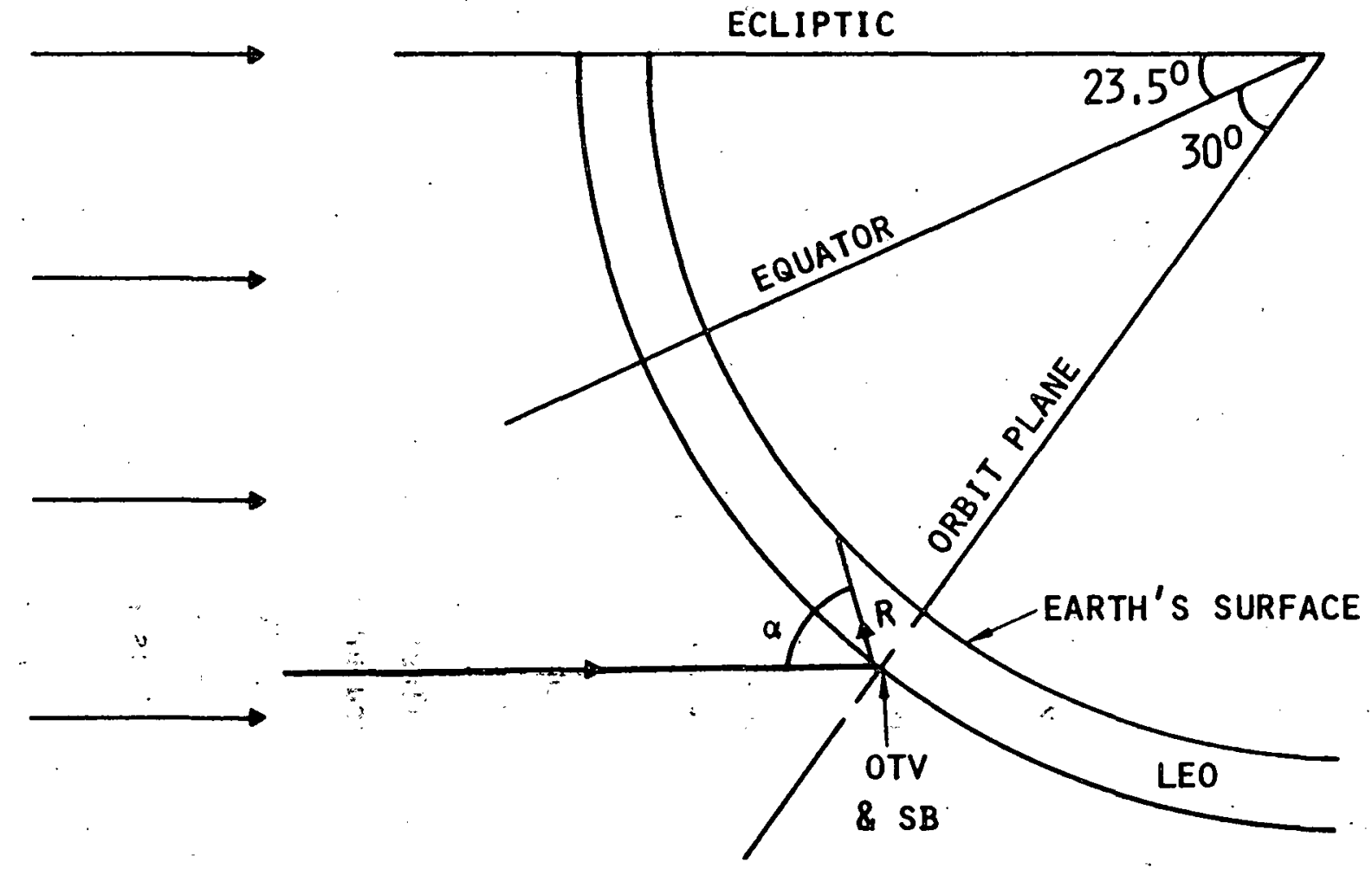

Figure 22. Diffuse Reflection From SB in LEO During OTV Construction (D1) 
It is assumed that the OTV and the SB both are diffuse reflectors with $r_{d}=0.05$ in Eq. (1). The following exemplar parameters will be chosen:

$$
\begin{aligned}
\kappa & =0.8 \\
H_{\odot} & =1.4 \times 10^{3} \mathrm{~W}^{2} \mathrm{~m}^{2} \\
\theta_{r} & =\theta_{i}=36.5^{\circ} \text { and } \\
R & =910 \mathrm{~km}
\end{aligned}
$$

To get the maximum total area the solar array area $\left(1.56 \mathrm{~km}^{2}\right.$ with direction cosine \pm 1 from Table 1) is added to the maximum area with direction cosine in a single direction for the SB. The latter (Table 1) with direction cosine +1 , is the sum of the lateral beam area $1.98 \times 10^{-2} \mathrm{~km}^{2}$ and the attached equipment area $4 \times 10^{-2} \mathrm{~km}^{2}$. Thus $a=1.62 \mathrm{~km}^{2}$ and the diffuse irradiance is $2.4 \times 10^{-5} \mathrm{~W} / \mathrm{m}^{2}$.

\section{CASE D2: SPS IN GE0, DIFFUSE CASE}

In this example it will be assumed that the total area of the SPS (58 $\mathrm{km}^{2}$ from Case S2) is a diffuse source with $r_{d}=0.05$, and the nightside geometry of Figure 23 will be assumed. Note that this geometry minimizes the value of $R$ which appears in Eq. (1) as an inverse square, thus maximizing the irradiance. The following parameters are used in Eq. (1):

$$
\begin{aligned}
\kappa & =0.8 \\
H_{\odot} & =1.4 \times 10^{3} \mathrm{~W} / \mathrm{m}^{2} \\
n_{r} & =\theta_{1}=5.2^{\circ} \\
R & =35,700 \mathrm{~km}
\end{aligned}
$$

resulting in an irradiance of $8 \times 10^{-7} \mathrm{~W} / \mathrm{m}^{2}$.

\section{CASE D3: OTV POWERED IN LEO}

After an OTV is constructed, its solar panels are turned toward the sun to suppiy thruster power. One geometry of concern is that shown in Figure 24 in which light is reflected to the night side of the earth (after some atmospheric refraction). Assume the following parameters:

$$
\begin{aligned}
r_{d} & =0.05 \\
K & =0.8 \\
H_{\odot} & =1.4 \times 10^{3} \mathrm{~W} / \mathrm{m}^{2}
\end{aligned}
$$




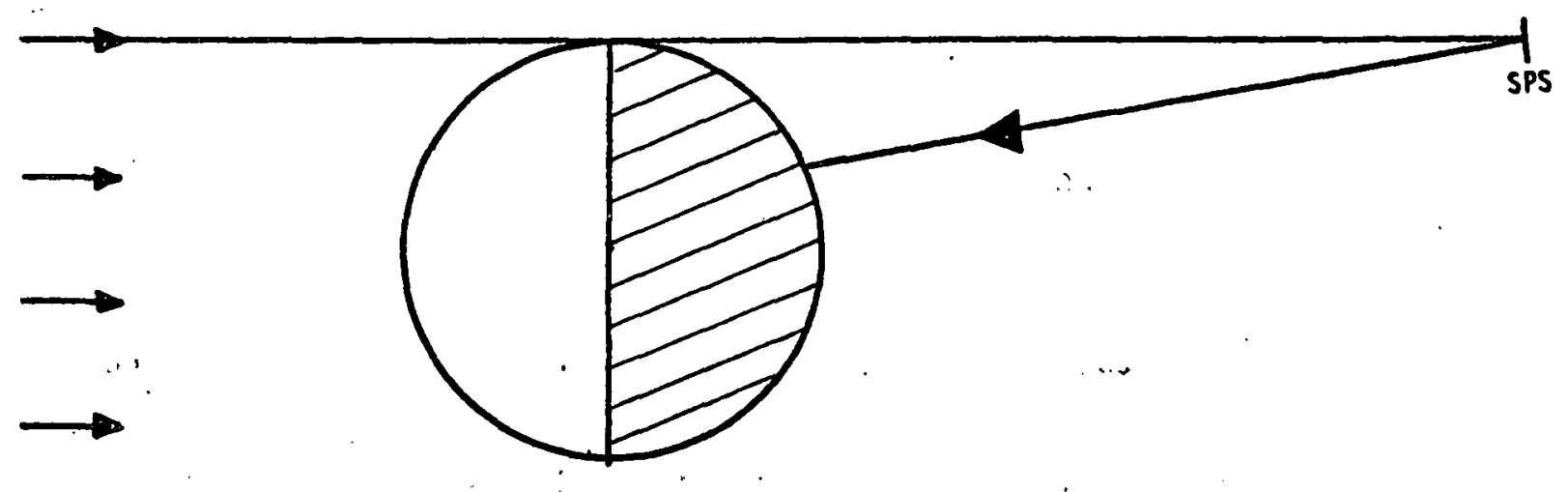

Jit.

Figure 23. Diffuse Reflection From SPS in GEO (02):
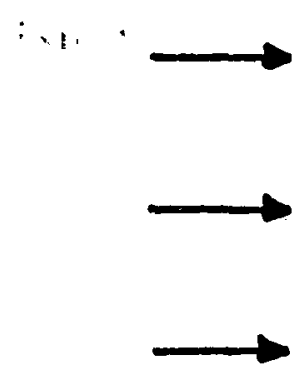

Figure 24. Diffuse Reflection From OTV During Transtt from LEO (D3)

OTV SOLAR PANEL 


$$
\begin{aligned}
\theta_{r} & =\theta_{i}=0^{\circ}, \text { and } \\
R & =2570 \mathrm{~km} \text { (calculated) }
\end{aligned}
$$

Assuming a Lambertian surface, Eq. (1) gives $H_{d}=4 \times 10^{-6} \mathrm{~W} / \mathrm{m}^{2}$.

\section{CASE D4: OTV BETWEEN LEO AND GEO}

As the OTV spirals out to GEO it can reflect light back to the earth with geometry similar to that in Case D3. Consider orbits at 2 and 4 earth radii with corresponding values of $R=11,000 \mathrm{~km}$ and $24,700 \mathrm{~km}$, respertively. Using the other parameters of Case $D 3$ the corresponding irradiances are $2 \times 10^{-7}$ and $5 \times 10^{-8} \mathrm{~W} / \mathrm{m}^{2}$. 
CASE S1: OTV IN LEO - CONSTRUCTION PHASE

This case is similar to Case DI (Geometry in Figure 24) except the specular Equation (2) is now used.

It was found that considerable light can be reflected to the earth over a number of daylight hours, so that the general case will be treated. The geometry is illustrated in Figure 25. The angle between the reflected beam $R$ and the orbital plane is $53.5^{\circ}$ (see Figure 22). The distance from the OTV in LEO to the illuminated spot on the ground is

$$
R \approx 4090 \cos \phi-{\sqrt{1.67 \times 10^{7} \cos ^{2} \phi-6.63 \times 10^{6}}}^{.}
$$

where $\phi$ is the angle from the moon meridian. The value of $R$ for the noontime case $\left(\phi=0^{\circ}\right)$ is $910 \mathrm{~km}$. Note that the reflected light just grazes the earth at $\phi=50.9^{\circ}$. Thus an illuminated spot moves across the day side of the earth from 0830 to 1530 locai time.

In Figure 26, $R$ is plotted as a function of $\phi$ and the irradiance (Equation (1)) as a function of $R$ for the following conditions:

$$
\begin{aligned}
\kappa & =0.8 \\
r_{s} & =0.8 \text { for the aluminum OTV back side } \\
& =0.05 \text { for the solar panel side } \\
a & =1.56 \mathrm{~km}^{2} \\
\alpha & =73^{\circ} \\
\sigma & =\tau=0 \text { (optically flat mirror case--see discussion below). }
\end{aligned}
$$

For these parameters, the peak irradiance at the ground for the front side is $1.2 \mathrm{~W} / \mathrm{m}^{2}$ while that for the back side is $19 \mathrm{~W} / \mathrm{m}^{2}$.

Not only would it be difficult to make the OTV optically flat, but it would be clearly disadvantageous if it were flat. It is estimated that misalignment of the OTV solar panels yields a beam spread of $1.5^{\circ}$ compared with the $0.5^{\circ}$ spread of the sun's disk produced by a flat mirror. Then the factor $\sigma^{2} /(\rho+\sigma+\tau)^{2}$ in Equation (2) reduces the irradiance by about an order of magnitude. Besides avoiding flat surfaces, other methods of reducing the 


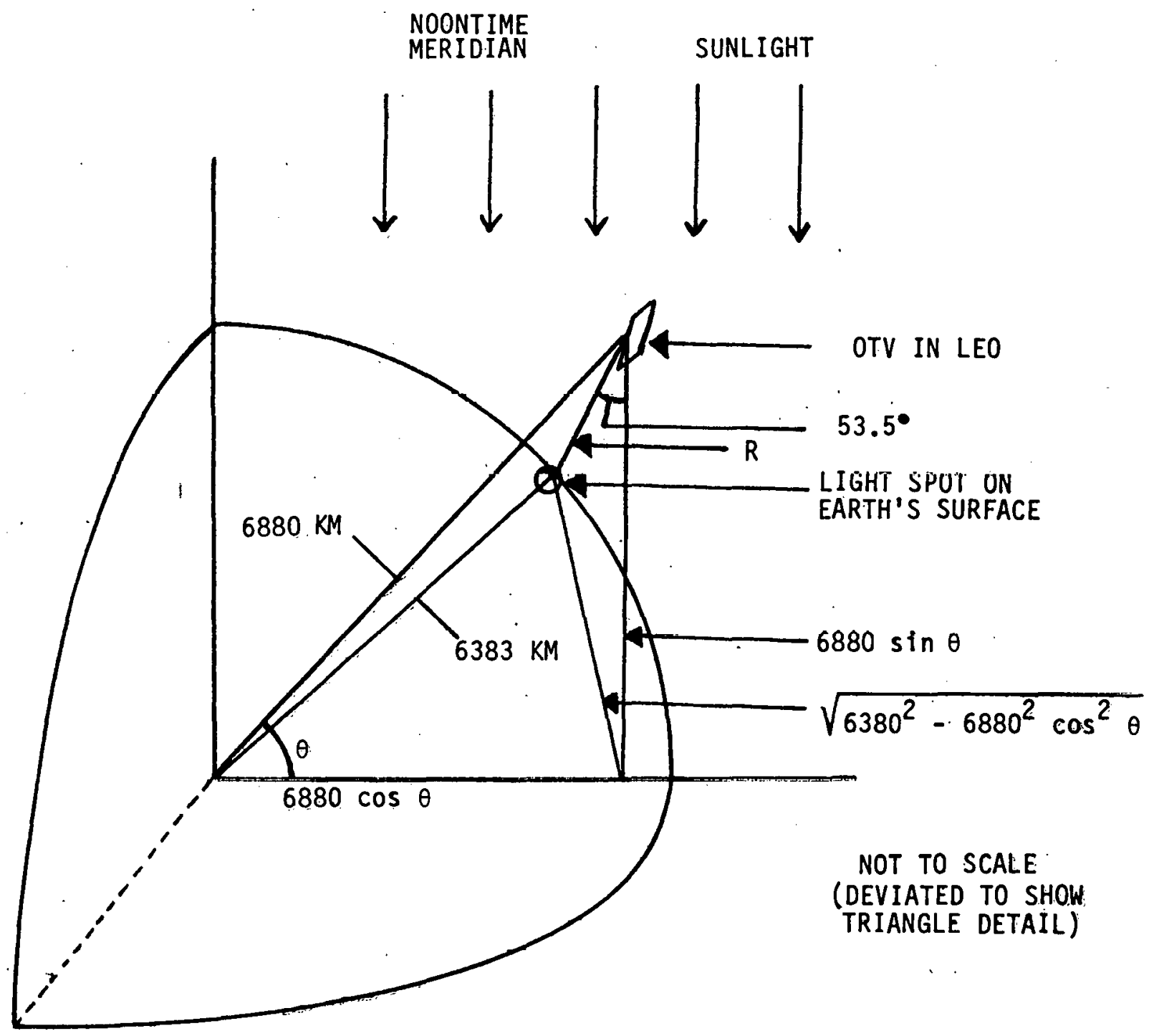

Figure 25. Specular Reflection Erom $S B$ and OTV During Construction Phase (ST) 


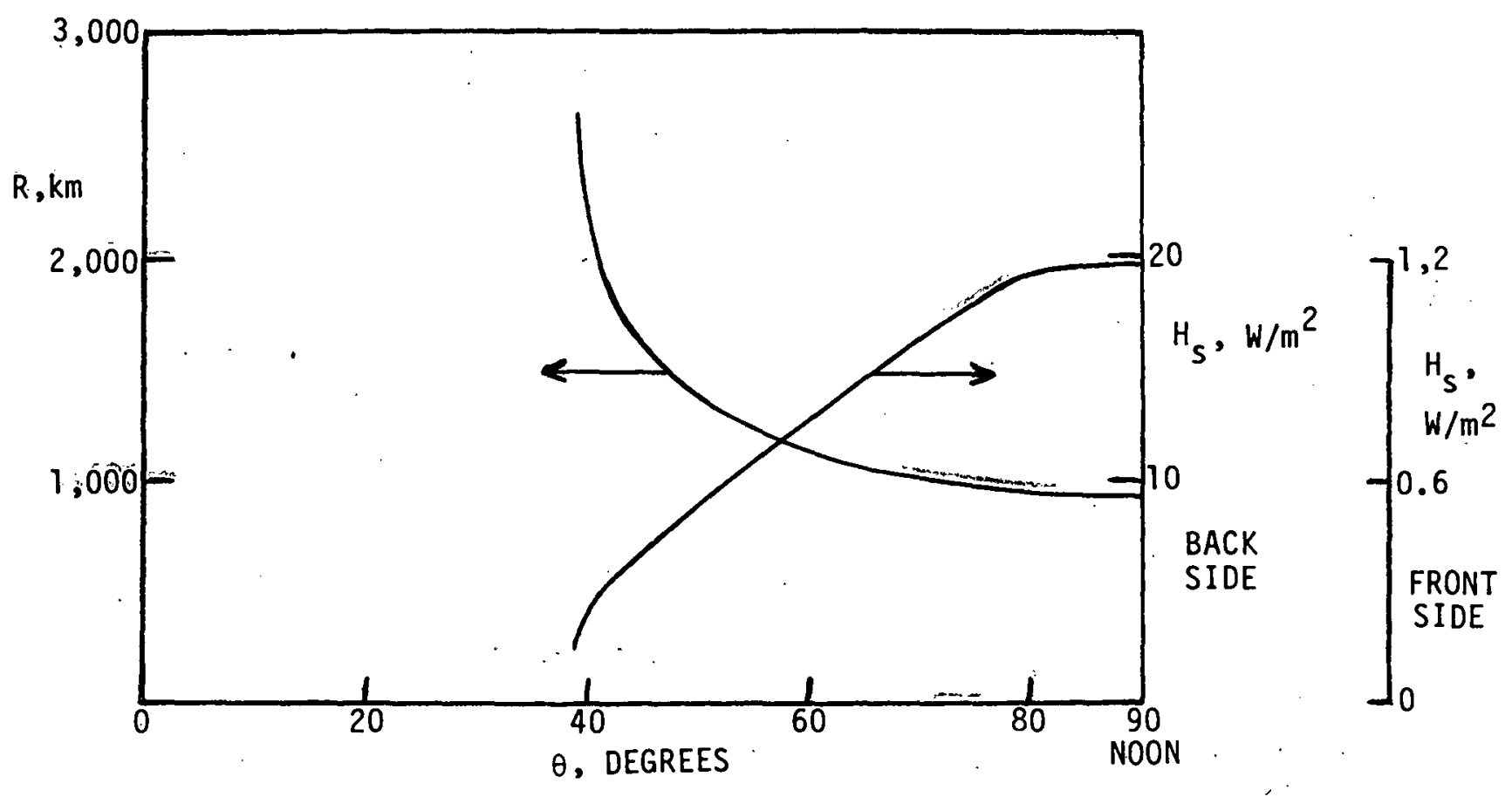

Figure 26. Angular Dependence of OTV-Earth Distance and Irradiance 
irradiance are to paint specular surfaces with diffuse paints, and to avoid unfavorable geometries with corrective thrusting.

The East-West width, $\mathrm{s}_{\mathrm{EW}}$, of the illuminated noontime spot on the earth (latitude $\left.21^{\circ} \mathrm{S}\right)$ can be found from the sun's diameter $\left(1.4 \times 10^{9} \mathrm{~m}\right)$, its distance from earth $\left(1.5 \times 10^{11} \mathrm{~m}\right)$ and the distance $\mathrm{R}=910 \mathrm{~km}$ :

$$
\begin{aligned}
S_{E W} & =910\left(\frac{1.4 \times 10^{9}}{1.5 \times 10^{17}}\right) \\
& =8.5 \mathrm{~km}
\end{aligned}
$$

The North-South length, $\mathrm{s}_{\mathrm{NS}}$, is found using the angle, $62^{\circ}$, between the reflected ray and the normal to the earth's surface:

$$
\mathrm{s}_{\mathrm{NS}}=\frac{8.5}{\cos 62^{\circ}}=18 \mathrm{~km}
$$

Neglecting the rotation speed of the earth, the speed of the spot is the same as the OTV/SB speed in LEO which is $8.2 \mathrm{~km} / \mathrm{sec}$. Thus, the spot requires about one second to pass the noontime longitude.

CASE S2: SATELLITE SOLAR PANEL IN GEO, EQUINOX CASE

This case is depicted in Figure 27. (The view is normal to the ecliptic plane.) Grazing sunlight is refracted about $1^{\circ}$ as it passes the earth's limb. For the satellite in the indicated position in GEO and at an equinox, the light will be reflected back to the earth's night side by the solar panel facing the sun.

The following representative parameters are used in Eq. (1):

$$
\begin{aligned}
\kappa & =0.8 \\
r_{a} & =0.05 \text { (solar panel cover glass) } \\
a & =58 \mathrm{~km}^{2} \\
\alpha & =2^{\circ} \\
R & =35,700 \mathrm{~km}
\end{aligned}
$$

Here, an irradiance of $0.03 \mathrm{~W} / \mathrm{m}^{2}$ is found for optically flat mirror conditions. 
Consider the more realistic case in which SPS solar panels are misaligned. Since the SPS is much larger than the OTV the misalignment is estimated to be ias much as $5^{\circ}$ for the SPS (compared with the $1.5^{\circ}$ estimated for the OTV). As a result the irradiance would be reduced up to two orders of magnitude.

There is a very simple way to avoid the Case 52 geometry. Since the solar panels are sized for solstice conditions, they are about 5\% 1arger than necessary for equinox conditions. Therefore, they can be rotated slightly out of the normal geometry of Figure 27 to move the reflected light off the earth.

Using calculations similar to those in Eqs. (2) and (3), it is found that $s_{N S}=350 \mathrm{~km}$ and $s_{E W}=520 \mathrm{~km}$. From a simple geometric construction for the spot near the limb the spot speed is about $550 \mathrm{~km} / \mathrm{min}$ so that the time for the spot to cross a point on the earth is about one minute. (Compare this with the one second in the LEO case.)

A similar case involves the reflection from the SPS panels during a partial eclipse. The geometry is quite similar to that in Figure 23 , and the irradiance varies from 0 (total eclipse) to the $0.03 \mathrm{~W} / \mathrm{m}^{2}$ of the refraction case discussed above. Since the latter is a worst case the partial eclipse cases will not be discuissed further.

\section{CASE S3: SATELLITE ANTENNA IN GEO, EQUINOX CASE}

In the baseline system the microwave beam is normal to the highly reflected aluminum antenna face. Since the beam points at a rectenna on the earth's surface there is no way to avoid reflecting light onto the earth for some geometries as depicted in Figure 28. This case has been covered in some detail by Livingston ${ }^{7}$. Similar results are obtained here.

The following representative parameters are used in Eq. (1):

$$
\begin{aligned}
K & =0.8 \\
r_{S} & =0.8 \text { (aluminum) } \\
a & =(0.5)^{2} \pi=0.79 \mathrm{~km}^{2} \\
\alpha & =0 \\
R & =36,000 \mathrm{~km} \text { (minimum distance for incident. light grazing earth) }
\end{aligned}
$$

An irradiance of $0.01 \mathrm{~W} / \mathrm{m}^{2}$ is obtained for these conditions. 


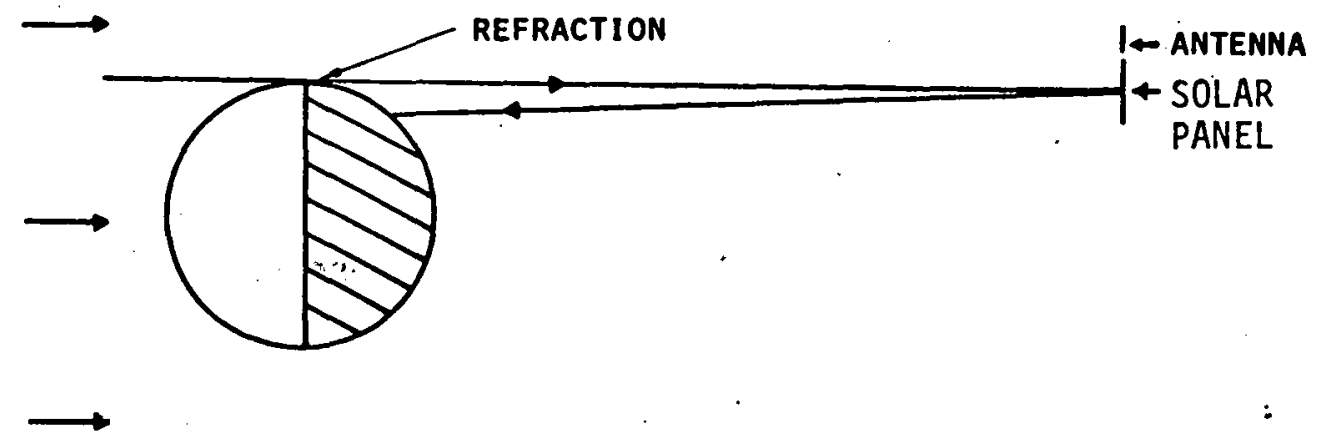

Figure 27. Specular Reflection From SPS Solar Panels in GEO Around Equinoxes (S2)
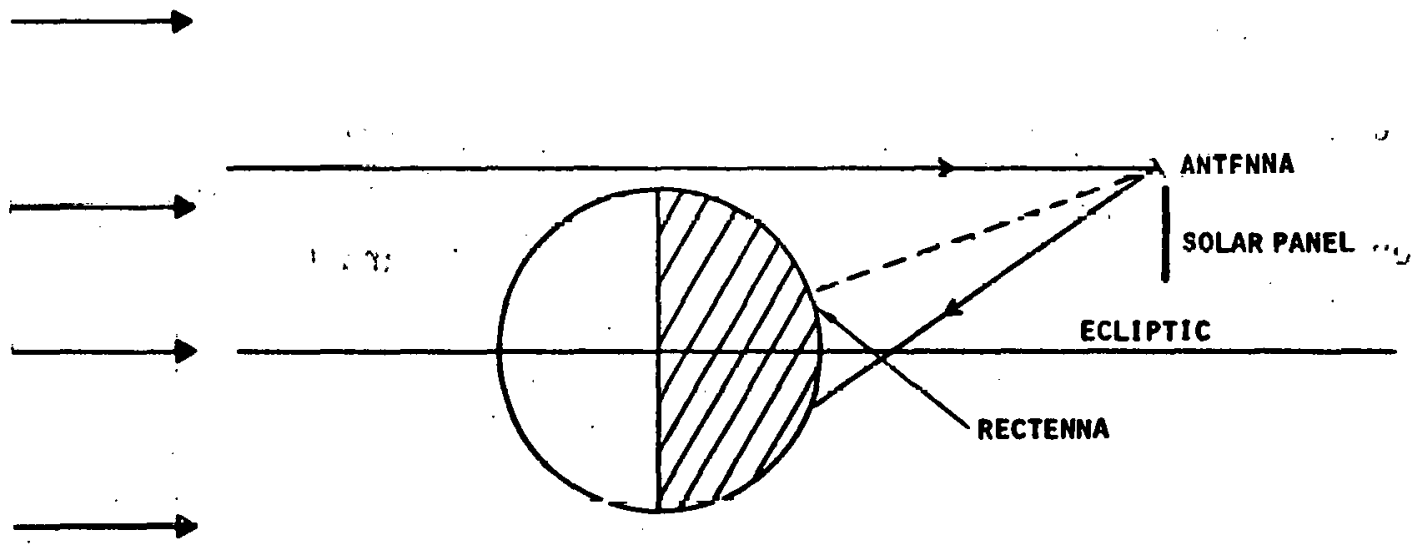

Flgure 28. Specular Reffection From SPS Antenna in $6 E 0$ Around Equinoxes (S3) 
The midnight spot diameter at the equator is about $350 \mathrm{~km}$. Its speed is about $150 \mathrm{~km} / \mathrm{min}$ so that the time for the spot to cross a point on the earth is just over two minutes.

CASE S4: OTV POWERED IN LEO

Consider the specular counterpart of the diffuse Case D2 using the following parameters:

$$
\begin{aligned}
\kappa & =0.8 \\
r_{s} & =0.05 \text { (solar panel) } \\
a & =1.56 \mathrm{~km}^{2} \\
\alpha & =0^{\circ} \\
\rho & =\tau=0 \text { (optically flat mirror) } \\
R & =2570 \mathrm{~km}
\end{aligned}
$$

Froin Eq. (2) $H_{S}=0.19 \mathrm{~W} / \mathrm{m}^{2}$

CASE S5: OTV BETWEEN LEO AND GEO

Consider the specular counterparts of the two diffuse examples covered in Case D4. The irradiances at the earth for an OTV at 2 and at 4 earth radii (other parameters the same as in Case S4) are 0.010 and $0.0021 \mathrm{~W} / \mathrm{m}^{2}$ respectively.

CASE S6: OTV IN LEO, OUT OF CONTROL

The worst case geometry is given in Figure 29. The highly reflective back side of the OTV reflects sunlight to a point on earth directly below. Parameters in Eq. (1) are now 


$$
\begin{aligned}
\kappa & =0.8 \\
r_{s} & =0.8 \text { (aluminum } \\
a & =1.56 \mathrm{~km}^{2} \text { (OTV, neglecting SB) } \\
\alpha & =90^{\circ} \\
R & =500 \mathrm{~km} \text { (LEO) }
\end{aligned}
$$

The irradiance is found to be about $56 \mathrm{~W} / \mathrm{m}^{2}$.

CASE S7: SATELLITE IN GEO, OUT ÖF CONTROL

This case is depicted in Figure 30. Parameters are

$$
\begin{aligned}
\kappa & =0.8 \\
r_{S} & =0.8 \text { (aluminum) } \\
a & =58 \mathrm{~km}^{2} \\
\alpha & =90^{\circ} \\
R & =36,000 \mathrm{~km}
\end{aligned}
$$

The resulting irradiance is $0.4 \mathrm{~W} / \mathrm{m}^{2}$ which compares with the $0.03 \mathrm{~W} / \mathrm{m}^{2}$ for the satellite solar panel in GEO (Case S2).

\subsection{SKY BRIGHTNESS}

Scattering which produces sky brightness can be derived for any point in the sky by determining the light which illuminates that point and the amount of that light which is scattered in the direction of the observer. Integration of all such points along the observer's line of sight yields the total iight which the observer receives. This approach is formalized in the derivation by Tousey and Hulburt. 8 Without reproducing their procedures, the resulting expressions are summarized below.

The intensity of the sky at any location as perceived by the observer is expressed as the sum of two contributors,

$$
B=B_{p}+B_{m}
$$




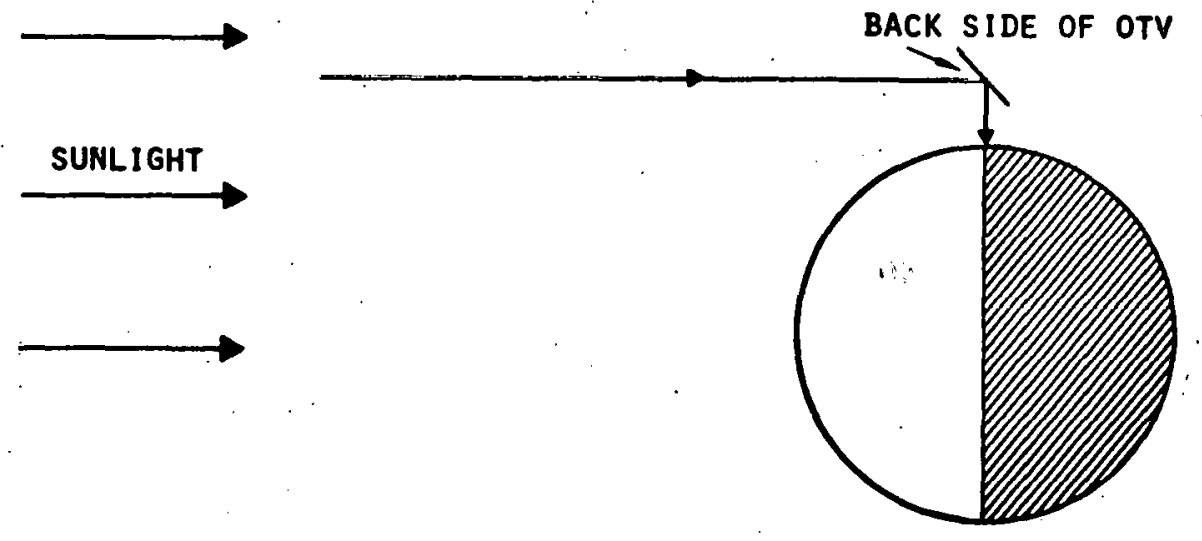

Figure 29. Specular Reflection From OTV In LEO During Uncontrolled Maneuvers

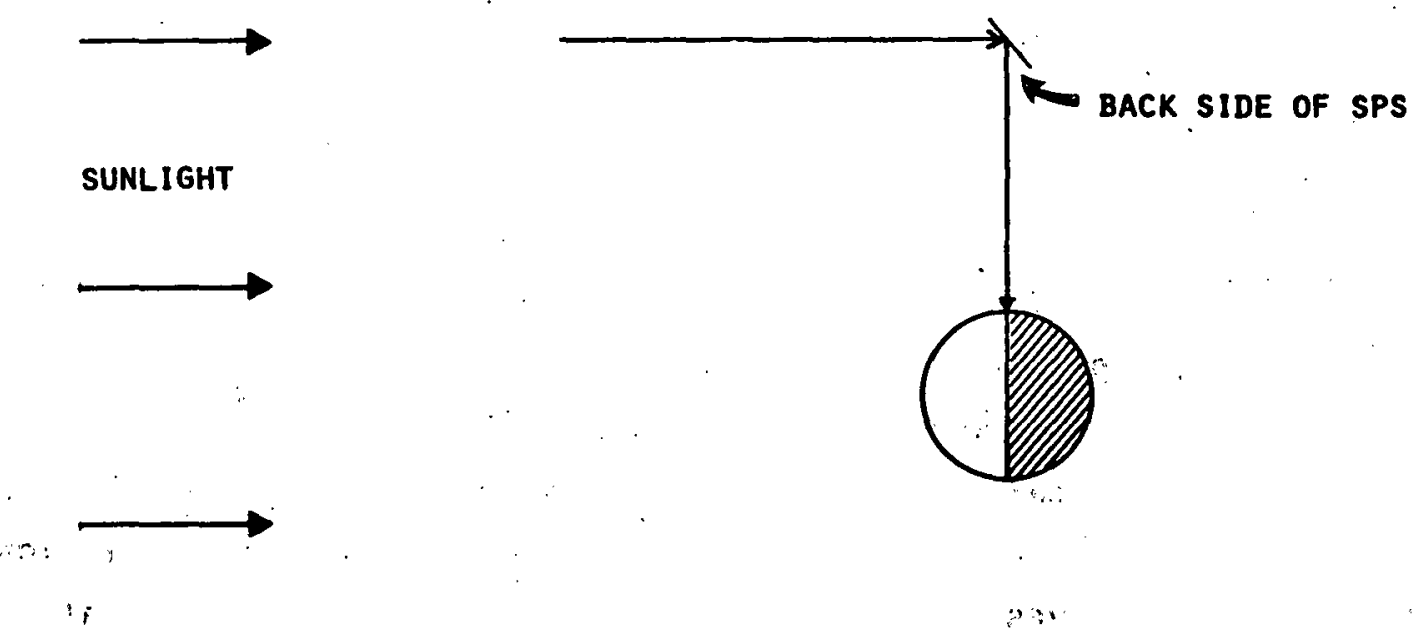

F1gure 30. Specular Reflection From SPS Solar Panels in dEO During Uncontrolled Maneuvers 
where $B_{p}$ is the intensity due to single scattering of the light from the major source, such as the sun, and $B_{m}$ is the brightness due to other less intense sources such as earth reflections and multiple scattering, typically about $1 / 4$ that of $B_{p}$.

By assuming that the sky is composed mostly of molecular scatterers, the following expression for $B_{p}$ was obtained:

$$
\begin{aligned}
& B_{p}=I_{0}{ }^{\prime} \frac{3}{4 \pi} \exp \left(-\beta^{\prime} \sec \zeta\right) \frac{1+\frac{1-\delta}{1+\delta} \cos ^{2} \phi}{3+\frac{1-\delta}{1+\delta}} \\
& \frac{\exp (-\beta x \sec \xi)-\exp \left(-\beta x_{1} \sec \xi\right)}{1-\sec \zeta \cos \xi}
\end{aligned}
$$

where $\beta^{\prime}$ is the absorption coefficient of the effective ozone region, $\beta$ is the visual attenuation coefficient, $\delta$ is the ratio of the weak to the strong polarized component, $I_{0} !$ is the irradiance at the top of the atmosphere, and $\phi, \zeta, x_{1}$, and $\xi$ are geometric relationships defined in Figure 31 . This expression with the assumptions made which simplify the expression to this form were found to be accurate to within about $4 \%$ for $\xi$ and $\zeta=75^{\circ}$, except for the molecular sky assumption. To account for particulate scatter it was necessary to increase the scattering coefficient from a theoretical value of $.0126 / \mathrm{km}$ to $.017 / \mathrm{km}$.

An expression for $B_{m}$ was similariy derived, resulting in the following expression:

$$
B_{m}=\frac{1}{8 \pi}\left(a_{1}+b_{1}+b_{0}\right)\left(1-\exp \left[-B x_{1} \sec \xi\right]\right)
$$

where $a_{1}$ and $b_{1}$ are the downward flux and the upward flux, respectively, of light from the secondary sources, evaluated at $x_{7}$, and $b_{0}$ is the upward flux evaluated at the surface of the earth. The other variables are as defined previously. The fluxes are obtained by the following expression:

$$
\begin{aligned}
& a=\frac{I_{0} \cos \zeta}{1+g t}\{(1+g t)(C-C X)-g x(C-C T+T)\} \\
& b=\frac{I_{0} \cos \zeta}{1+g t}\{(1+g t)(C-C X+X)-(g x+1-r)(C-C T+T)\}
\end{aligned}
$$




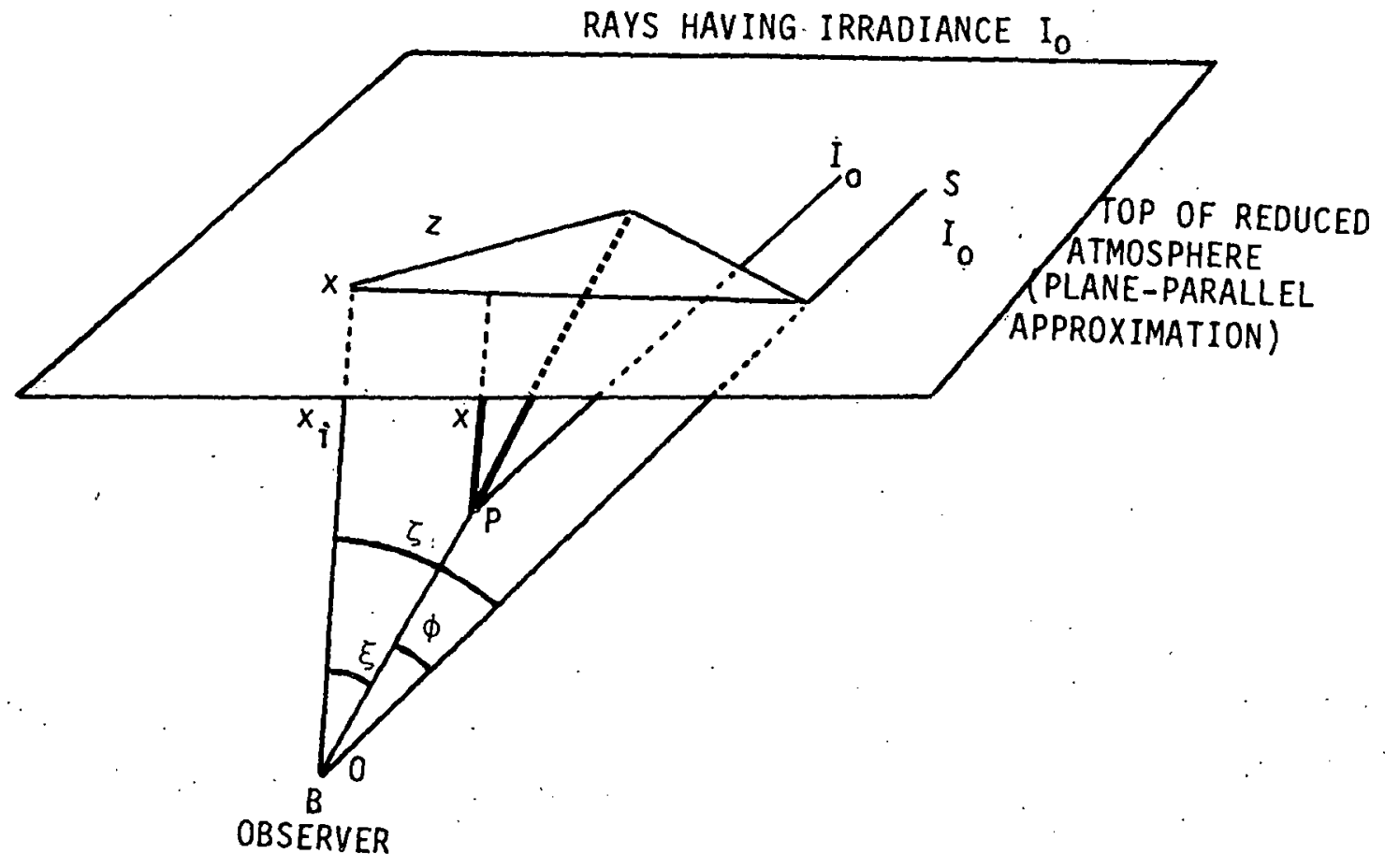

Figure 31. Sky Brightness Geometric Coordinate Relationships 
where $g=(1-r)(1-n)$

$$
X=\exp (-\beta x \sec \zeta)
$$

$$
\begin{array}{ll}
I_{0}=I_{0}{ }^{\prime} \exp \left(-\beta^{\prime} \sec \zeta\right) & T=\exp (-\beta t \sec \zeta) \\
C & =\eta+(1-\eta) \cos \zeta
\end{array}
$$

and $t$ is the equivalent total thickness of the atmosphere reduced to kilometers of air at standard temperature and pressure.

A sample result may be obtained by using the following values for the variables:

$$
\begin{aligned}
t & =8 \mathrm{~km} \\
x_{1} & =5.5 \mathrm{~km} \\
r & =.2 \\
\zeta & =.04 \\
\beta^{\prime} & =.023 \\
B & =.017 / \mathrm{km} \\
I_{0}{ }^{\prime} & =13600 \text { footcandles (lumens } / \mathrm{ft}^{2} \text { ) }
\end{aligned}
$$

Table 4 gives the theoretical sky brightness and polarization ${ }^{7}$ for several locations of the sun and the observer. The values of Table 4 may be scaled linearly from the intensity of the sun to the intensity of the SPS reflections since the irradiance is simply a constant multiplier in all. of the intensity expressions!. Since Table 4 provides intensity in lumens $/ \mathrm{ft}^{2}$, a conversion to watts $/ \mathrm{m}^{2}$ is convenient. For the solar spectrum and the sensitivity of the eye, the chonversion is closely a factor of 10 , that is, $1 \mathrm{watt} / \mathrm{m}^{2}=10$ lumens $/ \mathrm{ft}^{2}$.

The sky brightness due to the sun ran be obtained directly from Table 4 (by interpolation if necessary). The sky brightness caused by some other bright object can be obtained also since the sky brightness values of the sun and object will be in the same rate as that of the intensity of the sun to the bright object.

Using this approach is actually only a good approximation to the sky brightness since the derivation of the relationships assume that the source illuminated the entire depth of the atmosphere with parallel light. This is 
Table 4. Theoretical Sky Brightness and Polarization ${ }^{7}$ at 10,000 Foot Altitude in Clear Air $(\beta=0.017)$

Zenith Angle of Sun $\zeta=0^{\circ}$, All $Z$

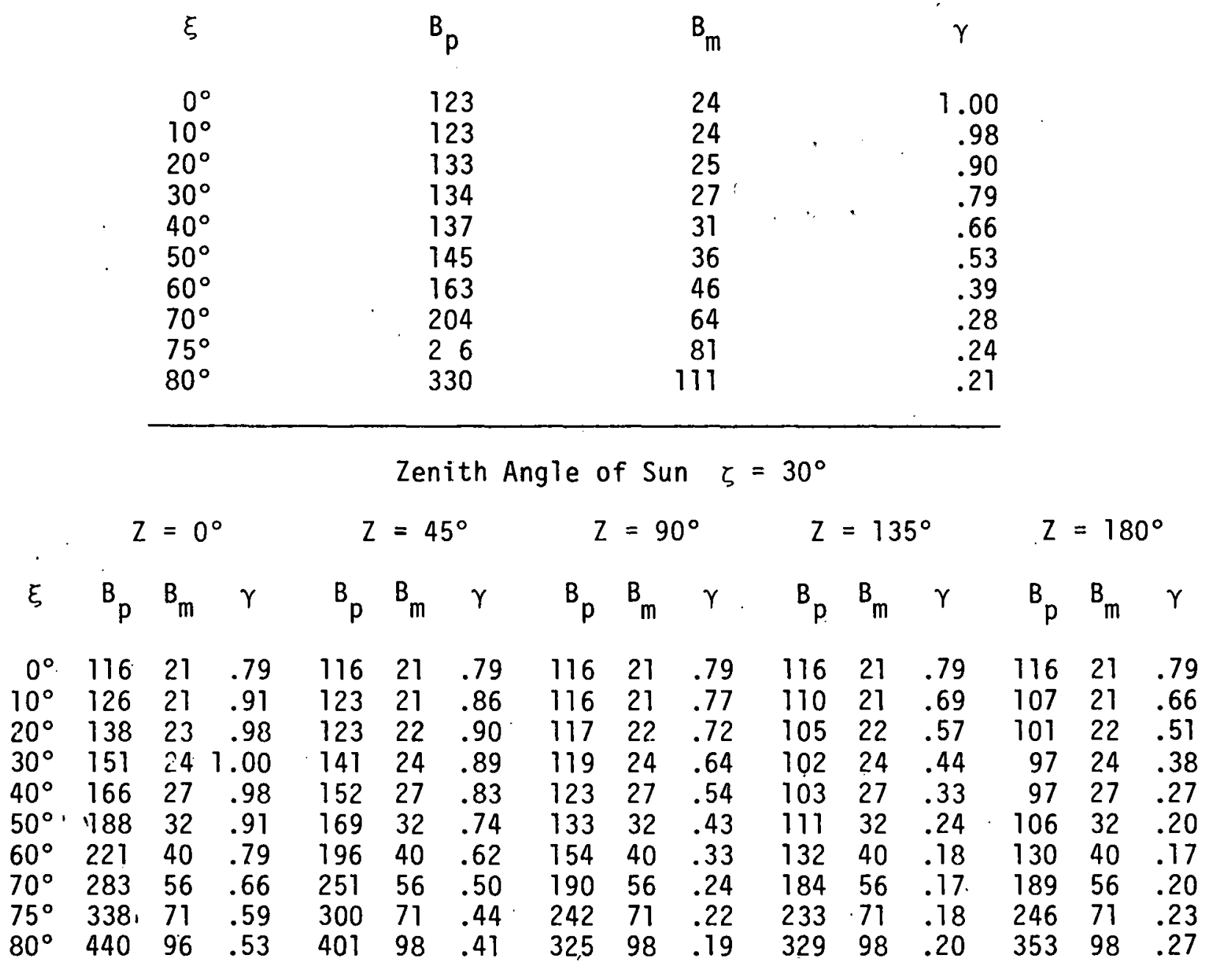

$$
\begin{aligned}
& \text { Zenith Angle of Sun } \zeta={ }^{\circ} 60^{\circ} \mathrm{S} \\
& Z=0^{\circ} \quad Z=45^{\circ} \quad Z=90^{\circ} \quad Z=135^{\circ} \quad Z=180^{\circ}
\end{aligned}
$$

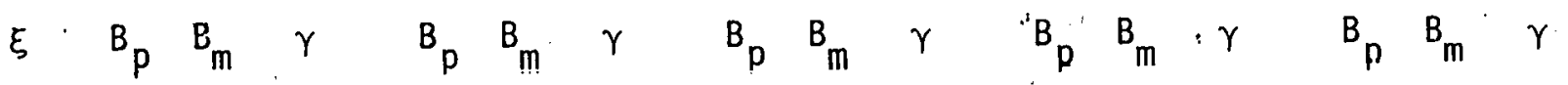$$
\begin{array}{rrrrrrrrrrrrrrrr}
0^{\circ} & 7.9 & 14 & .35 & 79 & 14 & .35 & 79 & 14 & .35 & 79 & 14 & .35 & 79 & 14 & .35 \\
10^{\circ} & 90 & 14 & .50 & 86 & 14 & .43 & 80 & 14 & .34 & 74 & 14 & .26 & 72 & 14 & .26 \\
20^{\circ} & 105 & 15 & .64 & 97 & 15 & .54 & 82 & 15 & .33 & 72 & 15 & .19 & 70 & 15 & .16 \\
30^{\circ} & 125 & 16 & .78 & 111 & 16 & .61 & 86 & 16 & .30 & 75 & 16 & .15 & 74 & 16 & .14 \\
40^{\circ} & 150 & 18 & .90 & 120 & 18 & .68 & 94 & 18 & .26 & 83 & 18 & .14 & 85 & 18 & .16 \\
50 & 185 & 21 & .98 & 154 & 21 & .68 & 107 & 21 & .22 & 100 & 21 & .15 & 108 & 21 & .24 \\
60^{\circ} & 233 & 26 & 1.00 & 189 & 26 & .65 & 128 & 26 & .10 & 130 & 26 & .20 & 149 & 26 & .35 \\
70^{\circ} & 325 & 37 & .98 & 260 & 37 & .62 & 176 & 37 & .16 & 197 & 37 & .28 & 237 & 37 & .49 \\
75^{\circ} & 404 & 46 & .94 & 321 & 46 & .58 & 220 & 46 & .15 & 260 & 46 & .32 & 317 & 46 & .57 \\
80^{\circ} & 541 & 64 & .90 & 429 & 64 & .55 & 300 & 64 & .14 & 371 & 64 & .37 & 460 & 64 & .64
\end{array}
$$ 
Table 4. Theoretical Sky Brightness and Polarization ${ }^{7}$
at 10,000 Foot Altitude in Clear Air $(B=0.017)$
(continued)

Zenith Angle of Sun $\zeta=90^{\circ}$

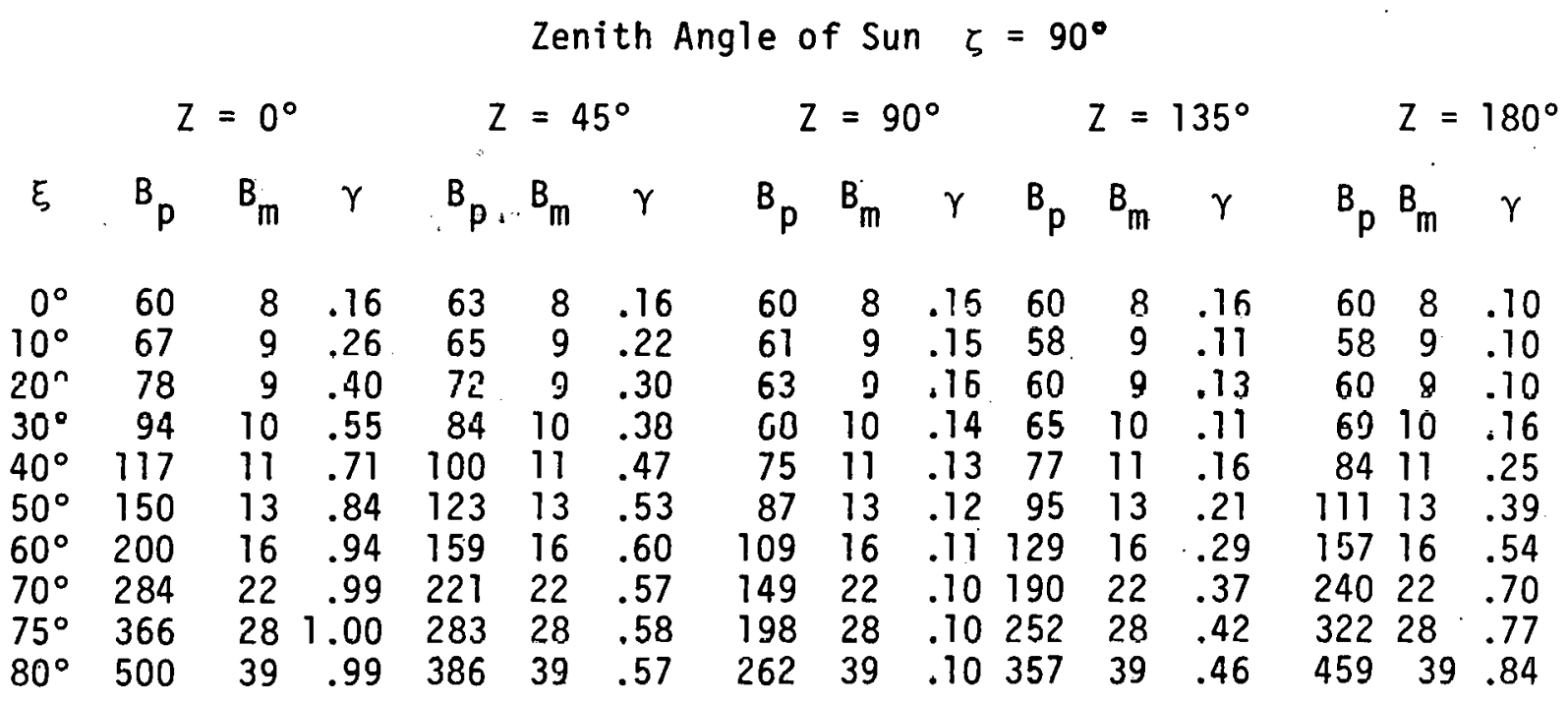


not strictly true for the reflected light from SPS: For the specular component of the reflection, only a narrow cone in the atmosphere is illuminated, leaving most of the sky essentially unaffected to the extent that multiple scattering can be neglected. However, as is shown in Figure 20, the angular distribution of the diffuse component of the reflection is fairly flat. Any point in the line of sight of the observer is therefore illuminated by about the same intensity. This is then nearly equivalent to a source such as the sun which illuminates the entire atmosphere with parallel light of the same intensity. Multiple scattering is treated by the same adjustments as were made for the sun. For the general case where the observer's line of sight does not intersect the specular component of the reflection, the sky brightness can be obtained from Table 4 .

To obtain the sky brightness of Satellite Power System vehicles, the ground irradiance $H$ is scaled to the direct solar irradiance by the formula

$$
I\left(W / m^{2}\right)=B\left(\text { lumens } / \mathrm{ft}^{2}\right) \cdot \frac{1 \mathrm{~W} / \mathrm{m}^{2}}{10 \text { lumens } / \mathrm{ft}^{2}} \cdot \frac{\mathrm{H}\left(\mathrm{W} / \mathrm{m}^{2}\right)}{1400 \mathrm{~W} / \mathrm{m}^{2}} \cdot
$$

As an example of the procedure, consider the diffuse reflection intensity of $8 \times 10^{-7} \mathrm{~W} / \mathrm{m}^{2}$ from the SPS solar panels in GEO (D2). At an apparent point in the sky of $\xi=30^{\circ}, \zeta=60^{\circ}$, and $Z=45^{\circ}$, Table 4 gives $B=B_{p}+B_{m}=$ $111+.16=127$ Tumens $/ \mathrm{ft}^{2}$. Thus $I=7.3 \times 10^{-9} \mathrm{~W} / \mathrm{m}^{2}$, and the sky irradiance is $0.9 \%$ of the direct irradiance from SPS. 


\subsection{CONCLUSIONS AND RECOMMENDATIONS}

\subsection{CONCLUSIONS}

The ground illumination from sunlight reflections off the Space Power System spacecraft have been evaluated for the Baseline Design. A variety of configurations, orientations, and operational conditions were considered in this analysis. Because of the expectation that these vehicles will be viewed by many ground observers, those conditions that are thought to produce the brightest ground irradiance have been selected for evaluation. For the most part. only normal operations with controlled orientations have been assumed; however, a couple out of control abnormal orientations are also treated. A summary of ground irradiance levels that have been calculated is presented in Table 5 .

The large size of the Space Power System elements causes even diffuse reflections to appear as very bright light sources. The present Baseline vehicles are held together by beams that are painted with highly reflective material. However, the dominant surfaces for reflected light are the solar panels of the OTV and SPS. These areas consist of highly specular, low reflectivity cover glass over dark absorbing cells on the front side and shiny aluminized plastic dielectric on the back (see Tables 2 and 3 ). Consequently, most of the reflected light is very directional; diffuse reflections are proportionately much dimmer due to a lack of large diffuse surfaces.

The diffuse cases summarized in Table 5 are all relatively bright in comparison with stellar sources. For example, the SPS in GEO is comparable to the stellar magnitude of Venus at its brightest. The OTV/SB combination in LEO is visible during daylight hours but, of course, is at too low an altitude to be illumirlated at night.

The specular cases cited in Table 5 produce much brighter ground illumination. However, this irradiance is restricted to small, fast moving spots. The actual duration of these "glints" of specular reflections varies from about one second for the OTV/SB in LEO to two minutes for the SPS antenna. An important consideration is the sudden onset of the specular irradiance compared to the much dimmer diffuse irradiance. Enhancements of $10^{5}$ are common.. An 
Table 5. Summary of Ground Irradiance

\begin{tabular}{|c|c|c|c|c|c|}
\hline Case & & Condition & $\begin{array}{l}\text { Iday M } \\
\text { /Dusk } \\
\text { ht N }\end{array}$ & $\begin{array}{c}\text { Range } \\
\mathrm{km}\end{array}$ & $\begin{array}{l}\text { Irradiance } \\
\quad \mathrm{W} / \mathrm{m}^{2}\end{array}$ \\
\hline Controlle & & entation - Worst Case & Geomet & & \\
\hline Diffuse & & OTV/SB in LEO & M & 910 & $2.4 \times 10^{-5}$ \\
\hline 2 & & SPS in GEO & N & 35,700 & $8 \times 10^{-7}$ \\
\hline$\therefore$ & & $\begin{array}{l}\text { OTV Powered } \\
\text { Near LEO }\end{array}$ & D & 2,570 & $4 \times 10^{-6}$ \\
\hline 2 & & OTV at $2 \mathrm{R}_{\mathrm{e}}$ & D & 11,000 & $2 \times 10^{-7}$ \\
\hline & & $4 \mathrm{R}_{\mathrm{e}}$ & $\mathrm{N}$ & 24,700 & $5 \times 10^{-8}$ \\
\hline Specular & & $\begin{array}{l}\text { OTV/SB in LEO } \\
\text { around solstices. }\end{array}$ & M & 910 & \\
\hline & & $\begin{array}{l}\text { flat front } \\
\text { solar panels }\end{array}$ & & & 1.2 \\
\hline & & $\begin{array}{l}\text { flat back } \\
\text { aluminum }\end{array}$ & & & 19 \\
\hline & & $\begin{array}{l}\text { misaligned front } \\
\left(1.5^{\circ}\right)\end{array}$ & & $x_{2}$ & 0.1 \\
\hline & & $\begin{array}{l}\text { misaligned back } \\
\left(1.5^{\circ}\right)\end{array}$ & & & 2 \\
\hline - & 2 & $\begin{array}{l}\text { SPS solar panel in } \\
\text { GEO around equi- } \\
\text { noxes }\end{array}$ & $\mathrm{N}$ & 35,700 & \\
\hline & & flat surface & & & 0.03 \\
\hline & & $\begin{array}{l}\text { misaligned surface } \\
\left(5^{\circ}\right)\end{array}$ & & $s+\infty$ & 0.0003 \\
\hline & 3 & $\begin{array}{l}\text { SPS antenna in GEO } \\
\text { around equinoxes }\end{array}$ & $\mathrm{N}$ & 36,000 & 0.01 \\
\hline & 4 & $\begin{array}{l}\text { OTV Powered } \\
\text { Near LEO }\end{array}$ & D & 2.570 & 0.19 \\
\hline & 5 & OTV at $2 \mathrm{R}_{\mathrm{e}}$ & D & 11,999 & 0.01 \\
\hline$\because$ & & $4 \mathrm{R}_{\mathrm{e}}$ & $\mathrm{N}$ & 24,700 & 0.002 \\
\hline
\end{tabular}

Out of Control Orientation - Worst Case Geometry

$\begin{array}{rlrrr}\text { Specular } 6 & \text { OTV in LEO } & \text { D } & 500 & 56 \\ 7 & \text { SPS in GEO } & N & 36,000 & 0.4 \\ & \text { flat back } & & & \\ & \text { alumillumil } & & & \end{array}$


exceptionaliy bright specular reflection is produced by the backside of the OTV solar panels during LEO construction. Although perfectly flat solar panel surfaces are assumed as worst cases for the OTV and SPS, more realistic situations are represented by the curved or misaligned surfaces that are also analyzed.

The truly abnormal conditions that out of control vehicles would create are also cited for completeness. There would undoubtedly be many safeguards in the orbit mechanics to prevent such an occurrence. It is noteworthy that at most the enhancement is only threefold in LEO and 15-fold in GEO beyond "I normal controlled operalioions.

Some perspective on the relative importance of these irradiance levels' can be derived by a comparison with the solar irradiance. Insolation is about $1400 \mathrm{~W} / \mathrm{m}^{2}$, substantially greater than any of the reflections. However, the sun is an extended source subtending 32 arc minutes, whereas the OTV in LEO subtends 11 arc minutes (500 km altitude) at the most, and well beyond LEO both OTV and SPS subtend less than one arc minute, the resolution of the eye: Thus, the power density in this direct solar image would be as much as 10-fold less than that for the OTV in LEO, and 1000-fold less than the OTV and SPS in GEO.

Apparent stellar magnitudes provide another useful basis for comparison: Using the sun as the standard, the formula for the visual magnitude of a light source is given by

$$
m=-26.7-2.5 \log _{10}\left[H\left(W / m^{2}\right) / 1400\right]
$$

where $H$ is the ground irradiance. Thus, for example, diffuse reflection from SPS in GEO (D2) has an apparent magnitude of -3.6 , and specular reflection from the SPS antenna in GEO (S3) has a magnitude of -13.8 , comparable to the full moon:l

The methodology for calculating sky brightness created by a diffuse source is also presented. This calculation requires elaborate tabular entries that" are given in Table 4 . The sky irradiance for a typical set of observation 1. directions, displaced a reasonable angular distance away from the source', is. on the order of $1 \%$ of the direct irradiance from the source. The sky brightness for other observation conditions should be evaluated on a case by case basis using the tables. 


\subsection{RECOMMENDATIONS}

The worst case conditions in Table 5 have ground irradiance levels that may exceed acceptable limits. Evaluation of the ocular irradiance levels that correspond to these ground irradiance levels is required to completely assess the reflection 1 imitations that will be imposed on the Space Power System. Nevertheless, it is prudent to consider options for reduction of reflected suniight from these vehicles. Possible methods for reducing reflections fall into three major categories.

Vehicle Orientation. Since the major ground illumination is produced by large flat surfaces on the OTV and SPS, it is appropriate to inquire about reorienting the vehicles to direct specular reflections away from earth. Since solar power collection falls with the cosine of the tilt angle, for example, an $8^{\circ}$ tilt of the solar panels causes a $1 \%$ power loss, but specular reflections are shifted $16^{\circ}$ off the sun-earth direction.

In the case of the SPS, if modest power losses can be tolerated on its solar panel, specular reflections can be eliminated. Specificaily, it requires a $5^{\circ}$ tilt at geosynchronous altitude for specular reflections to pass over the north or south pole. If the solar panels are misaligned $\pm 3^{\circ}$ from a perfectly plane surface, an $8^{\circ}$ tilt would assure no specular light is returned to earth from the SPS solar panels. The SPS antenna reflections will necessarily strike earth ${ }^{2}$ due to ground receiver pointing requirements, but other modifications are suggested below to alleviate this ground irradiance.

Similar power-reflection tradeoffs are workable for the OTV during its transit. Near LEO, the tilt constraint is quite small (a few degrees) since the vehicle is eclipsed. Orbit inclination considerations are required to evaluate the tilt profile during the full LEO to GEO transit. The construction phase requires. OTV solar panel orientation to be in the orbit $\mathrm{plane}$ to reduce atmospheric drag, and therefore no reorientation seems feasible.

Surface Curvature. Most of the large surfaces that produce strong reflections are nominally flat in the Baseline Design. In practice, however, the vehicles are expected to flex under thermal and propulsion loads causing some misalignment of flat elements. Intentional misalignment of large solar 
panels is also feasible. Both conditions will spread specular reflections and reduce the local intensity of ground irradiance by distributing the light over a larger area. For example a $5^{\circ}$ misalignment results in a. 100fold reduction in ground irradiance (see equation 2). This misalignment would, of course, be counterproductive to the vehicle reorientation discussed above.

Many other structural surfaces in the Space Power System spacecraft are nominaliy flat for structural convenience alone. Specular reflections from structural beams, astronaut housing on the SB, thermal control surfaces, and propellant storage systems might be drastically curtalled by introduciny surface curvature. Diffuse reflections are relatively unaffected by this procedure.

Surface Quality. The Baseline Space Power System Design includes many surfaces that have specular characteristics in visible light. This surface quality can be altered for some of the applications without affecting the serviceability of the element. For example, the surface of the SPS antenna is an electrical ground plate that presently is polished aluminum; but its electrical properties at the microwave frequencies of interest would not be affected by surface roughening (etching) on the scale size of visible wave $\rightarrow$ lengths to create a diffuse reflector.

Another large shiny surface is the aluminized backside of the solar panels on OTV. These surfaces might be painted without affecting the thermal or electrical quality of the system. Other smaller structures might be converted from specular to diffuse reflectors by etching or coating the material. The front side of the solar cells is covered with giass for ionizing radiation protection; its specularity might be reduced by use of nonglare glass that has an optically rough surface. These reductions in the specular components reappear, of course, as slight enhancements to the diffuse components of reflected light.

Clearly there are options available to reduce ground irradiance from sunlight reflections off the Space Power System spacecraft. How effective they would be and how practical they are for overall performance and cost remains to be assessed. 


\subsection{REFERENCES}

1. Satellite Power System, Concept Development and Evaluation Program, Reference System Report, U. S. Department of Energy, Office of Energy Research and National Aeronautics and Space Administration, October 1978.

2. Solar Power Satellite, System Definition Study, Phase I Final Report, Contract NAS 9-15636, Boeing Aerospace Company Document D180-25037-3, April 1, 1979.

3. Liemohn, H.'B., "Optical Tracking of Deep-Space Probes", ICARUS: International Journal of the Solar System, Vol. 9, No. 1, July 1968.

4. Zentner, R. C., R. K. MacGregor, and J. T. Pogson, "Bidirectional Reflectance Characteristics of Integrating Sphere Coatings", Progress in Astronautics and Aeronautics, Vol. 29, 1971.

5. Touloukian, Y. S. and D. P. DeWitt, Thermophysical Properties of Matter, Vol. 7,8, Plenum Press, N.Y., 1970.

6. Bidirectional Reflection Measurements, J. E. Anderson (private communication), Boeing Aerospace Company, Memorandum 2-1088-0005-707, January 21 , 1972 .

7. Livingston, L. E., "Visibility of Solar Power Satellites From the Earth", Johnson Space Center, NASA JSC-14715, February 1979.

8. Tousey, R. and E. 0. Hulburt, Brightness and Polarization of the Daylight Sky at Various Altitudes above Sea Level, J. Optical Soc. America 37, 78$92,1947$. 
APPENDIX A COMPUTER CODE FOR VECTOR ROTATIONS

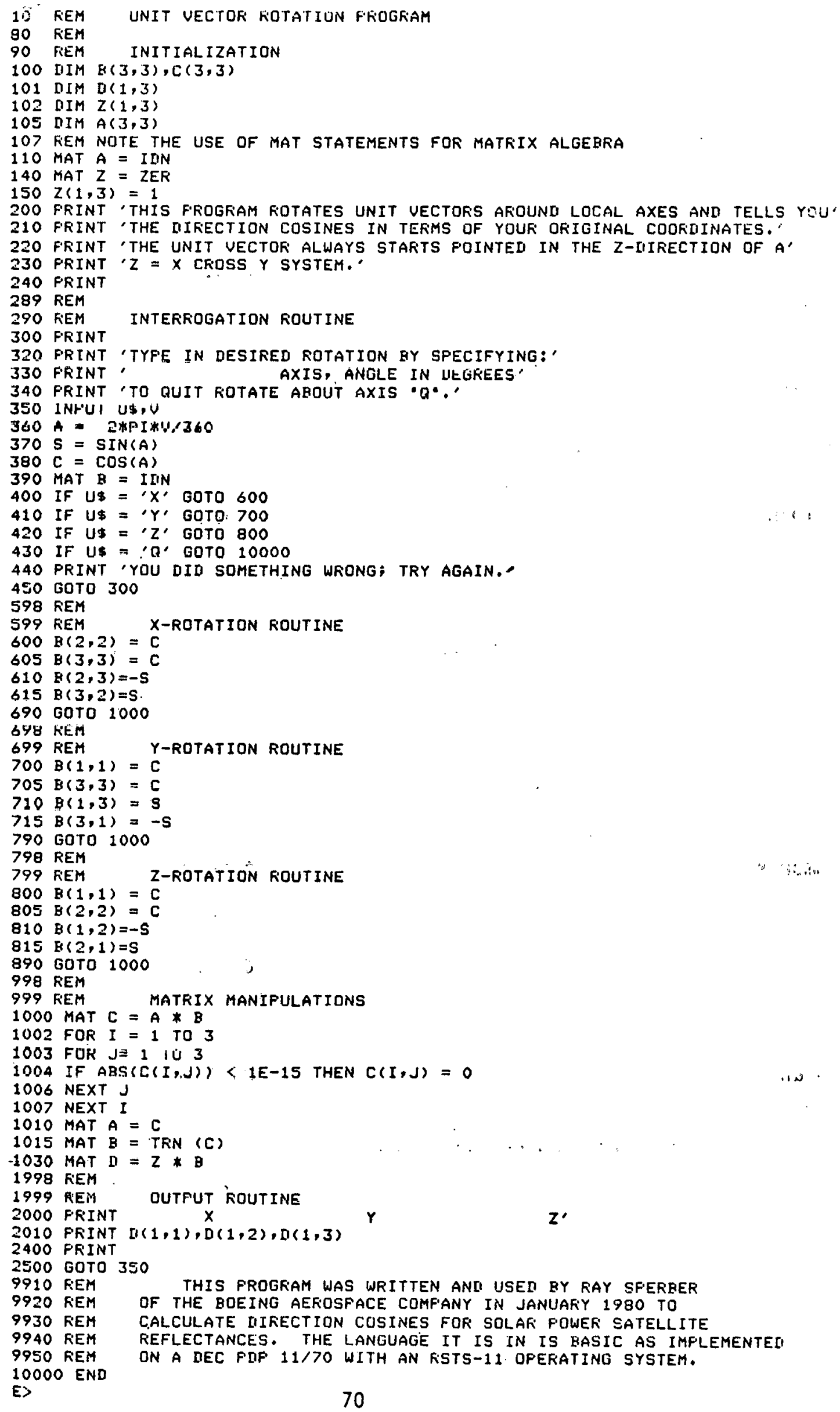




\section{APPENDIX B}

\section{RADIANT QUANTITIES AND UNITS}

There are two unit systems for measuring light quantities. The radiant quantities are derived from a measurement of energy, i.e., that which is measured by a thermal detector. Photometric quantities are based on visible radiation that is measured by the response of the eye. Table B.l lists the radiant quantities with their definitions, units, and the usual symbol by which it is known. Table B.2 is the parallel chart for luminous quantities and is arranged such that the quantities as numbered correspond to the radiant counterpart under the same number in Table B. 1 .

This study will use the radiant system. To avoid possible confusion a brief description of each of the listed quantities is provided to clarify what is intended when a quantity is used in this study.

The radiant energy is the basic unit from which the system is derived. This study will use the MKS system of units which makes that energy unit the joule. Note that the term radiation is often a synonym for radiant energy. The radiant energy density is, as implied, the energy per unit volume. This unit is seldom used and is included here only for comparison. The radiant flux is the time rate of energy transfer tu or from a surface. A common synonomous phrase is radiant. power, or just power.

The radiant flux density is the radiant flux leaving or entering $a$ surface per untet area of the surface normal to the directions of the flux. When the flux leaves the surface either by reflection or emittance, it is called radiant emittance. When it is incident on the surface, it is called irradiance. Radiance is the radiant emittance per unit:solid angle. Radiant intensity is radiance integrated over its surface area so that for small surface areas, the radiant flux density measured some distance away from the area will convenientiy include the energy emitted from the entire source. 
Table B.1. Radiant Quantities, Conventional Notation

\begin{tabular}{|c|c|c|c|c|}
\hline & & Symbol & Definition & Unit \\
\hline 1 . & Radiant energy & $U$ & & joule \\
\hline 2. & $\begin{array}{l}\text { Radiant energy } \\
\text { density }\end{array}$ & $u$ & $\frac{d U}{d V}$ & $\frac{\text { joule }}{\text { meter }}$ \\
\hline 3. & Radiant flux & $\mathbf{P}$ & $\frac{d U}{d t}$ & watt \\
\hline 1. & $\begin{array}{l}\text { Radiant. flux } \\
\text { density }\end{array}$ & W or $H$ & $\frac{d P}{d S}$ or $\frac{d P}{d A}$ & watt \\
\hline & $\begin{array}{l}\text { a. Radiant } \\
\text { emittance }\end{array}$ & w & $\frac{d P}{d A}$ & $\frac{\text { watt }}{\text { meter }^{2}}$ \\
\hline & b. Irradiance & $H$ & $\frac{d P}{d A}$ & $\frac{\text { watt }}{\text { meter }}$ \\
\hline 5. & Radiance & $\mathrm{N}$ & $\frac{d^{2} p}{\cos \theta d S d \Omega}$ & $\frac{\text { watt }}{\text { ster meter? }}$ \\
\hline 6. & Radiant intensity & J. & $\frac{d P}{d \Omega}$ & $\frac{\text { watt }}{\text { ster }}$ \\
\hline
\end{tabular}

$S=$ area of emitting surface

$A=$ area of receiving surface

$V=$ volume

$\Omega=$ solid angle

$\theta=$ angle between the normal to the surface and the direction of the ellitted ray. 
Table B.2. Luminous Quantities, Conventional Notation

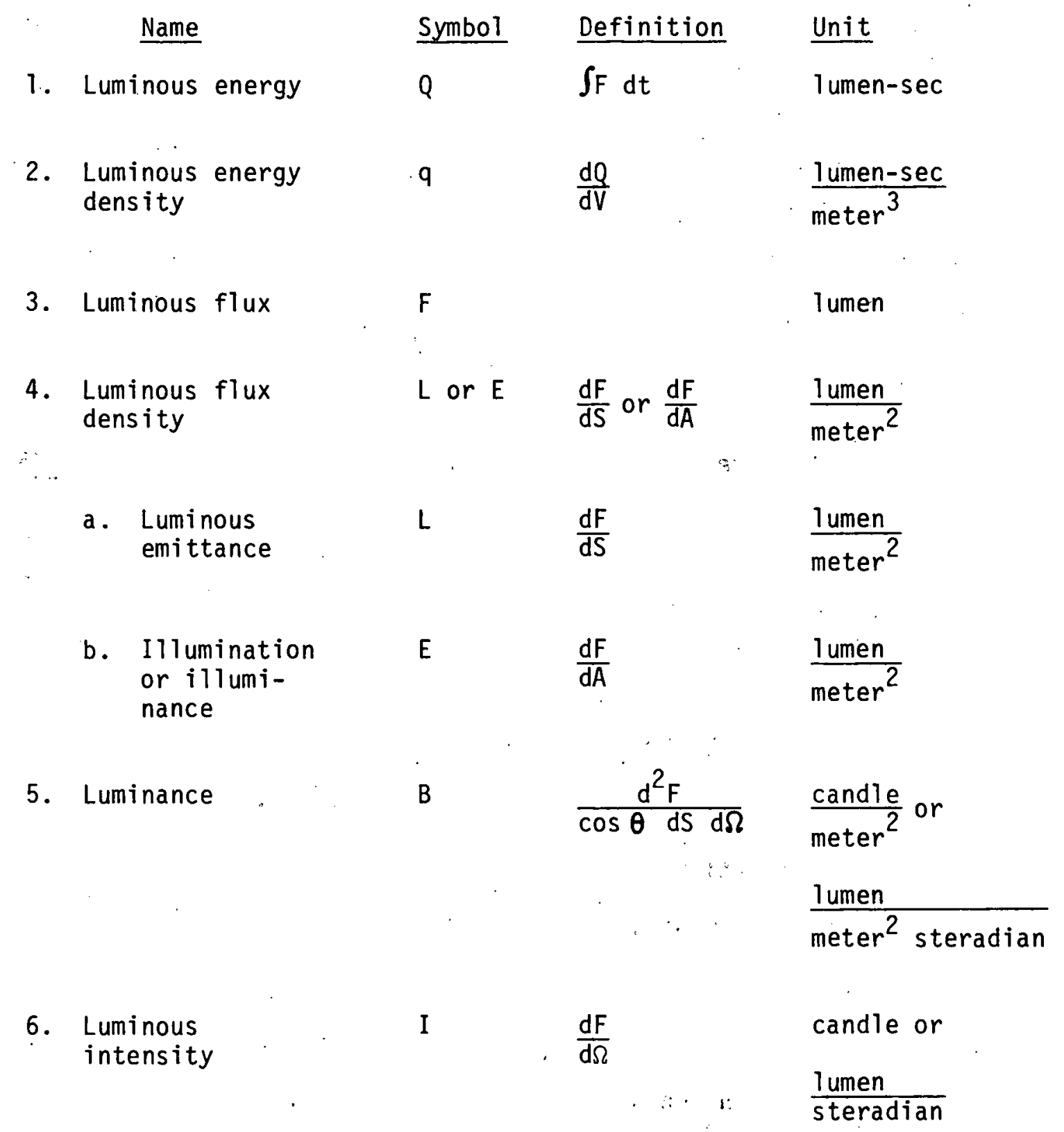




\section{United States}

Department of Energy

Washington, DC 20585
FIRST-CLASS MIAIL

POSTAGE \& FEES PAID

U.S. DEPT. OF ENERGY

PERMIT NO. G 20

FIRST CLASS MAIL

Official Business

Penalty for Private Use, $\$ 300$ 